


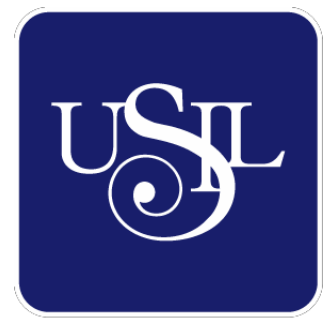

UNIVERSIDAD

SAN IGNACIO

DE LOYOLA

FACULTAD DE CIENCIAS EMPRESARIALES

Carrera de International Business

\title{
RELACIÓN ENTRE ADAPTACIÓN DE PRODUCTO Y EL DESEMPEÑO DEL EXPORTADOR DE LAS EMPRESAS EXPORTADORAS DE PALTA EN LIMA 2019
}

Tesis para optar el Título Profesional de Licenciado en International Business

JOHANNA ESTHEFANY CERVANTES ESCOBAL (0000-0002-8988-6981)

ISABEL LUCÍA TICONA QUISPE

(0000-0002-5122-2696)

\author{
Asesor: \\ Ph.D. FRIDA ROSA COAQUIRA NINA \\ (0000-0001-6531-595X)
}

Lima - Perú

2020 


\section{Dedicatoria}

A nuestros padres por el apoyo incondicional, por siempre impulsarnos a ser mejores, $\mathrm{y}$ motivarnos a lograr con éxito nuestros objetivos. 


\section{Resumen}

El objetivo de la presente investigación fue analizar la relación entre la Adaptación de producto y el desempeño del exportador en las empresas exportadoras de palta en Lima 2019. Con el fin de recabar información útil del sector que beneficie a las empresas, mejorando su desempeño y competitividad en el mercado exterior a través de una estrategia de marketing de adaptación de producto.

La investigación es de tipo correlacional con un diseño no experimental y transversal. Asimismo, se utilizó el método cuantitativo. El instrumento de investigación utilizado para la recolección de datos fue una encuesta que medían las variables adaptación de producto y desempeño del exportador, de los autores Tantong, Karande, Nair y Singhapakdi (2010). La encuesta estaba dirigida a gerentes o administradores de las empresas exportadoras de palta en Lima en una muestra de 117 empresas.

Finalmente, los resultados concluyeron que la adaptación de producto si se relaciona con el desempeño del exportador en las empresas exportadoras de palta en Lima 2019. Asimismo, la investigación validó la existencia de la relación de cada una de las dimensiones: adaptación de marca, adaptación de diseño, adaptación de calidad con el desempeño del exportador en las empresas exportadoras de palta en Lima.

Palabras clave: Adaptación de producto, desempeño del exportador. 


\begin{abstract}
The objective of this research was to analyze the relationship between product adaptation and export performance of avocado exporting firms in Lima 2019. In order to gather useful information on the sector, that benefits companies by improving their performance and competitiveness in the foreign market through a product adaptation marketing strategy.

The research is correlational with a non-experimental and cross-sectional design. Likewise, the quantitative method was used. The research instrument used for data collection was a survey that measured the variables: product adaptation and export performance, by the authors Tantong, Karande, Nair and Singhapakdi (2010). The survey was aimed at managers or administrators of avocado exporting companies in Lima in a sample of 117 companies.

Finally, the results concluded that product adaptation is related to the export performance in avocado exporting companies in Lima 2019. Likewise, the research validated the existence of the relationship of each of the dimensions: brand adaptation, design adaptation, quality adaptation and the export performance of avocado exporting companies in Lima.
\end{abstract}

Keywords: Product adaptation, export performance. 


\section{Índice}

Índice

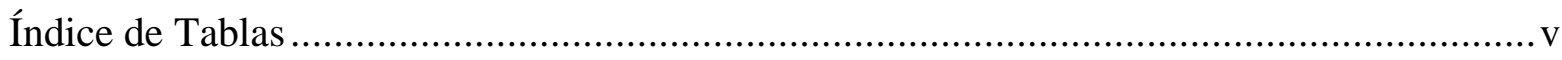

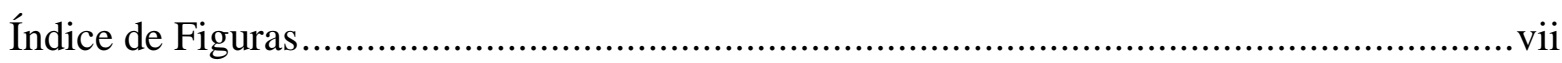

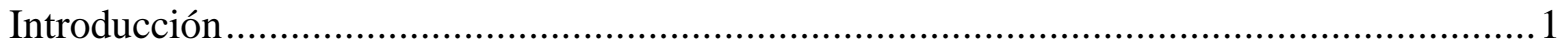

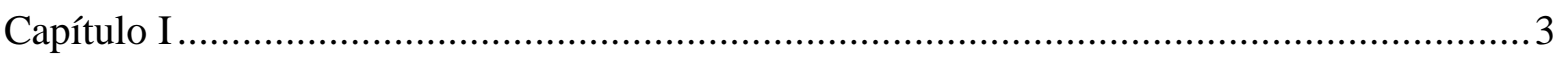

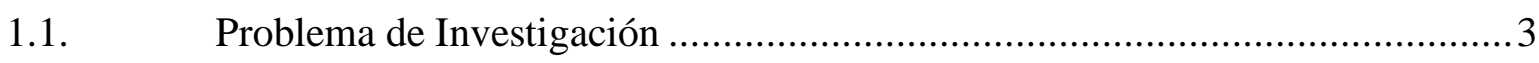

1.1.1. Planteamiento del problema.........................................................................

1.1.2. Formulación del problema..........................................................................

1.1.2.1. Problema general. ..............................................................................5

1.1.2.2. Problemas específicos. ............................................................................

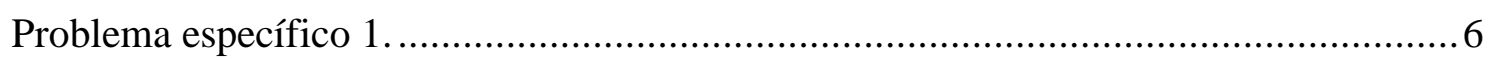

Problema específico 2..............................................................................6

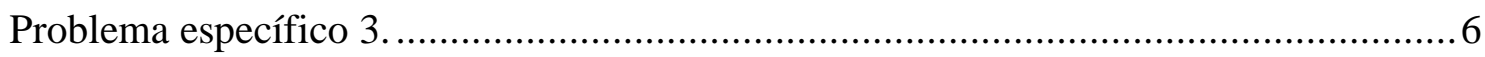

1.1.3. Justificación de la investigación....................................................................

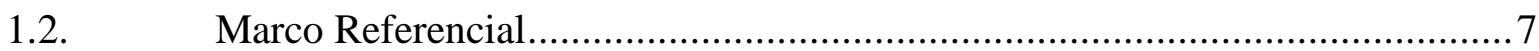

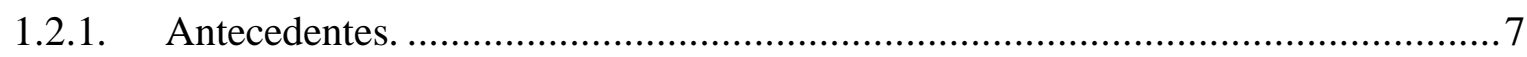

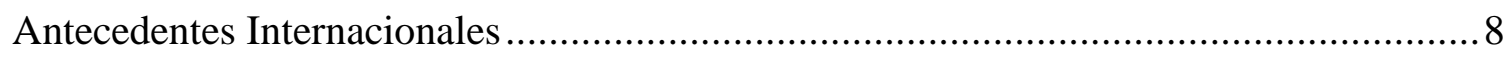

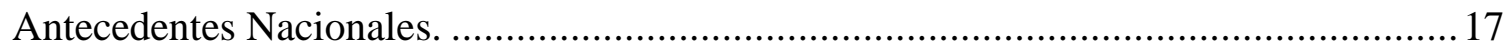

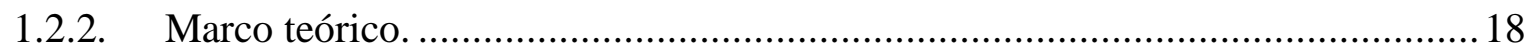

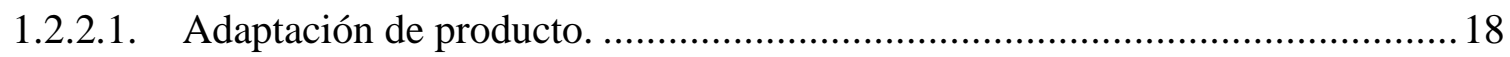

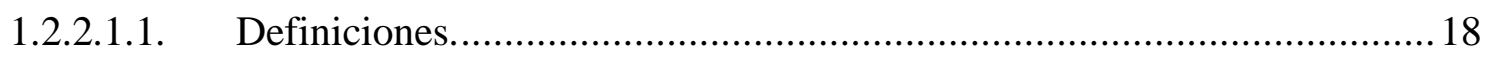

1.2.2.1.2. Dimensiones de adaptación de producto................................................20

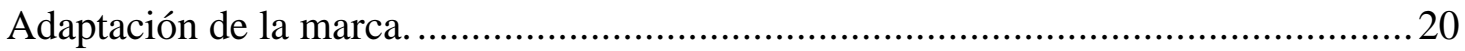


Adaptación del diseño. 20

Adaptación de la Calidad.

1.2.2.1.3. Teorías relacionadas a la adaptación del producto................................21

Adaptación relacionada al usuario (Marco de referencia de Boztepe). .......................21

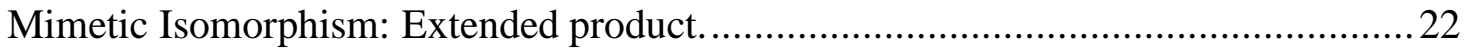

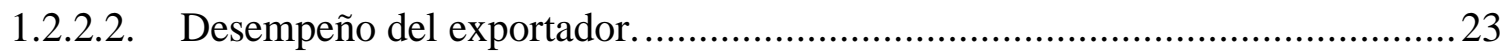

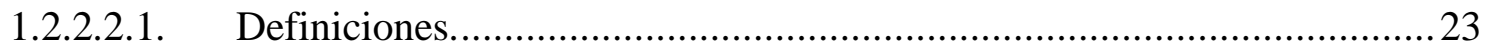

1.2.2.2.2. Dimensiones del desempeño del exportador...................................... 24

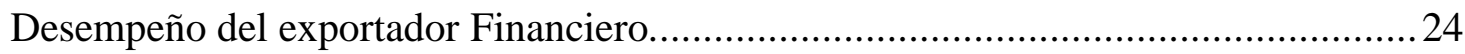

1.2.2.2.3. Teorías relacionadas al desempeño del exportador. ..............................25

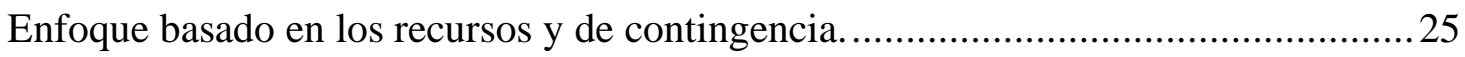

Teoría de Redes - NEP Scale (Lages et al., 2009) .............................................26

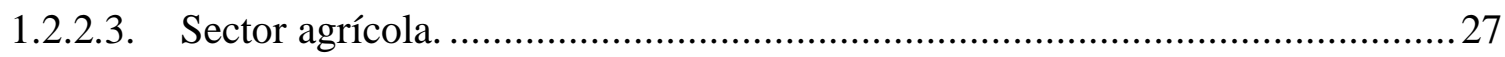

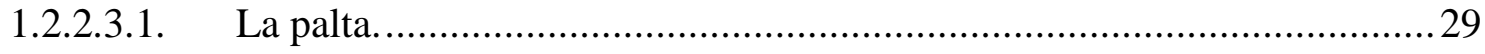

Principales países exportadores de palta en el mundo. ............................................30

Principales Importadores de palta en el mundo....................................................... 33

Principales productores de palta en el mundo. ................................................ 36

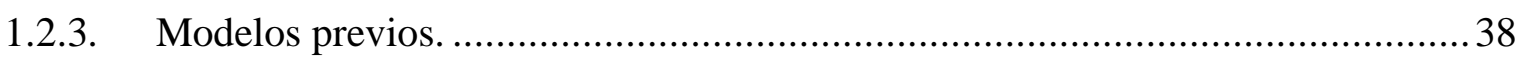

1.2.3.1. El efecto de la orientación de mercado en la adaptación de producto y el

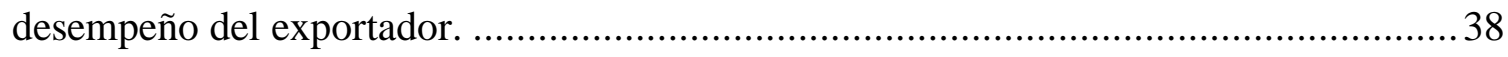

1.2.3.2. Influencia de características internas y externas de la empresa en la estrategia de adaptación de producto y su efecto en el desempeño del exportador............................ 39

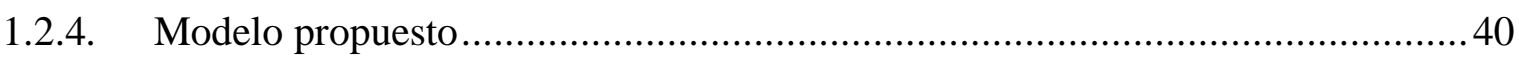

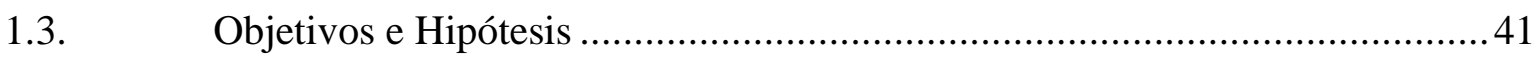

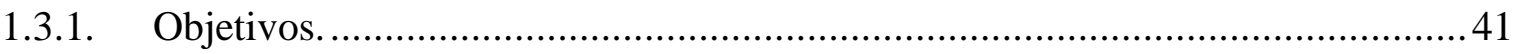


Objetivo General.

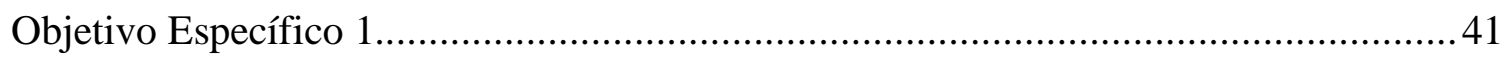

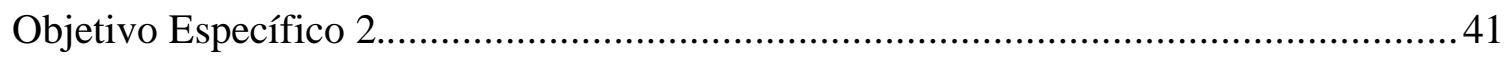

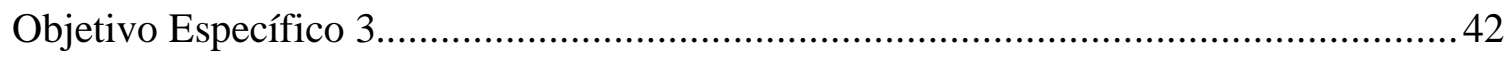

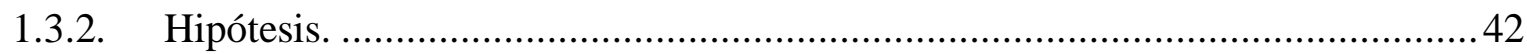

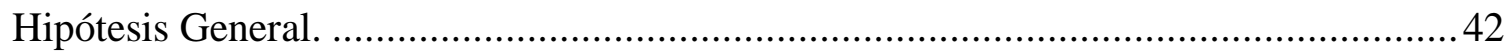

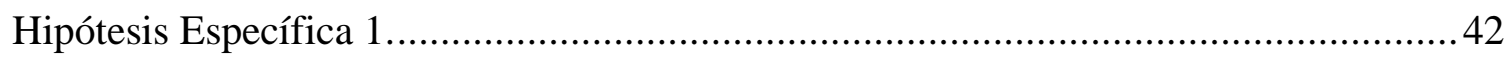

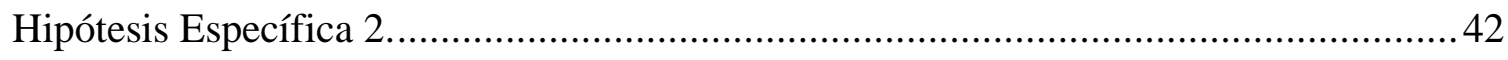

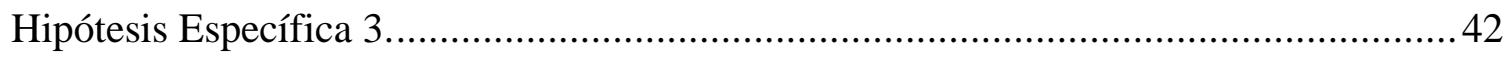

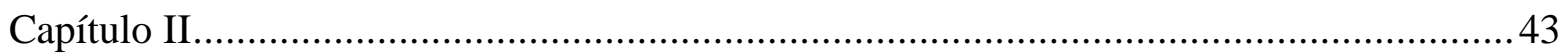

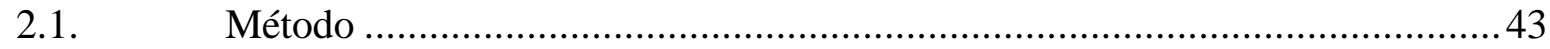

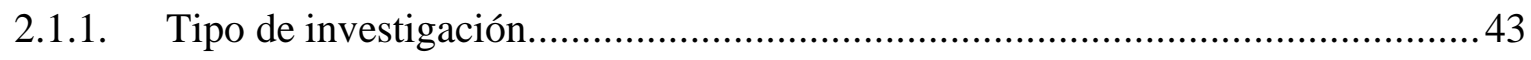

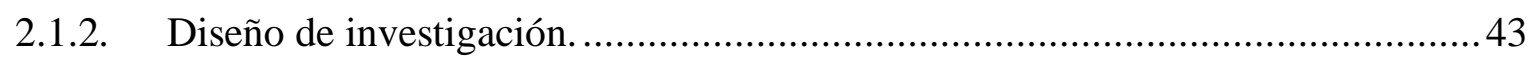

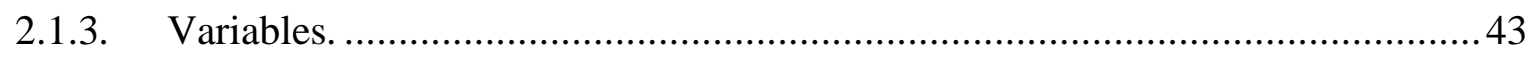

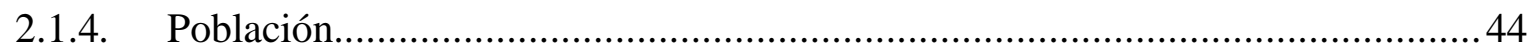

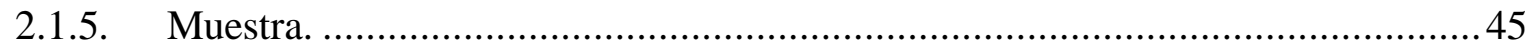

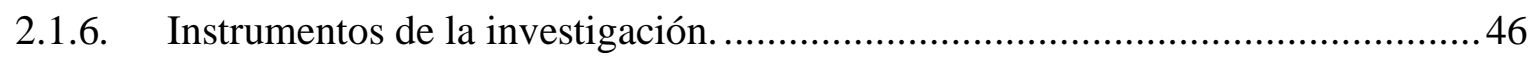

2.1.7. Procedimiento de recolección de datos........................................................... 49

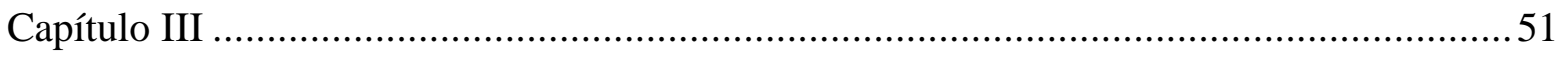

3.1. Análisis de los resultados del cuestionario................................................51

3.1.1. Análisis descriptivos de los estudios de adaptación del producto.......................51

3.1.2. Análisis descriptivos de los estudios del desempeño del exportador.................60

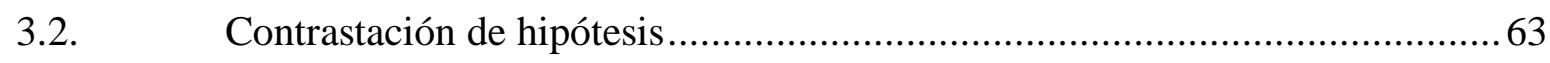

3.2.1. Pruebas de normalidad de Kolmogorov-Smirnov y Shapiro-Wilk....................63

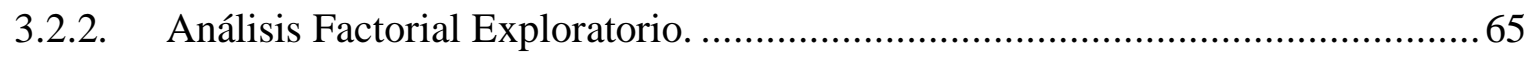




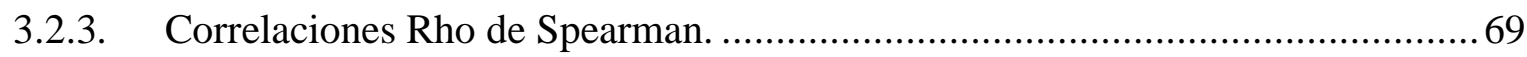

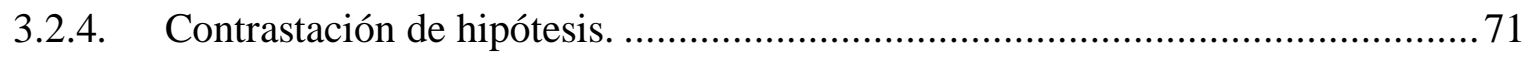

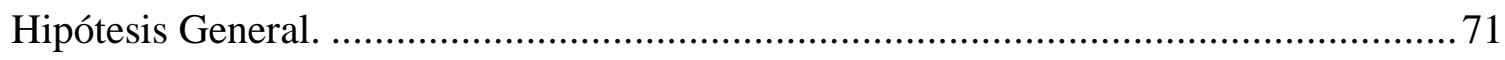

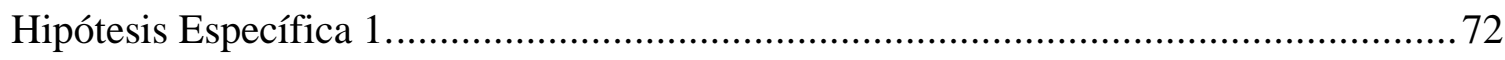

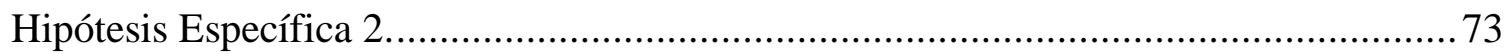

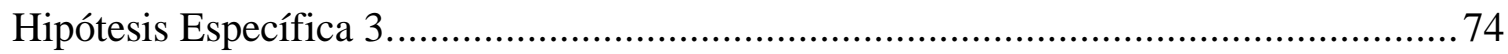

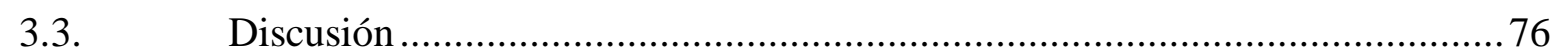

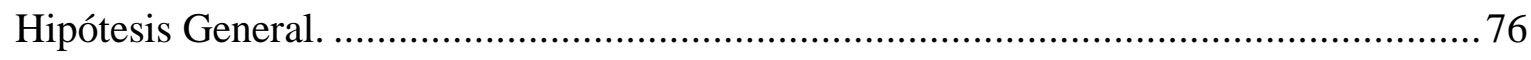

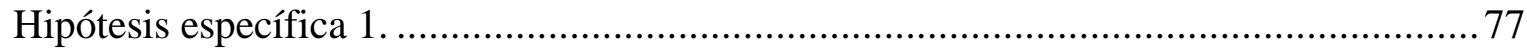

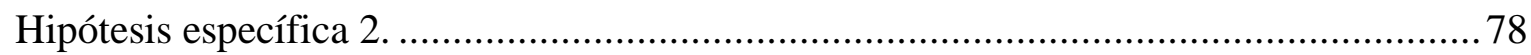

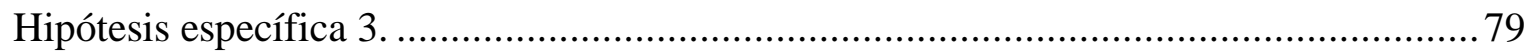

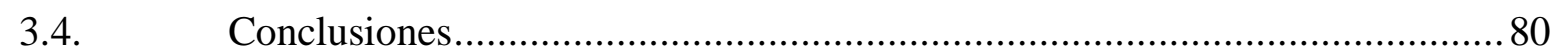

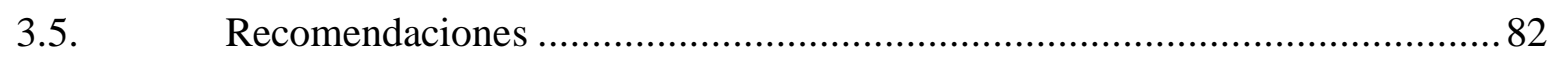

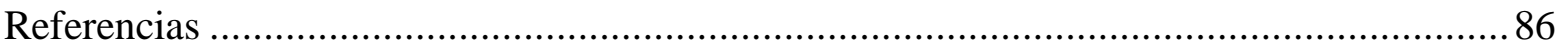

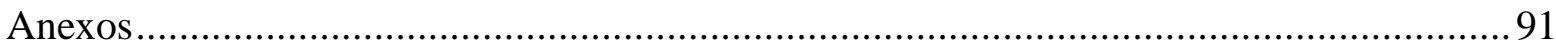

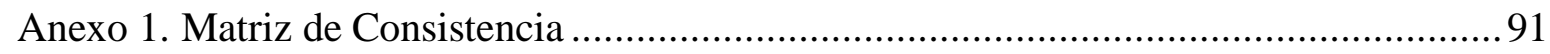

Anexo 2. Instrumento de Investigación: Cuestionario Adaptación de Producto y Desempeño

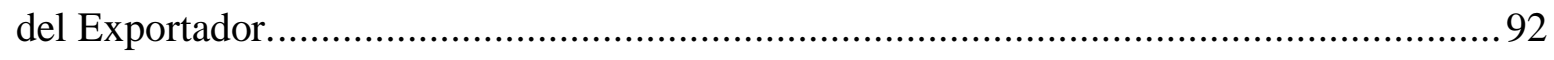

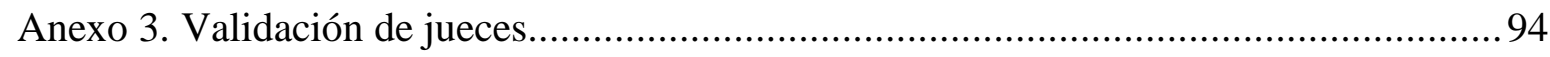

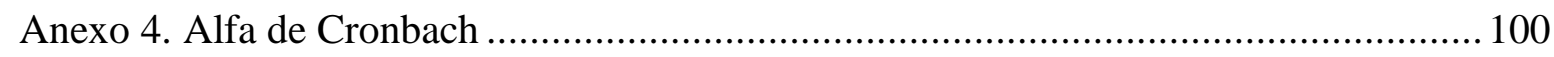

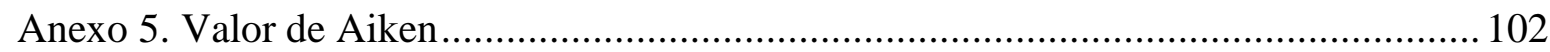




\section{Índice de Tablas}

Tabla 1 Resultados de la teoría de redes en el Desempeño Exportador............................... 26

Tabla 2 Principales variedades de palta en Perú........................................................... 29

Tabla 3 Exportaciones de palta en el mundo 2015-2019 (En miles de dólares) ................... 31

Tabla 4 Exportaciones de palta en el mundo 2015-2019 (En toneladas) ............................ 32

Tabla 5 Principales importadores de Palta en el mundo 2017-2019 (En toneladas) .............. 33

Tabla 6 Principales productores de palta en el mundo (En toneladas) ............................... 37

Tabla 7 Número de empresas exportadoras por tamaño de empresa ............................... 44

Tabla 8 Tamaño de muestra de empresas exportadoras por estratos .................................. 46

Tabla 9 Ficha técnica del instrumento - Adaptación de producto ..................................... 47

Tabla 10 Ficha técnica del instrumento - Desempeño del exportador ................................. 48

Tabla 11 Pregunta 1. Está de acuerdo en que la adaptación de nombres de marca tuvo un efecto

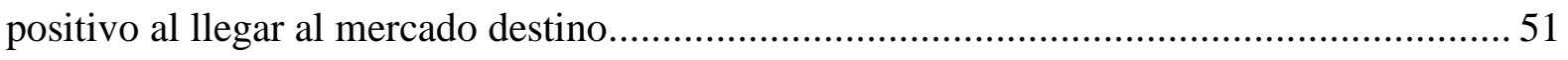

Tabla 12 Pregunta 2. Está de acuerdo en que la adaptación de etiqueta del producto tuvo un efecto positivo al comercializar el producto en el mercado destino. 52

Tabla 13 Pregunta 3. Está de acuerdo en que la adaptación de color del producto tuvo un efecto positivo al comercializar el producto en el mercado destino.

Tabla 14 Pregunta 4. Está de acuerdo en que la adaptación de diseño principal del producto tuvo un efecto positivo al comercializar el producto en el mercado destino.

Tabla 15 Pregunta 5. Está de acuerdo en que la adaptación del número de líneas de producto tuvo una buena aceptación del consumidor al comercializar el producto en el mercado destino

Tabla 16 Pregunta 6. Está de acuerdo en que la aceptación de garantía del producto tuvo una buena aceptación del consumidor al comercializar el producto en el mercado destino. 58 
Tabla 17 Pregunta 7. Está de acuerdo en que la adaptación de calidad del producto tuvo una buena aceptación del consumidor al comercializar el producto en el mercado destino. 59

Tabla 18 Pregunta 8. En esta empresa exportadora el margen de beneficio de las exportaciones fue mejor que lo esperado. 60

Tabla 19 Pregunta 9. En esta empresa se ha generado un gran volumen de venta 61

Tabla 20 Pregunta 10. Esta empresa exportadora ha logrado un rápido crecimiento 62

Tabla 21 Prueba de normalidad 64

Tabla 22 Prueba de KMO y Bartlett - Adaptación de producto 66

Tabla 23 Prueba de KMO y Bartlet - Desempeño del exportador. 67

Tabla 24 Varianza total explicada - Adaptación de producto 68

Tabla 25 Varianza total explicada - Desempeño del exportador 68

Tabla 26 Métodos de rotación: Varimax con normalización Kaiser - Adaptación de producto

Tabla 27 Métodos de rotación: Varimax con normalización Kaiser - Desempeño del exportador

Tabla 28 Correlación no paramétrica Rho de Spearman de las dimensiones 70

Tabla 29 Correlación no paramétrica Rho de Spearman de las variables .71

Tabla 30 Correlaciones en la hipótesis general 72

Tabla 31 Rho de Spearman - Hipótesis específica 1 73

Tabla 32 Rho de Spearman - Hipótesis específica 2. 74

Tabla 33 Rho de Spearman - Hipótesis específica 3 75 


\section{Índice de Figuras}

Figura 1. Precio Unitario anual FOB de los principales exportadores de palta en el mundo.

(US\$ $\mathrm{x} \mathrm{KG)}$ 32

Figura 2. Participación de mercado de las exportaciones de Perú 2019 33

Figura 3. Principales importadores de Palta en el mundo (2017-2019) 34

Figura 4. Precio Unitario de Importación anual CIF en los principales mercados de consumo de la Palta 36

Figura 5. Producción de avocado en Perú 2010-2018 (En toneladas) 37

Figura 6. Modelo conceptual de Tantong, Karande, Nair y Singhapakdi 39

Figura 7. Modelo conceptual de Zaiem y Zghidi. 40

Figura 8. Modelo Propuesto. Basado en la investigación de Tantong et al. (2010) 41

Figura 9. Nombre de marca del producto. 52

Figura 10. Etiqueta del producto. 53

Figura 11. Color del producto 54

Figura 12. Diseño principal del producto. .55

Figura 13. Número de líneas de producto. 56

Figura 14. Garantía del producto. 58

Figura 15. Calidad del producto. 59

Figura 16. Rentabilidad. 60

Figura 17. Ventas de exportaciones. 61

Figura 18. Crecimiento de las exportaciones 62 


\section{Introducción}

En los últimos años, el sector agropecuario está recibiendo mayor atención por parte de entidades públicas y privadas. Esto se debe al impulso que las agro exportaciones otorgaron al sector y del reciente boom de productos agroindustriales (Banco Central de Reserva del Perú, 2015), ubicando a la palta como el producto con mayor movimiento y ocupando el primer puesto en el subsector fruta, con una participación del $22.06 \%$ respecto de los otros productos y un crecimiento del $45 \%$ en el periodo 2017-2018 (Camtrade Plus, 2019). Sin embargo, el mayor flujo de exportaciones de palta se da en una presentación con un nivel bajo de transformación y pocas empresas ofrecen una presentación del producto adaptado a las demandas internacionales, lo que convierte al país en uno de los proveedores de los grandes comercializadores de este fruto en el mundo.

Por consiguiente, el objetivo primordial de esta investigación es analizar cómo la adaptación de producto se relaciona con el desempeño del exportador en las empresas exportadoras de palta en Lima 2019, estableciendo las dimensiones que intervinieron para determinar la relación. Los estudios cooperarán a una mayor comprensión a través de conocimientos relevantes que contribuyan a mejorar el desempeño del exportador.

El primer capítulo de la presente investigación tiene como finalidad identificar y plantear el problema para proceder con el análisis actual de la problemática y, posteriormente, ofrecer posibles soluciones que se adecuen frente a este escenario. En adición, se ofrece una lista de resúmenes de los antecedentes obtenidos de artículos académicos y se fijaron las variables competentes para este estudio. Finalmente, se establecieron los objetivos e hipótesis, generales y específicas.

El segundo capítulo comprende el método de investigación a ser utilizado, el tipo de diseño y las variables. Asimismo, se delimita la muestra de la investigación y el instrumento a ser utilizado para la recolección de datos. 
En el tercer capítulo se presentan los resultados de la investigación y la interpretación a través de un análisis estadístico. Asimismo, con la información obtenida se procedió a realizar la discusión con los resultados acerca de la relación entre las variables. Finalmente, se citaron las referencias y los anexos que apoyaron la presente investigación. 


\section{Capítulo I}

\subsection{Problema de Investigación}

\subsubsection{Planteamiento del problema.}

De acuerdo con el Banco Mundial (2019), a partir del 2014, el crecimiento económico del Perú se desaceleró a una tasa promedio anual de 3.1\%. Actualmente, el país ocupa el puesto 65 de 141 economías en el ranking global de competitividad 2019 (World Economic Forum, 2019). Como se sabe, la actividad en las exportaciones, tanto en Perú como los países de la región, se caracterizan por la exportación de commodities, cuyos precios han tenido una caída en los últimos años. Si bien se hacen esfuerzos para impulsar las exportaciones no tradicionales, la mayor cantidad de productos exportados corresponden a commodities del sector minero.

Según el BCRP, el sector agropecuario, conformado por los subsectores agrícola y pecuario representó el 5.5\% del PBI en el año 2018 y tuvo un crecimiento de $2.6 \%$ en el 2017. Pese a las limitaciones que pueda tener el sector, el agrícola es uno de los subsectores que ha presentado un crecimiento sostenido desde el año 2015 (BCRP), el cual en el 2017 fue de $2.6 \%$ y además representa un $60.9 \%$ del sector agropecuario. La agricultura peruana es reconocida como altamente heterogénea debido a la diversidad del clima y agraria (Banco Mundial, 2019). Asimismo, tiene un rol fundamental en el desarrollo económico y social de Perú, pues es una de las actividades que genera una gran cantidad de empleos y aporta en la reducción de la pobreza. Además de ser considerada como el segundo generador de divisas en nuestro país. Con respecto a las exportaciones del sector agro, es importante mencionar que en el 2019 se registró un crecimiento de $7 \%$ con respecto al año anterior, generando un total de 7,000 millones de dólares (Asociación de Gremios Productores Agrarios del país, 2020).

Dentro de los productos con mayor movimiento en las exportaciones, destaca la palta hass, pues ha tenido un crecimiento acelerado en los últimos años, con un aporte significativo para el sector agro en nuestro país. El crecimiento registrado en el 2019 fue de 4\%, con 
exportaciones por un total de 752 millones de dólares (AGAP,2020). Sin embargo, en el 2018, la participación de las exportaciones hacia mercados dispuestos a pagar más por el producto representó menos del 2\%. De acuerdo con Trade Map (2019), en el 2019, el 34\% de las exportaciones peruanas se destinaron a Holanda; el 27\%, a Estados Unidos; y a España y a Reino Unido, $16 \%$ y 9\%, respectivamente. Como es de conocimiento, estos países se caracterizan por la reexportación del producto, ya sea por mejor conocimiento de mercado en temas de embalaje, etiquetado, prácticas de calidad, presentación o estrategias de marketing; tal es el caso de Holanda que no se caracteriza por la producción (Ministerio de Agricultura y Riego, 2019), pero su control en el proceso de maduración, junto con altos estándares de calidad y conocimiento del mercado, le permite llegar al consumidor final (Nature's Pride, 2019).

Refiriéndose a los mercados mencionados anteriormente, se percibe que los precios promedio de compra se encuentran debajo de la media en el mundo; por lo que se infiere que el enfoque actual para las exportaciones peruanas predomina la cantidad, dejando un margen de ganancia reducido. Así, si se priorizan otros destinos como el mercado asiático, por ejemplo, Japón, cuya cuota de mercado representó $1.9 \%$ y se caracteriza por su alta exigencia en cuanto a la presentación del producto, se obtendrían mayores márgenes de ganancia (Sánchez, 2019). Asimismo, países como China, Indonesia, entre otros, han sido identificados como mercados potenciales, considerando el atributo de la palta hass peruana calidad-precio (Ministerio de agricultura y riego, 2019) y actualmente los precios negociados están por encima del promedio mundial. (Trade Map, 2019).

Con respecto a la demanda en el mercado asiático, existe un crecimiento en la tasa de consumo sobre productos orgánicos. Según "Consumer Lifestyles in Hong Kong, China" (Euromonitor, 2018), las ventas registraron un incremento de $13.5 \%$ a $29.3 \%$, en los últimos cinco años. Además, existe una tendencia hacia el consumo de productos más saludables, cuyo crecimiento en las ventas representó un 61.6\%, entre los años 2012 y 2017; una oportunidad 
que debería ser aprovechada por los exportadores peruanos y un motivo por el cual se deben realizar esfuerzos para mantener la calidad de la palta peruana (Asociación de Productores de Palta Hass del Perú, Prohass, 2018). Ello permitirá mejorar su posición no solo en Asia, sino también en el mercado internacional frente a un consumidor exigente que difícilmente confía en marcas de países emergentes o son poco probables a probar productos nuevos (Euromonitor, 2018).

Pese a que las condiciones para el cultivo de palta en Perú, considerado invernadero natural, optimizan el rendimiento de cultivo y representan una fortaleza para la palta hass peruana (Medina, 2015), no es suficiente para convencer al comprador asiático, quien opta por productos orgánicos considerados más seguros y buscan que la producción se dé bajo Buenas Prácticas de Agricultura (Cadilhon y Officer, 2009). Es bajo esta premisa que asocian las certificaciones con la calidad del producto y quienes tienen mayor ventaja son los productos importados de USA y Europa, pioneros en este destino y cuyas marcas están mejor posicionadas, por lo que el trabajo como sector debería enfocarse en consolidar la marca "Avocados from Peru". Finalmente, la apertura de estos nuevos mercados ha impulsado una mejor cooperación entre agricultores, asociaciones como Prohass, agroexportadores, Minagri y SENASA, y los resultados ayudarán a mejorar la introducción del producto en Asia y seguir liderando como tercer comercializador de palta en el mundo.

\subsubsection{Formulación del problema.}

\subsubsection{Problema general.}

¿Cuál es la relación entre la adaptación de producto y el desempeño del exportador en las empresas exportadoras de palta en Lima 2019? 


\subsubsection{Problemas específicos.}

Problema específico 1.

¿Cómo se relaciona la adaptación de marca en el desempeño del exportador en las empresas exportadoras de palta en Lima 2019?

\section{Problema específico 2.}

¿Cómo se relaciona la adaptación de diseño y el desempeño del exportador en las empresas exportadoras de palta en Lima 2019?

Problema específico 3.

¿Cómo se relaciona la adaptación de calidad en el desempeño del exportador en las empresas exportadoras de palta en Lima 2019?

\subsubsection{Justificación de la investigación.}

Entender el mercado destino es un desafío para los exportadores ya que el acceso a la información del mercado local es limitado. Asimismo, las preferencias están cambiando constantemente, por tanto, un exportador encuentra más difícil adaptar su producto en base a las necesidades de cada mercado y a las preferencias de los consumidores (Tantong, Karande, Nair y Singhapakdi, 2010). El enfoque de la presente investigación es descubrir el efecto de la adaptación del producto en el desempeño del exportador y estudiar cómo las tres dimensiones de adaptación (marca, diseño y calidad) afectan el desempeño en las empresas exportadoras de palta en Lima 2019.

Justificación teórica: Existen diversos estudios que proponen la adaptación de producto como estrategia para mejorar en el desempeño de los exportadores, sin embargo, en Perú pocas investigaciones están enfocadas en analizar la interrelación de estas dimensiones. Por tanto, el estudio permite demostrar como las empresas pueden mejorar su desempeño del exportador al adoptar una estrategia de adaptación de producto, a través de métodos estadísticos, lo cual permitirá ampliar el conocimiento con respecto a la adaptación de producto y desempeño del 
exportador, y ser de beneficio para futuras investigaciones que se desarrollen en el sector agrícola.

Justificación social: Uno de los factores que ha estado limitando las actividades de transformación a un nivel primario es la escasa información con respecto a las estrategias que se deben tomar para el posicionamiento de sus productos en el mercado exterior, optando muchas veces por las prácticas de las empresas del mismo sector. Por ende, el presente estudio, proporciona información que el exportador desconoce por falta de investigación, permitiendo adaptar su producto a un mercado más exigente. Esto conllevará a un incremento en el valor de sus exportaciones, favoreciendo también a los productores o agricultores pequeños de palta.

Justificación económica: Por otro lado, el país se beneficiará económicamente por la actividad exportadora y su aporte en la balanza comercial. Cabe resaltar que las exportaciones son la principal fuente de ingresos en los países de Latinoamérica y que la actividad no solo beneficia directamente a los agroexportadores, sino también influye, de manera indirecta, en las actividades de los operadores logísticos involucrados en la exportación de este fruto.

Justificación cultural: Finalmente, el estudio permitirá que los exportadores busquen la consolidación de una marca propia o de la marca país en la mente del consumidor, pues al ser percibida como una marca de prestigio, permitiría que nuevos productos de alimentos frescos se beneficien de este posicionamiento.

\subsection{Marco Referencial}

\subsubsection{Antecedentes.}

A continuación, se seleccionaron once artículos académicos con su respectiva descripción, posterior a una búsqueda exhaustiva de estudios afines al presente trabajo de investigación. Asimismo, con un enfoque de adaptación del producto en el desempeño del exportador. 


\section{Antecedentes Internacionales}

El artículo académico "The Influence of Internal and External Firm Factors on International Product Adaptation Strategy and Export Performance: A Three Country Comparison" (Calantone, Kim, Schmidt y Cavusgil, 2006) tuvo como objetivo general analizar cómo la dependencia de las empresas sobre las exportaciones afecta la estrategia de marketing de la corporación y su desempeño en las exportaciones. Asimismo, los objetivos específicos que guiaron la investigación fueron, en primer lugar, conocer las similitudes y diferencias entre las naciones al realizar un estudio multinacional en desempeño del exportador y, en segundo lugar, determinar la dependencia hacia la exportación, una característica interna de la empresa, y encontrar la relación con el desempeño del exportador a través de la estrategia de adaptación de producto. Para recabar información, se aplicó una encuesta por medio electrónico a una muestra de 1741 empresas de los siguientes países: Estados Unidos, Japón y Corea del Sur. Dentro de los hallazgos más importantes se encontraron los siguientes: En los tres países el desempeño del exportador está vinculado positivamente con el nivel de la estrategia de adaptación de producto. Asimismo, la estrategia de adaptación de la industria influye indirectamente en el desempeño; es decir las empresas se benefician de la estrategia de adaptación de la industria. Las empresas con alta dependencia hacia las exportaciones tendrán una estrategia de adaptación de producto más agresiva, excepto en mercados que son similares al mercado local. Las empresas más abiertas a la innovación tendrán un mejor desempeño del exportador. Por otro lado, se puede afirmar que la estrategia de adaptación del producto tiene un efecto positivo en el desempeño del exportador y un grado de innovación alto a nivel organizacional, sin dejar de lado mejoras en la comunicación que conlleva a un mejor desempeño del exportador en el mercado destino.

El artículo académico "Export product strategy fit and performance: An empirical investigation" (Hultman, Robson y Katsikeas, 2009), investiga el problema de hacer un balance 
entre los beneficios que se obtienen a través de estrategias de estandarización con aquellos logrados bajo la estrategia de adaptación de producto considerando las condiciones locales. El propósito de los autores es determinar como la adaptación de producto (o estandarización), alineado con el contexto en el que la estrategia desarrollada se está implementando, tiene un impacto en el desempeño del exportador. Adoptando una perspectiva en la que la estrategia de producto debe estar vinculada con factores del microentorno y macroentorno y su influencia en el desempeño del exportador. Se obtuvo data a través de encuestas aplicadas a una muestra de 1016 empresas exportadoras manufactureras de Suecia, dentro de tres sectores de exportación de Suecia, Equipos de transporte y maquinaria, productos de madera y papel, productos químicos y caucho. En cuanto al diseño de la investigación se consideraron las siguientes variables: Desempeño del exportador (Desempeño de mercado, desempeño financiero, desempeño cliente), adaptación de producto (nivel de adaptación de productocalidad, producto-diseño/estilo, producto-características/desempeño y producto-marca), factores del microentorno (características del cliente, características del mercado, infraestructura de marketing, intensidad competitiva) y factores del macroentorno (Factores económicos, factores regulatorios/legal, factores socioculturales y factores tecnológicos). Los resultados demostraron que la estrategia de adaptación de producto con un enfoque "strategic fit" tiene relevancia en el desempeño. Sin embargo, el patrón de hallazgos significativos y no significativos resultan de las diversas variables ambientales en el momento de la conceptualización de la estrategia "fit" producto-ambiente al vincularla con el desempeño.

El artículo de investigación "Relationship capabilities, quality, and innovation as determinants of export performance" (Lages, Silva y Styles, 2009) tiene como objetivo entender la relación entre un conjunto de capacidades (aprendizaje organizacional, relaciones y calidad), la estrategia de adaptación del producto (innovación y calidad) y el desempeño de las exportaciones (desenvolvimiento económico y de relaciones). El instrumento de medida 
fue evaluado en primera instancia basado en una investigación exploratoria donde expertos académicos en temas de marketing internacional, exportación, gestión de operaciones y gestión de la calidad examinaron a profundidad todas las medidas. Posterior a ello, se obtuvo una muestra aleatoria de 1332 empresas manufactureras exportadoras en Portugal adquirida de una base de datos de una agencia gubernamental portuguesa. Los resultados muestran que los gerentes deberían invertir en capacidades de gestión de relaciones para conseguir una mejora en la calidad del producto e innovación, lo que a su vez conduce a un desempeño exportador superior e indirectamente contribuye al éxito económico.

El estudio "Factors that reduce rigid product adaptation decisions: The case of exporting firms China" (Li, 2010), a diferencia de otras investigaciones, examina como una estrategia rígida en cuanto a decisiones de adaptación de producto resultaría en un bajo desempeño del exportador. Los autores señalan que la empresa se puede beneficiar de muchas formas permitiéndole anticipar las necesidades de los consumidores y mejorar el desempeño del exportador a través de un incremento de sus ventas. Se desarrolla un modelo de factores (Coordinación en las exportaciones y Proceso de control en las exportaciones) que serían de utilidad para reducir la probabilidad de aceptar una estrategia de decisiones rígidas de adaptación de producto. Los datos de la investigación fueron recabados a través de una encuesta a empresas manufactureras de China dedicadas a la exportación. Se obtuvo una muestra aleatoria de 1000 empresas de un directorio de empresas exportadoras de commodities a quienes se invitó vía mail a participar del estudio. Dentro de los hallazgos más relevantes, se afirma que los factores coordinación en las exportaciones y procesos de control en las exportaciones tienen un efecto negativo en las decisiones rígidas de adaptación de producto. A modo de conclusión, se comprobó que el desempeño de la empresa exportadora se ve afectada por la estrategia de decisiones rígida de adaptación de producto y que esta tiene un mayor efecto mientras la incertidumbre tecnológica aumente. Se recomienda a las empresas evitar tomar 
decisiones rígidas de adaptación de producto diseñando una estructura organizacional que asegure la coordinación entre el departamento de exportación y otras funciones de la empresa cuando se requiera resolver problemas de los mercados de exportación ; y adoptando un proceso de control que permita que los agentes del exterior y distribuidores se involucren al momento de monitorear a los competidores y permita tomar decisiones receptivas para los distintos mercados de exportación.

Según el artículo académico "The Effect of Product Adaptation and Market Orientation on Export Performance: A Survey of Thai Managers" (Tantong, Karande, Nair y Singhapakdi, 2010), se examina el efecto de la adaptación del producto sobre el desempeño de los exportadores en Tailandia y como la orientación del mercado modera la relación entre el desempeño y la estrategia de adaptación del producto. En este estudio se presentan datos del directorio de Exportadores de Tailandia de los cuales se seleccionaron empresas manufactureras excluyendo productos no commodities centrándose en una muestra de 2200 empresas de 13 industrias. Se desarrolló un cuestionario que incluye la orientación de mercado, calculado nivel de unidad de negocios de exportación y se operacionalizó con tres subconstructos: generación de inteligencia (10 ítems), diseminación de inteligencia (7 ítems) y capacidad de respuesta (14 ítems). Se utilizaron escalas de Likert de siete puntos para obtener respuestas a cada una de las 31 afirmaciones. Asimismo, el desempeño del exportador se midió utilizando la dimensión del desempeño de las exportaciones financieras de tres ítems de la escala EXPERF desarrollada por Zou, Taylor y Osland (1998). Por último, se desarrolló una escala de nueve elementos para la adaptación del producto al adoptar la escala de seis elementos de Zou, Andrus y Norvell (1997) tales como el nivel de adaptación de las marcas, el diseño del producto principal, la cantidad de líneas de productos, las garantías del producto y el diseño del paquete. Además, se incluyó elementos relacionados con diferentes aspectos de la adaptación del producto no incluidos en la escala de Zou, Andrus y Novell (1997). Por lo tanto, 
los elementos relacionados con la adaptación de la calidad del producto (Shoham, 1996), el etiquetado (Cavusgil y Zou, 1994) y el color (Whitelock, 1987) fueron incluidos. De acuerdo con Zou, Andrus y Norvell (1997), las respuestas a todos los ítems se obtuvieron en un formato tipo Likert de siete puntos. En vista que la estrategia de adaptación del producto se creó utilizando elementos de diferentes escalas, se realizó un análisis factorial exploratorio (EPT) para descubrir las dimensiones específicas de una estrategia de adaptación de productos. A partir de entonces, se realizó un análisis factorial confirmatorio (CFA) de todas las medidas para probar más la validez de esta escala (Gerbing y Anderson, 1988). En resumen, se conservaron tres componentes (factores) adaptación de marca, adaptación de diseño y adaptación de calidad, también se conservaron siete artículos para los tres factores de adaptación del producto. En conclusión, los resultados ofrecen una representación compleja de la adaptación del producto, la orientación del mercado y el rendimiento. Se encontró que la adaptación del diseño del producto se asocia positivamente con el rendimiento de la empresa; siendo esta una alternativa costosa, por ende, no muchas empresas se involucren en ella. Mientras tanto, la adaptación de marca y calidad no se asoció con el rendimiento; siendo el papel de la marca es irrelevante en esa industria. La adaptación de la marca también puede ser irrelevante si el producto se exporta a residentes tailandeses en el extranjero que realmente compran el producto por razones sentimentales y valoran la marca si es auténtica a sus raíces nativas. En lo que respecta a la adaptación de la calidad, se puede argumentar que la adaptación de la calidad es insignificante y es imposible segmentar los mercados basándose en esta. En cuanto a la orientación al mercado, se concluye que la construcción orientada al mercado subsume el efecto de la adaptación dentro de ella.

El artículo académico "Product Adaptation Strategy and Export Performance: The Impacts of the Internal Firm Characteristics and Business Segment” (Zaiem y Zghidi, 2011) tiene como objetivo examinar la relación entre la estrategia adaptación de producto y desempeño de 
exportación de una compañía, teniendo en cuenta el impacto de las características internas de una empresa y el segmento del negocio. La investigación se realizó a través de un cuestionario a 120 empresas exportadoras de Túnez, de tres sectores seleccionados: mecánica y electrónica, textil, agricultura y agro negocios. El instrumento fue administrado a través de la internet y por entrevistas en la empresa. Dentro de los hallazgos de la investigación destacan los siguientes: El tamaño de la empresa no es una característica determinante en las prácticas comerciales a nivel internacional de las empresas exportadoras (El tamaño de las empresas no influye en la estrategia de adaptación del producto). Mientras mayor es el número de empresas que se atiende en el mercado internacional menor es la necesidad de adaptar el producto, lo más recomendable es la estandarización. Asimismo, no se encontró relación entre el número de años exportando y la estrategia estudiada. Los productos dirigidos al consumidor final son más susceptibles a ser adaptados para el mercado internacional. El grado de adaptación varía de acuerdo al tipo de sector, el que tiene mayor grado es el textil y agro. La adaptación del producto tiene una influencia en el anterior desempeño del exportador y no en el esperado. En conclusión, el estudio demostró que tanto el segmento del negocio, el tipo de producto a exportar, la experiencia de la empresa, así como el número de países que se está atendiendo afectan la estrategia de adaptación del producto exportado. Asimismo, el desempeño de las empresas en el mercado internacional podría mejorar con una adecuada estrategia de marketing.

Según la investigación "Internationalization and the dynamics of product adaptation: The Case of Parfois" (Vladimirova, 2013) se centra en identificar y comprender la cantidad y diferentes cambios requeridos en un producto a causa de diferencias socioculturales y entender su trascendencia en la internacionalización de las empresas. El presente estudio se enfoca en el nivel del producto para comprender qué factores y dimensiones socioculturales pueden demandar adaptaciones y cuáles son las características físicas del producto que deben sufrir 
tales cambios. De este modo, identificar la motivación de las empresas para adaptar o no sus productos a mercados de exportación y percibir las implicaciones de rendimiento de la adaptación de productos. Para ello se planteó las siguientes interrogantes: ¿Cuál de la dimensión cultural requiere cambios en el producto? ¿Qué características del producto sufrieron más cambios debido a los factores socioculturales (y su peso relativo)? ¿Cuáles son los factores que influyen en más cambios en el producto (y su peso relativo)? ¿Qué estrategia de marketing internacional eligieron las empresas y cuáles fueron las motivaciones para eso? ¿Los cambios tienen implicaciones en el desempeño de la empresa (desempeño de exportación)? Se estudió el caso de los productos de Parfois, una empresa portuguesa que produce accesorios de moda para mujeres. Asimismo, se seleccionó el enfoque deductivo para este tipo de estudio. Se descubrió que, para la región del Medio Oriente, el factor que más influyó en cuanto cambios en el producto fue el sociocultural, la religión, seguido de los gustos y/o preferencias; mientras que los menos influyentes fueron el clima y la fisiología. Los resultados para Europa del Este difieren de la región árabe, entre los factores socioculturales, el menos influyentes en adaptación del producto es la religión y los más predominantes son los gustos y preferencias seguidos del factor socioeconómico y el clima. La característica del producto más modificada es la composición / materiales, seguida por la funcionalidad / forma y color. Las características menos modificadas fueron tamaño y diseño. Las características menos modificadas fueron tamaño y diseño. En ambas regiones, las principales adaptaciones se realizaron en forma de extensiones de línea, donde se agregaron o eliminaron colores, materiales, formas y características. La tasa de éxito del producto adaptado en ambas regiones estudiadas ha aumentado. En conclusión, este estudio contribuye a superar las inconsistencias existentes con respecto a la motivación a favor y en contra de la adaptación y brinda a los tomadores de decisiones de las empresas información importante sobre cómo deben promover sus productos. Cada empresa necesita entender si los factores socioculturales, que no son tan 
evidentes y fáciles de analizar, son importantes y requieren cambios en la estrategia de marketing internacional, en relación con el producto físico que se vende en distintos mercados extranjeros.

Según el artículo "Isomorphic Pressures, Peripheral Product Attributes and Emerging Market Firm Export Performance” (Brouthers, O’Donnell y Keig, 2013) Según el estudio, la estrategia más usada por las empresas para ingresar a un nuevo mercado con éxito es adaptar el producto considerando las normas locales. Sin embargo, esto implica altos costes para una empresa del mercado emergente, sobre todo si no cuenta con suficiente recursos financieros y experiencia en el mercado internacional. El objetivo de la investigación es descubrir el efecto de la nueva teoría que los autores plantean con respecto al comportamiento del consumidor en el momento de decisión de compra, los consumidores responden a señales externas como empaquetado y nombre de la marca en el momento de decisión de compra, por ende, adaptar estos dos atributos, tomando como ejemplo a los grandes proveedores del mercado local, tendrían un mejor resultado. Si el impacto de esta nueva estrategia es positivo, las empresas de los mercados emergentes lograrían satisfacer las demandas locales haciendo un uso eficiente de sus recursos limitados al momento de adaptar el producto que desean ingresar en el mercado exterior, y esto se vería reflejado en un mejor desempeño del exportador. Con la finalidad de desarrollar la investigación se recaba información de dos mercados emergentes tales como China y Rumania, a través de entrevistas presenciales usando como instrumento la encuesta. Para una mejor recolección se apoyaron en investigadores de instituciones locales reconocidas para administrar las encuestas. La muestra en China fue de 209 empresas que exportan activamente productos y que hayan enviado a los gerentes a un "Seminario Ejecutivo de Mercado Internacional”, ubicadas en las provincias de Fujian, Guandong, Jiangsu, Shangai and Zhejiang. En cuanto a Rumania se logró identificar a 93 empresas como muestra. Con respecto a los hallazgos encontrados, se identificó que las empresas de los mercados emergentes que 
cambian el nombre de la marca o el empaquetado demostraron niveles altos de satisfacción con el desempeño del exportador que aquellos que usaban otras estrategias de productos. Asimismo, las empresas que cambian el empaquetado para asemejarse más a los grandes proveedores domésticos tienen un mejor desempeño del exportador que las empresas que no lo aplican. Por otro se observó que las empresas industriales están más propensas a cambiar el empaque que cambiar la marca, mientras que las empresas de bienes de consumo se dividen entre cambiar la marca y el empaquetado. En conclusión, el estudio combina los conceptos "mimetic isomorphism" con el concepto producto extendido, obteniendo una nueva teoría que afirma que los consumidores deciden en base a señales externas del producto en la decisión de compra. Se formulan hipótesis y estas son evaluadas en empresas exportadoras de China y Rumania. Finalmente se comprueba que las empresas de mercados emergentes que cambian el nombre de la marca y empaque tienen un mejor desempeño de exportación que las empresas que aplican otras estrategias.

El estudio "The relationship between product adaptation and export performance: a research on the furniture, ready-to-wear, y sector cuero" (Öz, F., y Özmen, A. (2019), tiene como propósito determinar la relación existente entre las variables adaptación de producto y desempeño del exportador en las empresas del sector muebles, cuero y "ready-to-wear" en Turquía. El tipo de investigación es descriptiva. Asimismo, el modelo propuesto por los autores fue diseñado para demostrar la relación existente entre las variables que el estudio tiene como propósito estudiar, adaptación de producto y desempeño del exportador. Con la finalidad de recabar información, se utilizó el instrumento de medición, encuestas aplicado a una muestra de 389 empresas del sector muebles, cuero, ready-to-wear en MYPES exportadoras de Turquía. Los datos fueron analizados por el programa PASWStatistics20, se emplearon pruebas estadísticas como el chi-cuadrado, análisis de regresión. Dentro de los principales hallazgos se menciona: El 96.2\% de gerentes afirman que el adaptar el producto en el mercado de 
exportación marca la diferencia. Asimismo, los gerentes que implementen una estrategia de adaptación de producto y desempeño del exportador, resultan en la diferenciación del producto volviéndose más adecuados para el mercado de exportación. En conclusión, los resultados confirman la hipótesis que señala: Si existe una relación significativa entre la adaptación de producto y desempeño del exportador.

\section{Antecedentes Nacionales.}

Según la investigación "Impacto de la adaptación del producto en el desempeño exportador de las empresas exportadoras de café en Perú 2018” (Melgar y Clelia, 2018) se centra en demostrar la influencia positiva de adaptación del producto al desempeño del exportador, siendo óptimo, se busca maximizar al 100\% las capacidades y herramientas de productores y exportadores para incrementar sus exportaciones del grano de café. En este estudio se toma como muestra 34 empresas que exportan como mínimo 10,000 kilos por año en Perú, se utilizó como instrumento de investigación el Coeficiente de Aiken basadas en encuestas aplicadas. En conclusión, se afirma la hipótesis que existe una relación significativa entre adaptación del producto y desempeño del exportador. Por otro lado, la adaptación de la marca, diseño y calidad son factores claves para un buen desempeño del exportador.

Según la investigación, "La relación de adaptación de producto y orientación de mercado con el desempeño de exportador de las MYPES de Gamarra del sector confecciones 2018" (Espilco y Ramos, 2018), se enfoca en determinar si existe relación entre la adaptación de producto y la orientación de mercado con el desempeño del exportador, el estudio pretende identificar cual es la percepción del flujo de información dentro de la empresa, por este motivo se incluye la variable orientación de mercado. Con respecto a la muestra, el estudio está orientado a las MYPES del sector confecciones del emporio Gamarra dado que se identificó una baja tasa de empresas dedicadas a la exportación, explicado por el poco conocimiento sobre el proceso de internacionalización, y la limitada información con respecto a las tendencias lo 
que resulta en una baja orientación hacia el producto aumentado y se enfocan más en los costos del proceso logístico. Se toma una muestra de 70 empresas dedicadas a la exportación de confecciones, los resultados se obtienen al administrar una encuesta a empresarios de la categoría MYPE. El instrumento de investigación consta de 27 preguntas. El estudio concluye, demostrando la relación positiva de la variable adaptación de producto, orientación de mercado y desempeño del exportador.

\subsubsection{Marco teórico.}

En esta parte de la investigación se procede a definir la variable independiente, adaptación de producto, y la variable dependiente, desempeño del exportador, se mencionan las características, teorías y dimensiones.

\subsubsection{Adaptación de producto.}

\subsection{Definiciones.}

Los autores Cavusgil y Zou (1994), afirman que la estrategia de adaptación de producto es un conjunto de actividades que han sido planificadas por la empresa, consideradas también uniformes y que están enfocadas a satisfacer las preferencias y valores de los consumidores en el mercado local. La adaptación del producto está determinada tanto por fuerzas internas (competencias de la empresa, experiencia con el producto) como externas (cultura, tecnología en la industria, mercado destino competitivo).

Leonidou, Katsikeas y Samiee (2002), definen la adaptación de producto como el grado en el que las empresas adaptan sus productos y los elementos, considerando determinadas variables con la finalidad de introducir el producto actual o aumentado en el mercado destino. Dentro de estas variables se mencionan los factores ambientales, mercados competitivos, el uso de patrones y el comportamiento del consumidor. Esta estrategia beneficia a la empresa ya que se tiene un mayor conocimiento de las características del mercado y el comportamiento del consumidor. Asimismo, ofrece un mayor crecimiento en las ventas de las empresas puesto que 
sus productos satisfacen las expectativas del consumidor lo cual les da un mayor poder sobre sus competidores permitiéndoles determinar con libertad el precio del producto. Finalmente, dada la presión por satisfacer las demandas del mercado anfitrión, las empresas terminan creando productos innovadores tanto para el mercado exterior como para el doméstico.

Los autores Calantone, Tamer-Cavusgil, Schmidt y Shin (2004) definen adaptación de producto como productos cuyos atributos, características físicas y empaque han sido adecuados de tal forma que logran satisfacer las demandas de los consumidores generando de esta forma mayor rentabilidad e ingresos; estos a su vez son distintos en cada mercado en el exterior. Por otro lado, señalan que los determinantes para una adaptación de producto internacional son organización y prácticas de marketing, experiencia relativa del negocio, regulación del mercado de exportación. Asimismo, resalta que los costos asociados a la adaptación del producto serán más altos para la empresa, mientras estos se ajusten a las necesidades de un mercado en específico.

Según Horská, Ubreziova y Kekäle (2007) mencionan que la adaptación del producto es una de las decisiones claves que se debe considerar para el proceso de internacionalización de una empresa. Esta política modifica los atributos del producto o características físicas y embalaje para adecuarse a las necesidades requeridas de segmentos y países; satisfaciendo a los consumidores locales. No obstante, esto puede implicar costos adicionales.

Según Tantong et al. (2010), consiste en la modificación del bien al nivel producto, considerando tres dimensiones (diseño, marca y calidad). Asimismo, señalan que la adaptación de producto debe ser considerada por países emergentes puesto que dependen en gran manera de las exportaciones con distintos mercados, diferenciados por cultura y condiciones socioeconómicas, sistemas políticos y legales, infraestructura de marketing, valores de los clientes y estilos de vida. 


\subsection{Dimensiones de adaptación de producto.}

Los autores Tantong et al. (2010), mencionan tres dimensiones a ser consideradas en la adaptación del producto: Adaptación de marca, Adaptación de diseño y Adaptación de calidad. Asimismo, mencionan cuán decisivo debe ser la adaptación, en sus tres dimensiones, para las empresas de los países emergentes.

\section{Adaptación de la marca.}

De acuerdo con el autor Mengüç (1997), la marca es la imagen del producto cuyos elementos (nombre, símbolo, señal, entre otros) la diferencian de lo que ofrecen sus competidores, señala que los determinantes para la adaptación de la marca son las consideraciones legales y preferencias del consumidor. Asimismo, resalta que algunas empresas optan por mantener sus marcas ya que el cambio implica eliminar material promocional. Sin embargo, señala que esta adaptación se debe realizar cuando se generen problemas políticos, legales o malentendidos por la traducción.

De acuerdo con los autores Tantong et al. (2010), los elementos del "branding" estudiados por distintos autores son los siguientes: etiquetado, empaquetado, estilo, estética del empaquetado y color. Mientras que los estudios analizados por los autores señalan que la estandarización de la marca tiene un efecto negativo en la intensidad de las exportaciones, otros estudios señalan que la adaptación es crucial para el éxito de algunas industrias, como por ejemplo la ropa de cama en la industria británica. Por otro lado, señalan que este tipo de adaptación no tiene importancia si el público objetivo es el mercado de la nostalgia en el país a exportar.

\section{Adaptación del diseño.}

Los autores Tantong et al. (2010), mencionan que algunos de los elementos estudiados en este tipo de adaptación son diseño principal, número de líneas de producto, características del producto. Sin embargo, debido a su alto coste los gerentes no optan por el cambio en el diseño, 
sino la estandarización. En el caso de los países emergentes, se dice que este tipo de adaptación no tiene relevancia si se trata de productos industriales. Por otro lado, en países como Colombia los exportadores tienen un mayor compromiso con la adaptación de diseño.

\section{Adaptación de la Calidad.}

Tantong et al. (2010), señalan que las empresas exportadoras se ven obligadas a realizar este tipo de adaptación al momento de realizar sus actividades, puesto que cada mercado destino delimita normativas o regulaciones para asegurar la inocuidad del producto, en el caso del sector alimentario. Destacando la importancia de la adopción de estándares de calidad de cada país al que se está ingresando. Por otro lado, afirman que instrumentos como la garantía es de utilidad para atraer clientes, ya que se tiene una percepción que mientras mayor es el número de años mejor es la calidad. Finalmente afirman que la adaptación de calidad es tan importante como la adaptación de aspectos como etiquetado, estilo y embalaje.

Vladimirova (2013), define calidad de producto como aquel conjunto de características ya sea de un bien o servicio que logrará satisfacer necesidades. Asimismo, señala que la percepción de calidad varía de un país a otro, independientemente de la similitud del poder adquisitivo o las características socioeconómicas.

\subsection{Teorías relacionadas a la adaptación del producto.}

Adaptación relacionada al usuario (Marco de referencia de Boztepe).

Dado que no es muy común el estudio de la adaptación relacionada al usuario, se estudia la forma en la que el producto genera un valor para los usuarios en un nuevo lugar; en el que el valor es definido como el resultado práctico y simbólico que nace de la interacción entre el usuario y el producto; es decir surge de la experiencia del consumidor con el producto y de la interpretación con respecto al valor, teniendo en cuenta como las propiedades del producto se adaptan a las necesidades que se forman en el contexto social en su localidad, estas pueden ser: comportamientos del mercado local, significados y sistemas; dan una idea de lo que constituye 
el valor para el usuario. Dentro de la categoría de valor encontramos los siguientes: Valor de utilidad, valor de la importancia social, valor emocional, valor espiritual. (Vladimirova, 2013)

Tipos de adaptación según el marco de referencia de Boztepe:

- Adaptación por conveniencia; ayuda a incrementar su capacidad en el contexto local de forma práctica.

- $\quad$ Adaptación de desempeño; mejora el desempeño y la eficiencia en el contexto local.

- Adaptación económica; el propósito es mejorar el valor económico del producto mientras el producto es usado o en el momento de la compra.

- Adaptación por importancia social e identidad; modifica el producto en cualquier aspecto. Genera una conexión entre el usuario y el producto y logra que el cliente se sienta parte de un grupo social en específico.

- $\quad$ Adaptación placer; busca generar una experiencia agradable con el producto.

El estudio del valor en cada una de las categorías permite a las empresas entender cuáles son las dimensiones a ser adaptadas y de esta forma lograr satisfacer las necesidades específicas del cliente. (Vladimirova, 2013)

\section{Mimetic Isomorphism: Extended product.}

La teoría, isomorfismo mimético, sostiene que en el proceso de internacionalización las empresas se encuentran bajo condiciones de incertidumbre y para lograr el éxito al ingresar a nuevos mercados es necesario satisfacer las normas institucionales locales. Sin embargo, esto representa altos costos para una empresa con limitados recursos, por lo que se sugiere optar por una estrategia de imitación, tomando como referencia las estrategias más exitosas adoptadas por las firmas en el mercado local. Se desarrolla una nueva perspectiva de la teoría Isomorfismo Mimético al combinarlo con el concepto producto aumentado, cuyo enfoque se basa en la adaptación de los atributos del producto a través de una estrategia que utilice los recursos de manera efectiva y permita a las empresas exportadoras tener mejores resultados. La teoría 
señala que la decisión de compra de los consumidores se basa señales externas visibles, tales como: packing y marca, y al alterar estos atributos, para satisfacer las normas del mercado local, le otorga una ventaja competitiva y un mejor desempeño. (Brouthers, O’Donnell y Keig, 2013)

\subsubsection{Desempeño del exportador.}

\subsection{Definiciones.}

Morgan y Hunt (1984) y Webter (1992) explicaron que la relación empresa-cliente, son fundamentales para un superior desempeño debido a que, mediante la gestión de las relaciones con los clientes, las empresas aumentan su capacidad de generar beneficios tangibles.

Cavusgil y Zou (1994) definen el desempeño de las exportaciones como una respuesta estratégica de la administración a la interacción de fuerzas internas y externas. Asimismo, estos autores lo disponen como una medida o grado en el cual los objetivos de una empresa, tanto económicos como estratégicos, se logran a través de la planificación y ejecución de la estrategia de marketing con respecto a la exportación de un bien a un mercado extranjero.

Por otro lado, Shoham (1998) conceptualiza el desempeño de las exportaciones como el producto final compuesto de las ventas internacionales de una empresa. Por consiguiente, estudia el concepto como una construcción tridimensional, cuyas dimensiones son: la rentabilidad de la exportación, ventas de exportación, y el cambio en el rendimiento.

Katsikeas, Leonidou y Morgan (2000) detallaron el desempeño exportador como la medida en la cual las empresas obtienen resultados conexos a sus competidores en términos de ventas, rentabilidad, cuota de mercado, e ingresos percibidos. Asimismo, describe la relación entre la percepción y satisfacción general del importador con la oferta del producto.

De acuerdo con Lages et al. (2009) la relación entre el impacto de la estrategia del producto en el desempeño del exportador puede ser directa como indirecta; puesto que se puede incrementar a medida que se acrecienten las relaciones con los importadores. 
En adición, Johanson y Vahlne (1977); Ling-yee y Ogunmokun (2001) señalaron que establecer una relación estable con los importadores brindará conocimiento experimental acerca de los mercados de exportación, de esta manera guiará en aterrizar el conocimiento tácito en conocimiento explícito conduciendo así a mejores resultados económicos y ventajas competitivas.

Asimismo, Tantong et al. (2010) definen el desempeño de las exportaciones como la manifestación de los resultados del comportamiento de las exportaciones cuando se exponen a distintas circunstancias específicas de la empresa y del entorno. Asimismo, señalan que el desempeño de exportación es "multifacético y no puede ser capturado por ningún indicador de desempeño único", lo que muestra la necesidad de seguir un enfoque multidimensional al definir la medición para evaluar el desempeño de exportación, en lugar de utilizar un solo grupo de medición; ya que son insuficientes para cualquier evaluación sólida.

Por último, se puede considerar que el rendimiento de las exportaciones es un concepto idiosincrásico para cada operacionalización, conceptualización y definición de medidas que se adecuan a la realidad en análisis, el tipo de empresa considerada y su entorno (Roxo, Silva y Lisboa, 2014).

\subsection{Dimensiones del desempeño del exportador.}

Según Tantong et al. (2010) el desempeño del exportador, variable unidimensional, se evalúa usando como base la escala EXPERF desarrollado por Zou, Taylor y Osland (1998), desempeño del exportador - financiero, el cual engloba ventas de las exportaciones, crecimiento de las exportaciones y rentabilidad.

\section{Desempeño del exportador Financiero.}

De acuerdo con Tantong et al. (2010) se evalúa el desempeño según las ventas efectuadas de exportación pues estas constituyen una ruta importante para el crecimiento de una pequeña empresa a una mediana. Asimismo, estas son tradicionalmente usadas como un indicador que 
mide el rendimiento de las exportaciones, lo que se define como el porcentaje de las ventas corporativas totales, denominándose intensidad de exportación. Asimismo, se mencionan otras variables como el crecimiento de las exportaciones, y rentabilidad.

\subsection{Teorías relacionadas al desempeño del exportador.}

Enfoque basado en los recursos y de contingencia.

La teoría basada en los recursos se centra en los determinantes internos de la empresa, mientras que el de contingencia se enfoca en los externos. Los determinantes internos hacen referencia a la creación de una ventaja competitiva empleando un conjunto de recursos tales como: todos los activos, capacidades, atributos de la empresa, procesos organizativos, información y conocimiento, etc., dirigidos por una empresa". En otras palabras, "las fuentes de ventaja competitiva son considerados recursos consistentes que son valiosos, raros, inimitables y no sustituibles. Asimismo, se señala que la adquisición y explotación de los recursos únicos de la empresa conllevan a un rendimiento superior. Adicionalmente, se establece que la ventaja competitiva representa los determinantes internos de los resultados de exportación. Mientras que el enfoque de la teoría de la contingencia se centra en la propuesta de que los factores ambientales/ externos de la empresa afectan su desempeño. Esto está respaldado por la estructura-conducta-desempeño (SCP) de la organización industrial (IO), donde propone que la intensidad competitiva de una empresa está delimitada por las características estructurales del mercado, y que la ventaja posicional solo se podrá lograr y conservar si el plan de la estrategia competitiva se efectúa de manera eficiente y efectiva. Por otro lado, se sugiere que "el tipo de desempeño que resulta de las actividades de mercadeo depende de la naturaleza de la tarea, la forma en que se organiza la tarea y la naturaleza de su entorno". Finalmente, se afirma que "el desempeño de las exportaciones está determinado por la medida en que el comportamiento de una empresa coincide o se ajusta a su contexto interno y / o externo". (Sousa, Martínez-López y Coelho, 2008) 
Katsikeas et al. (2000), quienes revisaron numerosas investigaciones empíricas, señala que la mayoría de las investigaciones empíricas han sido limitadas a estudiar los factores determinantes del desempeño del exportador; no obstante no se vinculó dichas relaciones en el marco de una teoría más compleja, pese a que se detecta más acertero construir progresivamente una teoría del resultado exportador sobre la base de la recopilación de hechos confiables que muestren la asociación entre variables independientes y variables dependientes, en oposición de desarrollar primero una plataforma teórica y después probarlas en estudios empíricos

Lages y Lages (2004), crearon una escala múltiple con el objetivo de medir el desempeño exportador en el corto plazo, teniendo como referencia el artículo de Madsen (1998). Básicamente señalaron que la mayoría de autores prestaron pocos esfuerzos por avanzar en la teoría de exportación concerniente a escalas múltiples para evaluar el rendimiento exportador (por ejemplo, Styles, 1998, y Zou et al., 1998). Dando prioridad a la evaluación de corto plazo como un pre requisito para el buen rendimiento del exportador a largo plazo.

La presente escala múltiple está compuesta por tres dimensiones: (1) satisfacción con el desempeño exportador en el corto plazo, (2) incremento de la intensidad exportadora en el corto plazo, y (3) expectativa de mejora del desempeño exportador en el corto plazo. Asimismo, en el 2009 Lages incorporó la teoría de redes, denominándose la "NEP scale", añadiendo indicadores vinculados con la red de proveedores y clientes. Estos últimos agentes son considerados una importante fuente de creación de valor y ventajas competitivas.

Tabla 1

Resultados de la teoría de redes en el Desempeño Exportador

\begin{tabular}{ll}
\hline Autores & Resultados según escalas \\
\hline \multirow{3}{*}{ Lages y Lages (2004) } & Escala múltiple: STEP scale \\
& $\begin{array}{l}\text { Satisfacción con el desempeño exportador. } \\
\text { - Incremento de la intensidad exportadora. }\end{array}$ \\
\hline
\end{tabular}




\begin{tabular}{|c|c|}
\hline & $\begin{array}{l}\text { - Expectativas de mejora en el desempeño } \\
\text { exportador }\end{array}$ \\
\hline Lages et al. (2009) & $\begin{array}{l}\text { Escala múltiple: NEP scale } \\
\text { - Aspectos generales del performance exportador. } \\
\text { - Relaciones con el importador. } \\
\text { - Relaciones con los proveedores. } \\
\text { - Calidad de componentes. }\end{array}$ \\
\hline $\begin{array}{l}\text { Papadopoulos y Martín } \\
\text { Martín (2010) }\end{array}$ & $\begin{array}{l}\text { - Obtención de nichos en los mercados de } \\
\text { exportación. } \\
\text { - Mejora en la cuota del mercado. } \\
\text { - Diversificación de clientes externos. } \\
\text { - Medidas de ventas de exportación e intensidad } \\
\text { exportadora. }\end{array}$ \\
\hline Mysen (2013) & $\begin{array}{l}\text { - Medidas financieras } \\
\text { - Medidas de ventas } \\
\text { - Medidas de rentabilidad. } \\
\text { - Desempeño en mercados externos en relación al } \\
\text { mercado local. } \\
\text { - Medidas no financieras. } \\
\text { - Satisfacción. } \\
\text { - Desempeño estratégico. } \\
\text { - Escalas compuestas. }\end{array}$ \\
\hline
\end{tabular}

Fuente: "Conceptualización del desempeño exportador: análisis de los avances en la literatura de los negocios internacionales". Horta, Roberto (2015). Elaboración propia

\subsubsection{Sector agrícola.}

Según el BCRP, el sector agrícola ha demostrado un crecimiento sostenido desde el año 2015, y representa un $60.9 \%$ del sector agropecuario. Este sector forma una parte importante de la economía, con un crecimiento de $3.3 \%$ anual promedio, representa el $7.3 \%$ del PBI en Perú (Banco Mundial, 2018). Asimismo, en el 2010, el gasto público destinado a este sector fue de 2.5 billones de soles, que equivale $0.6 \%$ del PBI.

La producción del sector agrícola está orientada al mercado interno, la agroindustria y la agro exportación, siendo este último de vital importancia y que ha demostrado un gran aporte al crecimiento del sector. Con más de 2017 empresas agroexportadoras aproximadamente, el valor de las exportaciones agrícolas en el 2016 fue de 5.78 billones de dólares, debido a la 
diversificación de productos, crecimiento en las exportaciones de productos no tradicionales, incremento de exportadores e ingreso a nuevos mercados. (Banco Mundial, 2018)

Se describe a la agricultura peruana como altamente heterogénea debido a la diversidad de su clima y la diversidad agraria. Asimismo, es considerada como un generador de empleo e ingresos sobre todo en las zonas más alejadas de nuestro país. Se dice que el sector emplea aproximadamente un cuarto de la población urbana informal.

Por otro lado, el estudio menciona que el crecimiento en este sector ha tenido diferencias entre las regiones y se pueden observar dos tipos de sistemas: sistemas agrícolas dinámicos y sistemas agrícolas estáticos. El primer sistema se puede visualizar en gran parte de la costa de nuestro país y en ciertas áreas de la selva se caracteriza por su alta productividad y por contar con un mayor acceso a mejores equipos tecnológicos. En cambio, el sistema estático se caracteriza por su improductividad y está enfocado a la subsistencia, este tipo de sistema se puede observar en grandes áreas de la sierra y la selva.

En nuestro país, según censo 2012, el 80\% de las unidades agrícolas cuentan con menos de 5 hectáreas, dentro de estas unidades encontramos a los pequeños agricultores con una baja producción y con ingresos demasiados bajos; sin embargo, las pocas opciones de empleo obligan a estas personas a continuar laborando en una unidad familiar. Gran parte de estas unidades estarían ubicadas en la sierra de nuestro país ya que según el censo en el 2012 el 42\% de lo cosechado se destinó a la comercialización. En la costa el porcentaje fue de $81 \%$ y en la selva 67\%. (Banco Mundial, 2018).

Dentro de los desafíos que enfrenta este sector es el cambio climático debido a las inundaciones, sequías, huaycos, olas de frío. Por otro lado, este sector se verá afectado por la disponibilidad del agua sobre todo en la costa de nuestro país cuyo porcentaje de cosecha destinado a la comercialización es mayor al de otras regiones. Asimismo, se resalta la importancia de la formulación de políticas en la agricultura peruana y de un mayor apoyo a 
este sector por el efecto que tendría en cuanto a la reducción de dependencia en la industria extractiva, específicamente de productos mineros que tienen una cuota mayor en la participación de las exportaciones en nuestro país (Banco Mundial, 2018).

\subsection{La palta.}

Según Minagri (2019), la palta, conocida también como aguacate o avocado, es una fruta cuya demanda ha crecido en los últimos, sus propiedades y beneficios a la salud han llamado la atención de los consumidores en los países de las economías emergentes lo que ha resultado en un incremento en la demanda de esta fruta. El producto es considerado climatérico, lo cual ha resultado en una oportunidad para el proceso de exportación, ya que el tratamiento de post cosecha permite que el consumidor final reciba un producto en óptimas condiciones.

Actualmente una de las variedades más exportadas es la palta hass cuya participación es de un $80 \%$ con respecto a otras variedades. La característica física del producto ha permitido que el proceso de logística no dañe su calidad es por eso que esta variedad está reemplazando los cultivos de la palta fuerte en el mundo. Entre otras variedades, se pueden mencionar: fuerte, nabal, Pinkerton, bacon, reed, ettinger, gween, entre otros. (Minagri, 2019).

Respecto a la estacionalidad de la palta, el producto alcanza los volúmenes más importantes entre los meses de marzo hasta setiembre, un periodo que debería ser usado como ventaja en las exportaciones ya que es la estación en donde se registran niveles bajos de abastecimiento de las exportaciones mexicanas. (Minagri, 2019)

Tabla 2

Principales variedades de palta en Perú

\begin{tabular}{ll}
\hline Variedad & \multicolumn{1}{c}{ Descripción } \\
Hass & $\begin{array}{l}\text { Variedad más demandada en el mercado } \\
\text { internacional. } \\
\text { Color de cáscara oscuro cuando madura. }\end{array}$ \\
\hline
\end{tabular}


- Cáscara medianamente gruesa, ayuda a que el producto se mantenga en todo el proceso logístico.

- Estacionalidad: Mayo- Julio

- Temporada baja de cosecha: marzo, abril, agosto, setiembre.

- No cambia de color en el proceso de maduración.

- Cáscara es de color verde.

- La pulpa de calidad buena y el tamaño de la semilla es más grande a comparación de la semilla de la Hass.

- Estacionalidad: marzo - agosto.

- Temporada baja de cosecha: Enero, febrero, setiembre - noviembre.

- Se caracteriza por su forma casi redonda.

- Cáscara lisa y algo gruesa de color verde oscuro.

Nabal

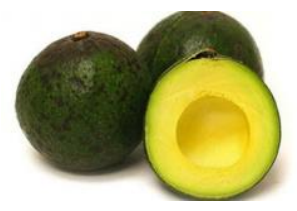

- Tiene el contenido más bajo en grasas de las otras variedades. (15\%-18\%)

- Estacionalidad: setiembre - noviembre.

- Temporada baja de cosecha: julio, agosto y diciembre.

Fuente: Minagri (2017), Palta avocado fact sheet y Minagri (2015) La palta producto estrella de exportación.

Principales países exportadores de palta en el mundo.

Según Minagri (2019), México era el mayor exportador de palta en el mundo (en toneladas), en segundo lugar, se ubicaba Perú cuya tasa de crecimiento superaba a la de importantes países comercializadores, la participación de mercado de estos países fue $45 \%$ y $12.4 \%$ respectivamente.

Con el pasar de los años, México es uno de los países que se ha mantenido como el país que lidera en las exportaciones de palta en el mundo. Su participación de mercado fue de $43.8 \%$ en el año 2019, mientras que la participación de Perú fue 11.8\% (Trademap, 2020). Si bien su crecimiento anual promedio era 17\% hasta el 2017 (Minagri, 2019) su participación de 
mercado ha reducido en porcentaje debido al crecimiento en las exportaciones de países como Países Bajos, Perú, España y Chile. (Trademap, 2020).

Con respecto a las exportaciones de Países Bajos, se puede observar un crecimiento acelerado en las exportaciones. Hasta el año 2018, se posicionaba como el tercer exportador de palta en el mundo, en toneladas, pero en el año 2019 logró desplazar a Perú colocándose como segundo en el top 10 de los principales exportadores de palta. (Trademap, 2020). Se puede apreciar que el precio FOB por kilogramo de palta (anual promedio), supera el de los países latinoamericanos. Según Minagri (2019), este país, se caracteriza por la reexportación de insumos provenientes de Latinoamérica y actúa como un centro de distribución mundial debido a su ubicación y la logística disponible. Cabe resaltar que Países Bajos es uno de los principales mercados destino de las exportaciones peruanas. En el 2019 su participación fue de 34\% del total de las exportaciones de Perú. (Trademap, 2020)

Tabla 3

Exportaciones de palta en el mundo 2015-2019 (En miles de dólares)

\begin{tabular}{clccccc}
\hline $\mathrm{N}^{\circ}$ & \multicolumn{1}{c}{ País } & 2015 & 2016 & 2017 & 2018 & 2019 \\
\hline 1 & México & 1662366 & 2050763 & 2827913 & 2562387 & 2789668 \\
2 & Países Bajos & 426151 & 644611 & 796910 & 888435 & 1033150 \\
3 & Perú & 303779 & 396583 & 581229 & 722310 & 751330 \\
4 & España & 221402 & 272677 & 348130 & 353580 & 384646 \\
5 & Chile & 161881 & 297326 & 391115 & 273628 & 300699 \\
6 & Estados Unidos de & 99365 & 128665 & 152283 & 179635 & 154309 \\
7 & América & 52695 & 63901 & 78011 & 118289 & 102397 \\
8 & Kenya & 46569 & 58280 & 70921 & 61602 & 91569 \\
9 & Colombia & 10279 & 35040 & 52948 & 62732 & 89053 \\
10 & República Dominicana & 16586 & 33449 & 48860 & 50757 & 86904 \\
& Mundo & 3328409 & 4374611 & 5824594 & 5848061 & 6370156 \\
\hline
\end{tabular}

Fuente: Trademap (2020) 
Tabla 4

Exportaciones de palta en el mundo 2015-2019(En toneladas)

\begin{tabular}{|c|c|c|c|c|c|c|}
\hline $\mathrm{N}^{\circ}$ & País & 2015 & 2016 & 2017 & 2018 & 2019 \\
\hline 1 & México & 863503 & 926597 & 897748 & 1091936 & 1112136 \\
\hline 2 & Países Bajos & 151605 & 209970 & 243811 & 312266 & 317984 \\
\hline 3 & Perú & 175640 & 194098 & 247364 & 359428 & 312073 \\
\hline 4 & Chile & 97768 & 160740 & 193309 & 144422 & 156973 \\
\hline 5 & España & 84384 & 91665 & 107098 & 108891 & 119144 \\
\hline 6 & Kenya & 38858 & 46682 & 51507 & 71879 & 63356 \\
\hline 7 & $\begin{array}{l}\text { Estados Unidos } \\
\text { de América }\end{array}$ & 37869 & 53350 & 50907 & 68477 & 59377 \\
\hline 8 & Sudáfrica & 57666 & 57866 & 43492 & 89343 & 47948 \\
\hline 9 & Colombia & 5543 & 18201 & 28487 & 30009 & 44570 \\
\hline \multirow[t]{2}{*}{10} & $\begin{array}{l}\text { República } \\
\text { Dominicana }\end{array}$ & 15272 & 26357 & 35374 & 36090 & 44202 \\
\hline & Mundo & 1643565 & 1948739 & 2064017 & 2497716 & 2496739 \\
\hline
\end{tabular}

Fuente: Trademap (2020)

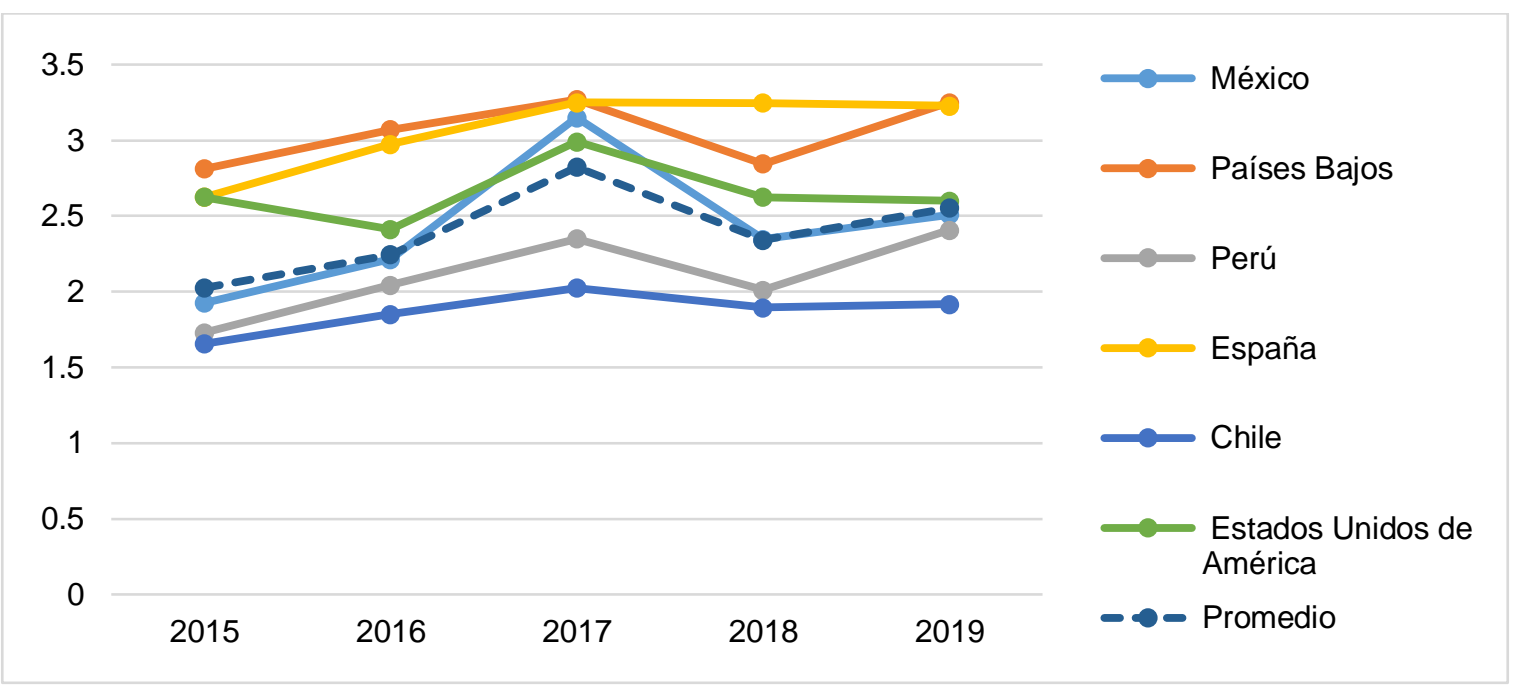

Figura 1. Precio Unitario anual FOB de los principales exportadores de palta en el mundo. (US\$ x KG)

Fuente: Trademap (2020). Elaboración Propia. 


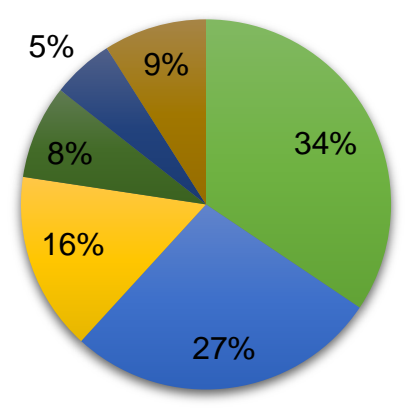

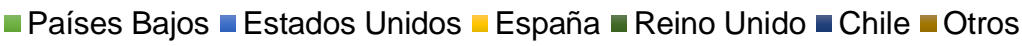

Figura 2. Participación de mercado de las exportaciones de Perú 2019

Fuente: Trademap (2020). Elaboración propia.

Principales Importadores de palta en el mundo.

Dentro de los países importadores en el mundo se puede identificar a Estados Unidos, Holanda, Francia, España y Reino Unido. Las importaciones registran un crecimiento sostenido y se registra una tasa de crecimiento promedio de $11 \%$ anual, en general. España tiene un crecimiento promedio de $18 \%$, Holanda $15 \%$ y Estados Unidos con un $11 \%$.

Tabla 5

Principales importadores de Palta en el mundo 2017-2019 (En toneladas)

\begin{tabular}{lrcccc}
\hline \multicolumn{1}{c}{ Importadores } & $\mathbf{2 0 1 7}$ & $\mathbf{2 0 1 8}$ & $\mathbf{2 0 1 9}$ & Acum. & $\begin{array}{c}\text { Market } \\
\text { Share }\end{array}$ \\
\hline Estados Unidos & 900,198 & $1,038,111$ & $1,105,375$ & $3,043,684$ & $45 \%$ \\
de América & & & & & \\
Países Bajos & 267,197 & 345,261 & 348,883 & 961,341 & $16 \%$ \\
Francia & 146,034 & 157,370 & 164,970 & 468,374 & $10 \%$ \\
España & 98,902 & 129,323 & 136,013 & 364,238 & $9 \%$ \\
Reino Unido & 105,023 & 117,667 & 116,304 & 338,994 & $8 \%$ \\
Otros & 634,859 & 828,871 & 786,356 & $2,250,086$ & $13 \%$ \\
\hline Total & $2,152,213$ & $2,616,603$ & $2,657,901$ & $7,426,717$ & $100 \%$
\end{tabular}

Fuente: Trademap (2020). Elaboración propia. 


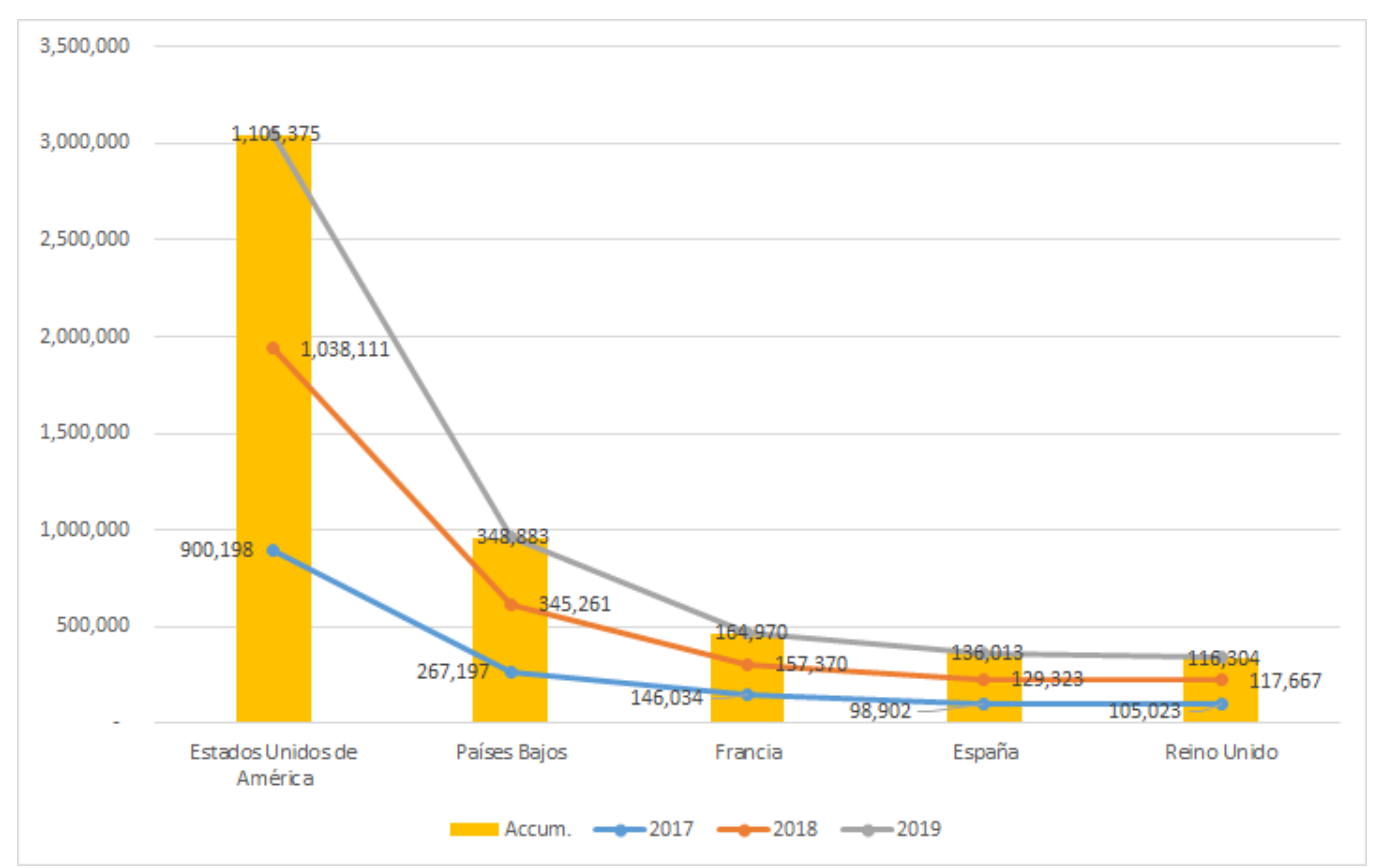

Figura 3. Principales importadores de Palta en el mundo (2017-2019)

Fuente: Elaboración propia.

En el caso de Estados Unidos se puede mencionar que gran parte de sus importaciones provienen de México con una participación de mercado de 88.2\%, importando en el 2019 un total de 976613 toneladas. Asimismo, en el 2019 registró una tasa de crecimiento de $18 \%$ (valores importados) con respecto al año anterior. Cabe resaltar que la tasa de crecimiento anual es de 13\% (Trademap, 2020). La ventaja de México con respecto a sus competidores es su ubicación (proximidad al principal importador de palta en el mundo) lo cual le permitiría llegar al consumidor final con precios competitivos. En cuanto a la estacionalidad, los meses de mayor producción se dan entre septiembre y mayo (Minagri, 2019). Seguido de México, se encuentra Perú con un total de 85174 toneladas importadas en el 2019 y una participación de mercado de 8.6\%. En tercer lugar, se encuentra Chile con 45782 toneladas en el 2019 y una participación de 1.6\%. (Trademap, 2020). Finalmente, la demanda de Estados Unidos con respecto a la del mundo es significativa lo cual le permite determinar el comportamiento de precio y demanda en el mercado.

Respecto a las importaciones del bloque económico Unión Europea, Países Bajos figura como el principal importador del bloque con 348883 toneladas importadas en el 2019, 
considerado como uno de los grandes comercializadores, ya que no se caracteriza por la producción de este tipo de producto sino por la importación y exportación, su participación es de $36.5 \%$ del total importado por el bloque, con una tasa de crecimiento anual de $22 \%$. En este mercado los abastecedores latinoamericanos como Perú, México y Chile compiten contra países africanos como Kenya, Israel y Sudáfrica, quienes registran tasas de crecimiento anuales de $23 \%, 17 \%$ y $7 \%$ respectivamente. Por otro lado, países como Francia y España se muestran como mercados potenciales debido a una creciente demanda sostenida y no cuentan con una mayor producción interna para abastecer el mercado. (Trademap, 2020)

Después de la Unión Europea se puede identificar nuevos mercados potenciales tales como Reino Unido, Canadá, Japón con un total de toneladas importadas de 116 304, 94961 y 77287 respectivamente. En el caso de Reino Unido, Perú lidera en la lista de los mercados que proveen el producto en este país con una participación de mercado de $20.7 \%$ seguido de Chile, quien es el principal competidor de Perú, con una participación de mercado de $20.6 \%$ y una tasa de crecimiento anual de $153 \%$. Con respecto a Canadá, se puede identificar que el principal proveedor es México con una cuota de mercado de $94.1 \%$ mientras que Perú solo tiene una participación de 3.6\%. Finalmente, en Japón, las importaciones de procedencia peruana empiezan a mostrar un crecimiento significativo a partir del año 2016 luego de la implementación del protocolo fitosanitario en el 2015, que regula el ingreso del fruto libre de enfermedad. (Minagri,2019) Si bien la cuota de mercado es de 5.9\%, un porcentaje muy bajo a comparación de México quien tiene la mayor cuota del mercado, Perú registra una tasa de crecimiento anual de 265\%. En el 2019 se registraron un total de 4480 toneladas importadas de Perú, esperando que esta cifra muestre un crecimiento teniendo en cuenta la calidad y el precio competitivo de la palta peruana. (Trademap, 2020)

A continuación, se muestra la evolución de los precios internacionales de la palta valor CIF, en donde se puede apreciar que mercados como Estados Unidos y Holanda importan a precio 
por debajo del promedio mundial, mientras que mercados como China y Japón demandan el producto a un precio mayor al promedio mundial. De acuerdo con Minagri (2019), los mercados mencionados inicialmente han logrado consolidarse y los productos que usualmente llegan a este destino son usados para la reexportación a Asia, Medio Oriente u otros destinos en Europa.

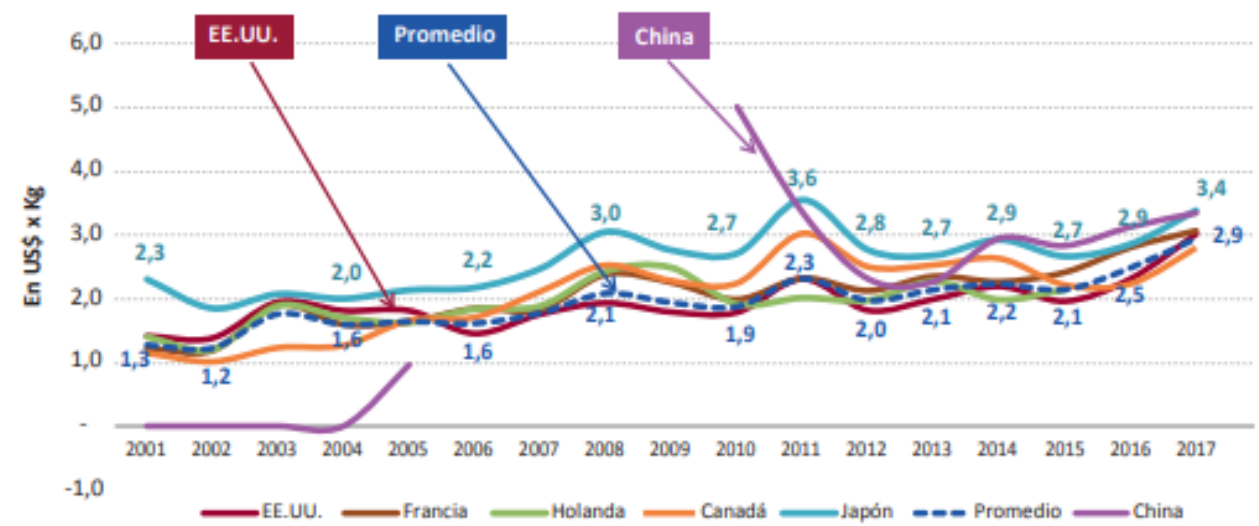

Figura 4. Precio Unitario de Importación anual CIF en los principales mercados de consumo de la Palta

Fuente: Minagri (2019)

Principales productores de palta en el mundo.

Según Minagri (2019), señala que existe un crecimiento de 5.1\% en la producción mundial de palta en el mundo. Asimismo, señalan que México es uno de los países con mayor cuota de participación (34\%), seguido por República Dominicana con una cuota de $11 \%$ y en tercer lugar se ubica Perú que representa un $8 \%$ de la producción mundial, con respecto a los datos del 2017 del FAOSTAT. La producción de Perú registra tasa de crecimiento promedio de 14.4\%, mayor a la del promedio del mundo, lo cual nos permitiría obtener una mayor participación del total de la producción a largo plazo, desplazando de esta forma a República Dominicana. Actualmente el rendimiento está incrementando a una tasa promedio de $0.2 \%$ en el mundo. El rendimiento de República Dominicana ha duplicado las toneladas producidas en 
el periodo 2007-2017 pasando de 26 a 43 toneladas producidas por hectárea. Cabe resaltar que en la data de FAOSTAT, no se registraron países como Reino Unido y Países Bajos.

Tabla 6

Principales productores de palta en el mundo (En toneladas)

\begin{tabular}{|c|c|c|c|c|c|}
\hline $\mathrm{N}^{\circ}$ & País & 2015 & 2016 & 2017 & 2018 \\
\hline 1 & México & 1644226 & 1889354 & 2029886 & 2184663 \\
\hline 2 & República Dominicana & 526438 & 601349 & 637688 & 644306 \\
\hline 3 & Perú & 367110 & 455394 & 466796 & 504517 \\
\hline 4 & Indonesia & 382530 & 304938 & 363157 & 410094 \\
\hline 5 & Colombia & 309852 & 294389 & 308166 & 326666 \\
\hline 6 & Brasil & 180652 & 196545 & 212873 & 235788 \\
\hline 7 & Kenya & 136420 & 176045 & 217688 & 233933 \\
\hline 8 & $\begin{array}{l}\text { Estados Unidos de } \\
\text { América }\end{array}$ & 207750 & 125237 & 170261 & 168528 \\
\hline 9 & Venezuela & 128601 & 130290 & 133453 & 139685 \\
\hline 10 & Israel & 93000 & 101500 & 110000 & 131720 \\
\hline
\end{tabular}

Fuente: FAOSTAT (2019).

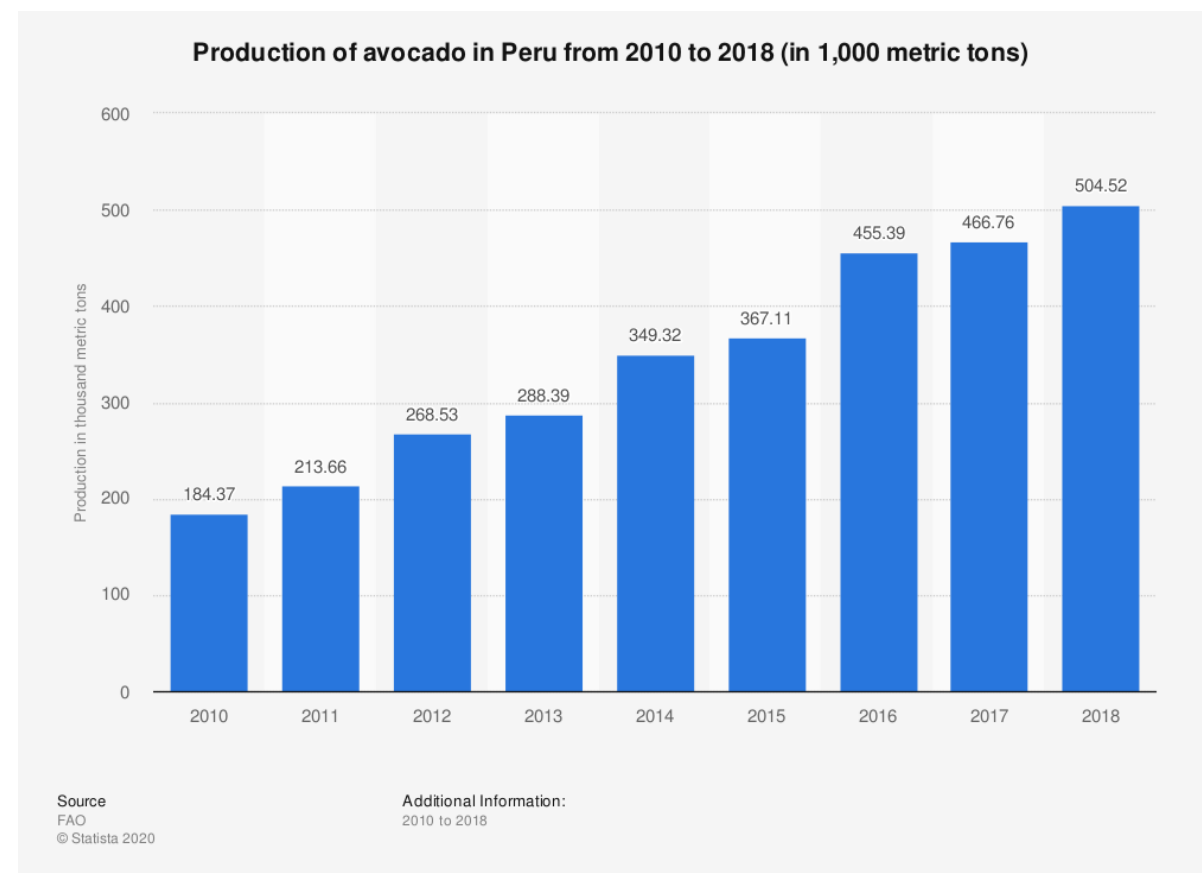

Figura 5. Producción de avocado en Perú 2010-2018 (En toneladas)

Fuente: STATISTA (2020) 


\subsubsection{Modelos previos.}

1.2.3.1. El efecto de la orientación de mercado en la adaptación de producto y el desempeño del exportador.

En el modelo expuesto se propone los efectos de la estrategia de adaptación del producto en el desempeño del exportador que tienen una alta orientación de mercado. Según los resultados del estudio la estrategia de adaptación se vincula positivamente con el diseño, la marca y calidad. Queda en evidencia que el grado de orientación de mercado desempeña un rol moderador en la relación de adaptación y desempeño, pues si las empresas tienen un nivel bajo de orientación, la relación de adaptación y desempeño es alto. No obstante, las empresas con un mayor nivel de orientación generan una muy alta relación entre adaptación y desempeño.

Dentro de los elementos de marca se encuentra el nombre, el símbolo y el signo los cuales permiten diferenciar los productos de sus competidores, según Mengüç (1997). Por otro lado, la modificación de los nombres de la marca involucra costos adicionales que las empresas deberían tomar en cuenta. Se reafirmó que la adaptación del diseño y la calidad fueron elementos importantes para el éxito de las exportaciones sobre todo para empresas de mercados emergentes pues en comparación con las compañías de mercados desarrollados, que cuentan con consumidores sofisticados con expectativas de mayor calidad, ofrecen productos garantizados y de una alta calidad brindando confianza a los consumidores finales. En defecto, las empresas de mercados emergentes deben estar enfocadas en lograr conseguir este objetivo. 


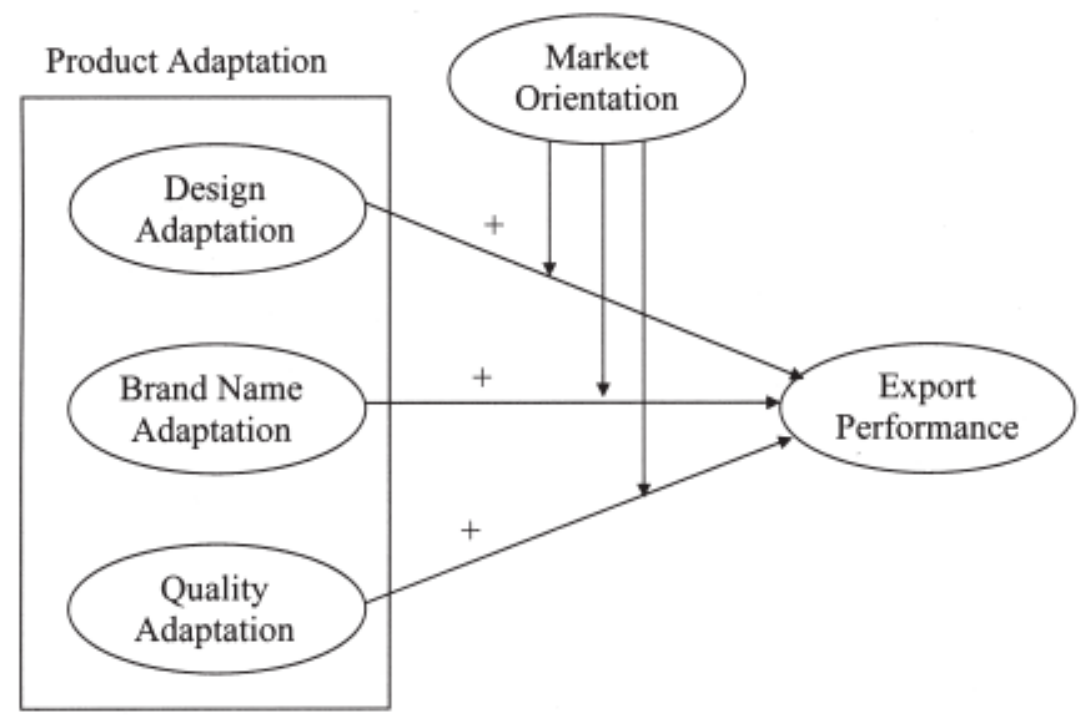

Figura 6. Modelo conceptual de Tantong, Karande, Nair y Singhapakdi Fuente: Tantong Karande, Nair y Singhapakdi (2010)

\subsubsection{Influencia de características internas y externas de la empresa en la estrategia de adaptación de producto y su efecto en el desempeño del exportador.}

El modelo sugiere 4 hipótesis que estudian la influencia de los factores internos y externos de una empresa en la estrategia de marketing adaptación de producto y 1 hipótesis con respecto a la influencia de la adaptación de producto sobre el desempeño del exportador. Dentro de los factores internos el marco incluye las siguientes variables: el tamaño de la empresa (-), la experiencia de la empresa en las exportaciones (Número de años en las exportaciones (-), número de países atendidos (+)) y el tipo de producto (+) (industrial, bienes de consumo). Asimismo, el modelo propone la variable segmento de negocio (+) como un factor externo y estudia cómo la estrategia adaptación de producto está influenciada por esta variable. Finalmente, el modelo plantea identificar como la estrategia adaptación de producto influye el desempeño del exportador puesto existe una controversia con respecto al efecto de cada una de las estrategias en el desempeño del exportador. Además, los autores señalan que no hay antecedente que haya usado la estrategia de marketing de exportación como mediador entre las 
características de una empresa y el desempeño del exportador (desempeño previo (+), desempeño esperado (-)).

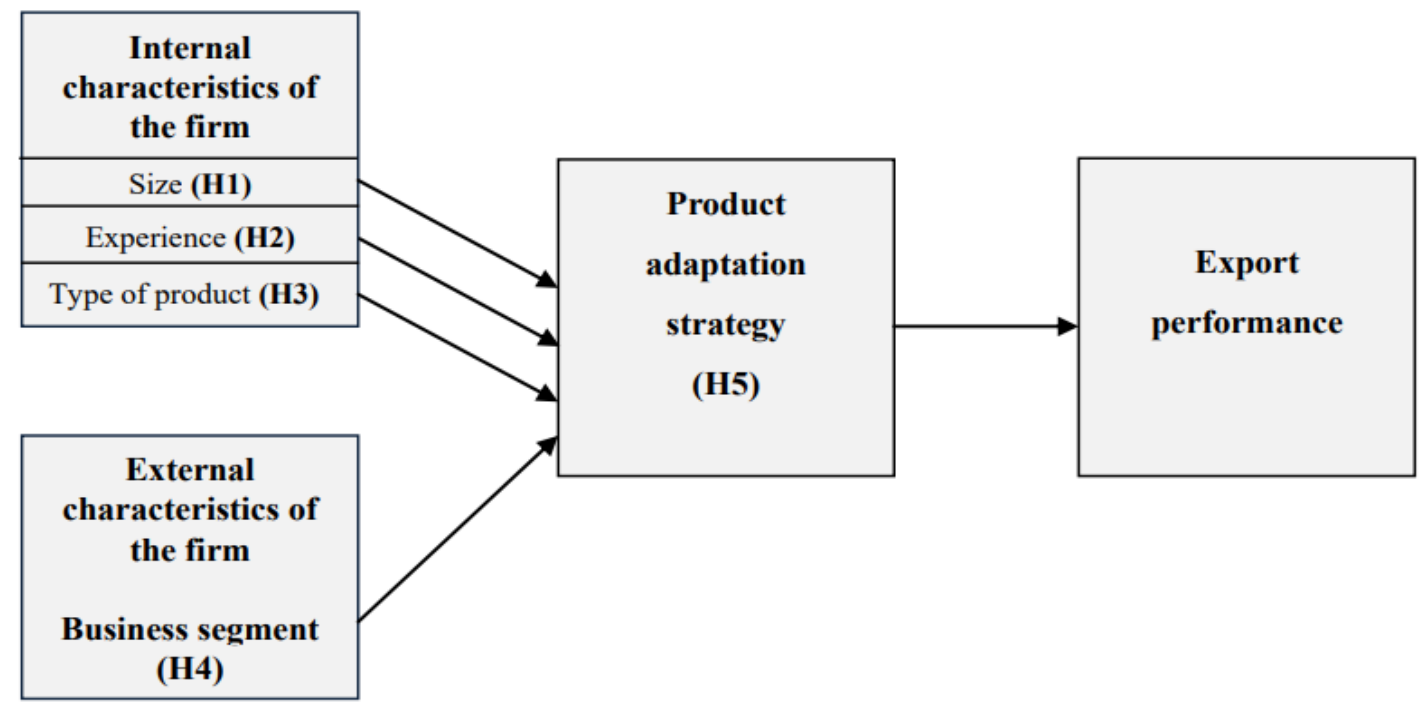

Figura 7. Modelo conceptual de Zaiem y Zghidi

Fuente: Zaiem y Zghidi (2011)

\subsubsection{Modelo propuesto}

En esta investigación se analizó la relación entre la variable adaptación de producto y desempeño del exportador. La primera variable, adaptación de producto, posee 3 dimensiones las cuales son: adaptación de marca, adaptación de diseño y adaptación de calidad. Asimismo, se tiene la variable desempeño del exportador la cual nos permitirá formular junto con la primera variable, las hipótesis y objetivos en la presente investigación. A continuación, se muestra el modelo planteado para la presente investigación, en donde se puede visualizar el cruce de las variables adaptación de producto y desempeño del exportador y los ítems que corresponden a cada variable. 


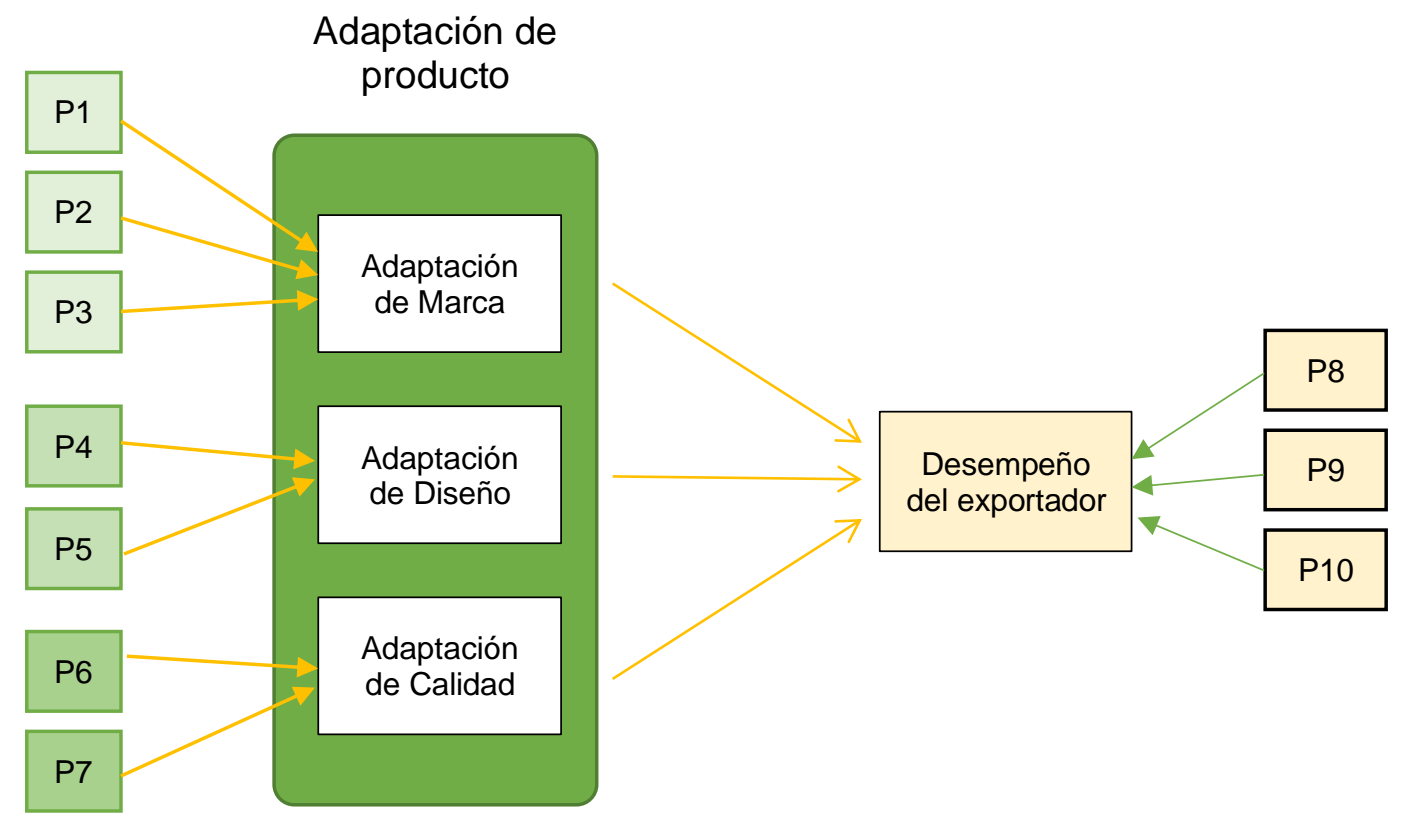

Figura 8. Modelo Propuesto. Basado en la investigación de Tantong et al. (2010)

Fuente: Adaptado de Tantong, Karande, Nair y Singhapakdi (2010)

\subsection{Objetivos e Hipótesis}

\subsubsection{Objetivos.}

Objetivo General.

Analizar la relación de la adaptación de producto con el desempeño del exportador en las empresas exportadoras de palta en Lima 2019.

\section{Objetivo Específico 1.}

Determinar la relación de la adaptación de marca con el desempeño del exportador en las empresas exportadoras de palta en Lima 2019.

\section{Objetivo Específico 2.}

Determinar la relación de la adaptación de diseño con el desempeño del exportador en las empresas exportadoras de palta en Lima 2019. 


\section{Objetivo Específico 3.}

Determinar la relación de la adaptación de calidad con el desempeño del exportador en las empresas exportadoras de palta en Lima 2019.

\subsubsection{Hipótesis.}

Hipótesis General.

La adaptación de producto tiene relación con el desempeño del exportador en las empresas exportadoras de palta en Lima 2019.

\section{Hipótesis Específica 1.}

La adaptación de marca está relacionada con el desempeño del exportador en las empresas exportadoras de palta en Lima 2019.

\section{Hipótesis Específica 2.}

La adaptación de diseño está relacionada con el desempeño del exportador en las empresas exportadoras de palta en Lima 2019.

\section{Hipótesis Específica 3.}

La adaptación de calidad está relacionada con el desempeño del exportador en las empresas exportadoras de palta en Lima 2019. 


\section{Capítulo II}

\subsection{Método}

La presente investigación se desarrolló bajo un enfoque cuantitativo, caracterizado por el orden secuencial en el proceso y por emplear métodos estadísticos para la recolección de datos (Hernández, Fernández y Baptista, 2010).

\subsubsection{Tipo de investigación.}

El tipo de investigación empleado es de tipo correlacional. De acuerdo con los autores Hernández et al. (2010), los estudios con alcance correlacional se enfocan en determinar si existe vínculo entre dos variables (a más) en la muestra a estudiar.

\subsubsection{Diseño de investigación.}

Con respecto al diseño de investigación que se usó es un diseño no experimental, de tipo transversal y con un alcance correlacional. Hernández et al. (2010) definen el diseño no experimental como aquel estudio cuyas variables dentro de la investigación no son manipuladas para observar el efecto en otras variables, la situación se observa en un contexto natural. El tipo de diseño no experimental es transversal (o transeccional); definido como aquel diseño que recaba información en un periodo determinado, describiendo la interrelación de las variables en un determinado momento. Con respecto al alcance del diseño, es correlacional ya que busca determinar la relación entre dos a más variable en un momento específico.

\subsubsection{Variables.}

Variable X: Adaptación de Producto; consiste en la modificación del bien al nivel producto, Tantong et al. (2010), los autores delimitan la adaptación de producto en 3 dimensiones: Adaptación de diseño, adaptación de marca y calidad.

X1: Adaptación de marca; Tantong et al. (2010), señalan que dentro de la dimensión se debe analizar la adaptación de nombre de marca, adaptación de etiqueta del producto, adaptación de color. 
X2: Adaptación de diseño; Tantong et al. (2010), miden la adaptación en esta dimensión a través de los siguientes conceptos: Adaptación del diseño principal del producto, adaptación de número de línea de productos.

X3: Adaptación de calidad; Tantong et al. (2010), mencionan los siguientes ítems para medir el nivel de adaptación de calidad: Adaptación de garantías de producto, Adaptación de calidad de producto.

Variable Y: Desempeño del exportador; Tantong et al. (2010), definen el desempeño de las exportaciones como la manifestación de los resultados del comportamiento de las exportaciones cuando se exponen a distintas circunstancias específicas de la empresa y del entorno. Los autores miden el desempeño del exportador al usar 3 ítems de la dimensión Desempeño del exportador-financiero, una dimensión de la escala EXPERF desarrollado por Zou, Taylor y Osland (1998), que comprende los conceptos: Rentabilidad, Ventas de exportaciones, Crecimiento de las exportaciones.

\subsubsection{Población.}

Para la presente investigación, se obtuvo una lista de 168 empresas que registraron exportaciones de palta, extraído de la base de datos Adex Data Trade (2019) con la finalidad de obtener un grupo que pueda representar la muestra para el desarrollo de la investigación. Asimismo, la población fue segmentada según el siguiente cuadro para determinar la población por estratos.

Tabla 7

Número de empresas exportadoras por tamaño de empresa

\begin{tabular}{cc}
\hline Tamaño de empresa & Cantidad de empresas \\
\hline Grandes & 12 \\
Medianas & 52 \\
Pequeñas & 14 \\
Micro & 90 \\
\hline Total & 168 \\
\hline
\end{tabular}

Fuente: Adex Data Trade (2019) 


\subsubsection{Muestra.}

Para efectos de cálculo del tamaño de la muestra en la presente investigación, se empleó la fórmula MAE (Muestreo Aleatorio Estratificado), puesto que la población estuvo dividida en estratos.

$$
n=\frac{\left(\sum_{h}^{H}=1 N_{h} \cdot \sqrt{p_{h}\left(1-p_{h}\right)}\right)^{2}}{\left(N^{2}\left(\frac{e^{2}}{Z_{1-\frac{\alpha}{2}}}\right)+\sum_{h}^{H}=1 N_{h} P_{h}\left(1-p_{h}\right)\right.}
$$

Donde:

- $\mathrm{N}$ = Tamaño de la población, está conformada por 168 empresas exportadoras de palta de Lima.

- $\quad N_{h}=$ Tamaño del estrato h, número de empresas por Tamaño de empresa (Tabla 7)

- $\quad Z_{1-\frac{\alpha}{2}}=1,96$, con un nivel de confianza de $95 \%$.

- $p_{h}=0.5$, proporción de éxito en el estrato $\mathrm{h}$

- $e=$ Error de estimación máximo aceptado 0.05

$$
\begin{gathered}
n=\frac{(12 . \sqrt{0.5 \times 0.5}+52 . \sqrt{0.5 \times 0.5}+14 . \sqrt{0.5 \times 0.5}+90 . \sqrt{0.5 \times 0.5})^{2}}{\left(168^{2}\left(\frac{0.05^{2}}{1.96^{2}}\right)+(12 \times 0.5 \times 0.5+52 \times 0.5 \times 0.5+14 \times 0.5 \times 0.5+90 \times 0.5 \times 0.5)\right.} \\
n=116.884=117
\end{gathered}
$$

Con la finalidad de realizar un muestreo estratificado y al mismo tiempo proporcional se realizó el cálculo del tamaño de la muestra por estrato con el que se determinó el número de empresas exportadoras de palta a encuestar por tamaño de empresa.

$$
\begin{gathered}
n_{1}=\frac{N_{1}}{N} \times n=\frac{12}{168} \times 117=8.3571 \\
n_{2}=\frac{N_{2}}{N} \times n=\frac{52}{168} \times 117=36.2143 \\
n_{3}=\frac{N_{3}}{N} \times n=\frac{14}{168} \times 117=9.75
\end{gathered}
$$




$$
n_{4}=\frac{N_{4}}{N} \times n=\frac{90}{168} \times 117=62.6786
$$

De esta manera, la presente investigación tomo una muestra de 117 empresas, que fueron seleccionadas al azar de la base de datos de empresas exportadoras de palta en Lima. Asimismo, se consideró el cálculo de la muestra desarrollado anteriormente en donde se estableció el número de empresas por tamaño de empresa.

Tabla 8

Tamaño de muestra de empresas exportadoras por estratos

\begin{tabular}{cc}
\hline Tamaño de empresa & Cantidad de empresas \\
\hline Grandes & 8 \\
Medianas & 36 \\
Pequeñas & 10 \\
Micro & 63 \\
\hline Total & 117
\end{tabular}

Fuente: Elaboración propia.

\subsubsection{Instrumentos de la investigación.}

Hernández et al. (2014) define al instrumento de medición como aquel recurso usado por los investigadores "que registra datos observables que representan verdaderamente los conceptos o variables que el investigador tiene en mente". Es aplicado en las investigaciones cuantitativas para medir las variables dentro de las hipótesis y debe cumplir con requisitos tales como: confiabilidad, validez y objetividad. Para la presente investigación, el instrumento utilizado para la recolección de datos es el cuestionario. Asimismo, es importante mencionar que el instrumento de medición pasó por un análisis de fiabilidad del instrumento a través del alfa de Cronbach y por la validación de expertos, pues de acuerdo a Hernández et al. (2014) la validez por voces calificadas también forma parte del procedo de validez de contenido. Cabe resaltar que el instrumento, fue aplicado a través de correo electrónico y llamadas, y está dirigida a gerentes y administradores.

Partes del cuestionario: 
- Adaptación de producto (con 7 afirmaciones extraídas del instrumento de medición de los autores Tantong et al. (2010); y que fueron medidas en escala de Likert de 5 puntos. Ver Anexo 2)

- Desempeño del exportador (con 3 afirmaciones tomadas del modelo de los autores Tantong et al. (2010), que fueron medidas en una escala de Likert de 5 puntos. Ver anexo 2). Asimismo, para efectos de la comparación de hipótesis planteadas, se empleará la prueba estadística Rho de Spearman.

A continuación, se presenta la ficha técnica del cuestionario usado en la investigación:

Tabla 9

Ficha técnica del instrumento - Adaptación de producto

Cuestionario Adaptación de Producto y Desempeño del Exportador en empresas exportadoras de palta en Lima 2019

Cuestionario "Relación entre

Nombre: $\quad$ adaptación de producto y el desempeño del exportador de las empresas exportadoras de palta en Lima 2019" Phattarawan Tantong, Kiran Karande, Autores: Anil Nair \& Anusorn Singhapakdi (2010)

Administración: Individual

Miguel Loo Rodríguez (2019), Carla

Validación: Arriola Alvarado (2019) \& Jimmy Sánchez Gómez (2019) (Ver Anexo $\mathrm{N}^{\circ} 3$ ). Valor de Aiken: 0.94

Cantidad de 7

ítems:

Duración: $\quad 5$ minutos

Confiabilidad Alfa de Cronbach: 0.817 Administración
del cuestionario: Correo electrónico y llamada.

Lugar y Año: $\quad$ Lima, Perú 2019 
Tabla 10

Ficha técnica del instrumento - Desempeño del exportador

Cuestionario Adaptación de Producto y Desempeño del Exportador en empresas exportadoras de palta en Lima 2019

\begin{tabular}{|c|c|}
\hline & \\
\hline Nombre: & $\begin{array}{l}\text { Cuestionario "Relación entre } \\
\text { adaptación de producto y el desempeño } \\
\text { del exportador de las empresas } \\
\text { exportadoras de palta en Lima 2019" }\end{array}$ \\
\hline Autores: & $\begin{array}{l}\text { Phattarawan Tantong, Kiran Karande, } \\
\text { Anil Nair \& Anusorn Singhapakdi } \\
(2010)\end{array}$ \\
\hline Administración: & Individual \\
\hline Validación: & $\begin{array}{l}\text { Miguel Loo Rodríguez (2019), Carla } \\
\text { Arriola Alvarado (2019) \& Jimmy } \\
\text { Sánchez Gómez (2019) (Ver Anexo } \\
\mathrm{N}^{\circ} 3 \text { ). Valor de Aiken: } 0.97\end{array}$ \\
\hline $\begin{array}{l}\text { Cantidad de } \\
\text { ítems: }\end{array}$ & 3 \\
\hline Duración: & 5 minutos \\
\hline Confiabilidad & Alfa de Cronbach: 0.920 \\
\hline $\begin{array}{l}\text { Administración } \\
\text { del cuestionario: }\end{array}$ & Correo electrónico y llamada. \\
\hline Lugar y Año: & Lima, Perú 2019 \\
\hline
\end{tabular}

El instrumento ha sido validado por docentes de la Universidad San Ignacio de Loyola, Miguel Loo Rodríguez (2019), Carla Arriola Alvarado (2019) y Jimmy Sánchez Gómez (2019) (Ver Anexo $\mathrm{N}^{\circ} 3$ ), quienes calificaron los ítems del cuestionario cuyo objetivo es medir la relación entre las variables adaptación de producto y desempeño del exportador, mediante el uso de criterios tales como: claridad, congruencia, contexto y dominio del constructo.

En cuanto al valor del Aiken, el cual refiere al promedio de la calificación y es calculado como las valoraciones de un conjunto de jueces respecto a un grupo de ítems, se obtuvo el valor de 0.94 y 0.97 , tanto para el cuestionario de adaptación del producto y desempeño del exportador, respectivamente. Estos resultados reflejan que los ítems de ambos cuestionarios obtuvieron una alta validez de contenido. 
Asimismo, se midió la fiabilidad del cuestionario mediante el alfa de Cronbach cuyos resultados fueron los siguientes: Con respecto a la adaptación de producto fue de 0.817 mientras que el coeficiente de fiabilidad del desempeño del exportador fue de 0.920. (Ver Anexo 4).

\subsubsection{Procedimiento de recolección de datos.}

En la presente investigación, el proceso de recolección se realizó en una muestra de 117 empresas exportadoras de palta en Lima, a través de un cuestionario, un instrumento de medición que pasó por un proceso de validación de jueces, considerando que toda medición debe cumplir con requisitos tales como: la confiabilidad (asegura resultados consistentes y coherentes), validez (asegura que el instrumento mida la variable que la investigación tiene como objetivo medir) y objetividad (evita que los sesgos influyan negativamente en la investigación). (Hernández et al., 2014)

Con la finalidad de facilitar el proceso de recolección se creó una base de datos que reunía datos como: razón social, dirección, teléfono, elaborado a partir de la lista de empresas exportadoras de palta en Lima descargada de Adex Data Trade (2019). Con esta información se procedió a realizar una selección al azar de las empresas que iban a ser contactadas para el desarrollo de la investigación. Luego de haber seleccionado las 117 empresas al azar de la base de datos, se procedió a llamar a cada una de las empresas para solicitar el correo del gerente o administrador de cada empresa. Con el correo electrónico, se procedió con el envío de los cuestionarios a los gerentes y administradores de las empresas exportadoras de palta desde un correo corporativo, proceso que se desarrolló durante un periodo de un mes aproximadamente, entre el 03 de enero del 2020 hasta el 22 de febrero del 2020. Se solicitó a los gerentes y administradores, responder como representantes de las empresas exportadoras de palta, en donde laboraron en el 2019. Las respuestas de los cuestionarios, en su mayoría, se obtuvieron en el mismo día y luego de algunas horas, mientras que en un número reducido se tuvo que 
hacer el seguimiento a través de una llamada de recordatorio para que puedan enviar sus respuestas. Finalmente, para el procesamiento de los datos obtenidos de las encuestas se utilizó el programa SPSS (versión 26), que permitió la tabulación de encuestas y el análisis estadístico. 


\section{Capítulo III}

Según Hernández, et al. (2014), el margen de error a ser considerado en las investigaciones es de $1 \%$ y $5 \%$. Pero el margen más utilizado en las investigaciones en las ciencias sociales es de 5\%. Por ello en la presente investigación se tomó el nivel de error de 5\%, y un nivel de confianza de $95 \%$.

\subsection{Análisis de los resultados del cuestionario}

A continuación, se mostrarán los resultados de los 117 cuestionarios administrados en las empresas exportadoras de palta de Lima, obtenidos a través del programa SPSS (Versión 26).

\subsubsection{Análisis descriptivos de los estudios de adaptación del producto.}

\section{Adaptación de la marca}

Tabla 11

Pregunta 1. Está de acuerdo en que la adaptación de nombres de marca tuvo un efecto positivo al llegar al mercado destino

\begin{tabular}{|c|c|c|c|c|c|}
\hline & & $\begin{array}{c}\text { Frecuenci } \\
\mathrm{a}\end{array}$ & $\begin{array}{c}\text { Porcenta } \\
\text { je }\end{array}$ & $\begin{array}{l}\text { Porcentaj } \\
\text { e válido }\end{array}$ & $\begin{array}{l}\text { Porcentaje } \\
\text { acumulado }\end{array}$ \\
\hline \multirow{6}{*}{ Valid } & $\begin{array}{l}\text { Muy en } \\
\text { desacuerdo }\end{array}$ & 8 & 6.8 & 6.8 & 6.8 \\
\hline & En desacuerdo & 26 & 22.2 & 22.2 & 29.1 \\
\hline & $\begin{array}{l}\text { Ni de acuerdo ni } \\
\text { en desacuerdo }\end{array}$ & 62 & 53.0 & 53.0 & 82.1 \\
\hline & De acuerdo & 18 & 15.4 & 15.4 & 97.4 \\
\hline & Muy de acuerdo & 3 & 2.6 & 2.6 & 100.0 \\
\hline & Total & 117 & 100.0 & 100.0 & \\
\hline
\end{tabular}

Fuente: Extraído de SPSS 26.0.0.0. Elaboración propia 


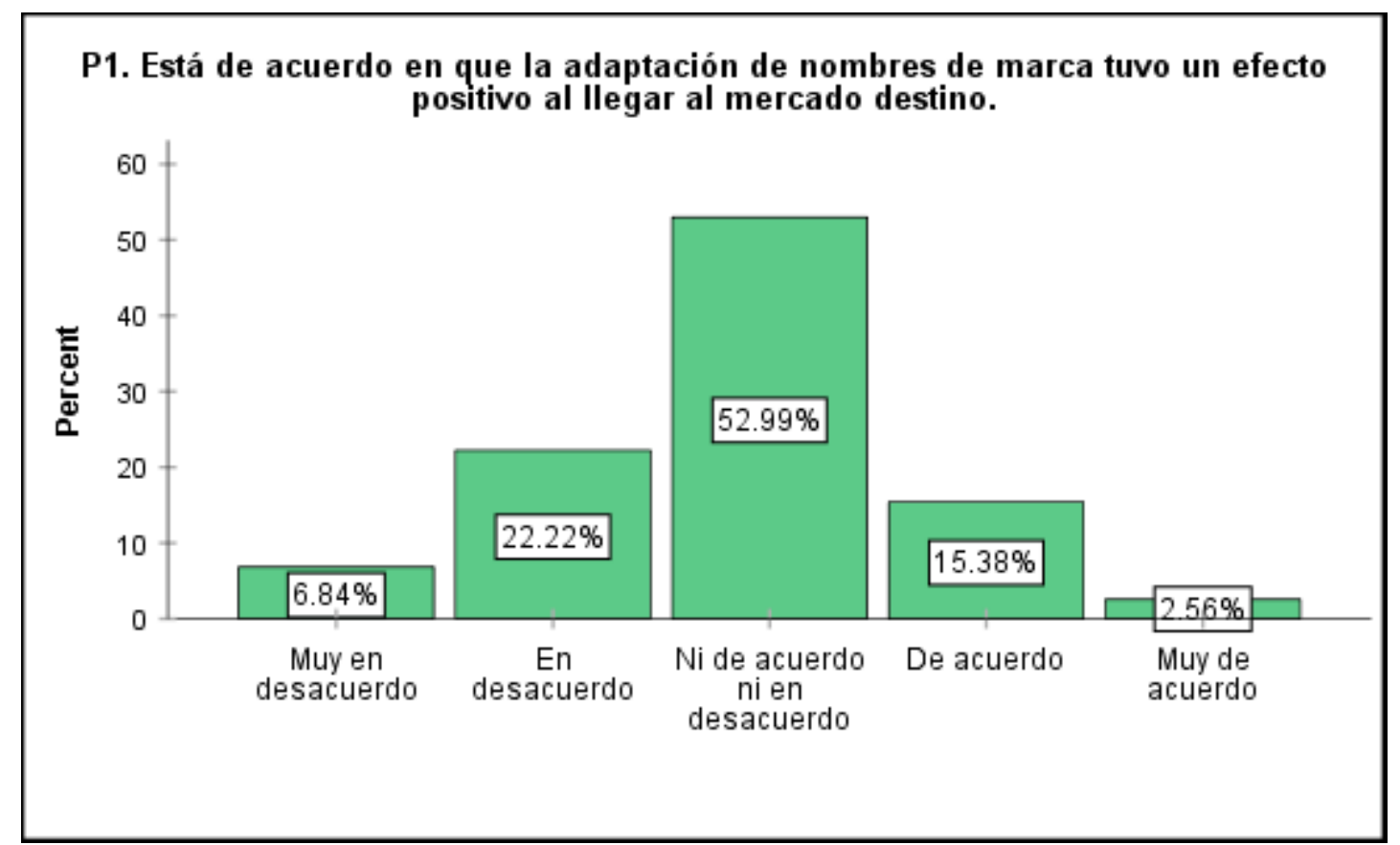

Figura 9. Nombre de marca del producto.

Interpretación: Se puede observar que casi un 53\% de los encuestados se encuentra indeciso con la afirmación "Está de acuerdo en que la adaptación de nombres de marca tuvo un efecto positivo al llegar al mercado destino". Asimismo, un 18\% de los encuestados está de acuerdo con la afirmación. Por otro lado, un $29 \%$ se encuentra en desacuerdo con la afirmación mencionada.

Tabla 12

Pregunta 2. Está de acuerdo en que la adaptación de etiqueta del producto tuvo un efecto positivo al comercializar el producto en el mercado destino.

\begin{tabular}{llcccc}
\hline & $\begin{array}{c}\text { Frecuenci } \\
\text { a }\end{array}$ & $\begin{array}{c}\text { Porcenta } \\
\text { je }\end{array}$ & $\begin{array}{c}\text { Porcentaje } \\
\text { válido }\end{array}$ & $\begin{array}{c}\text { Porcentaje } \\
\text { acumulad } \\
\text { o }\end{array}$ \\
\hline \multirow{5}{*}{ Valid } & Muy en desacuerdo & 1 & .9 & .9 & .9 \\
& $\begin{array}{l}\text { En desacuerdo } \\
\text { Ni de acuerdo ni en }\end{array}$ & 7 & 6.0 & 6.0 & 6.8 \\
& desacuerdo & 21 & 17.9 & 17.9 & 24.8 \\
& De acuerdo & 63 & 53.8 & 53.8 & 78.6 \\
& Muy de acuerdo & 25 & 21.4 & 21.4 & 100.0 \\
\cline { 2 - 6 } & Total & 117 & 100.0 & 100.0 & \\
\hline
\end{tabular}

Fuente: Extraído de SPSS 26.0.0.0. Elaboración propia 


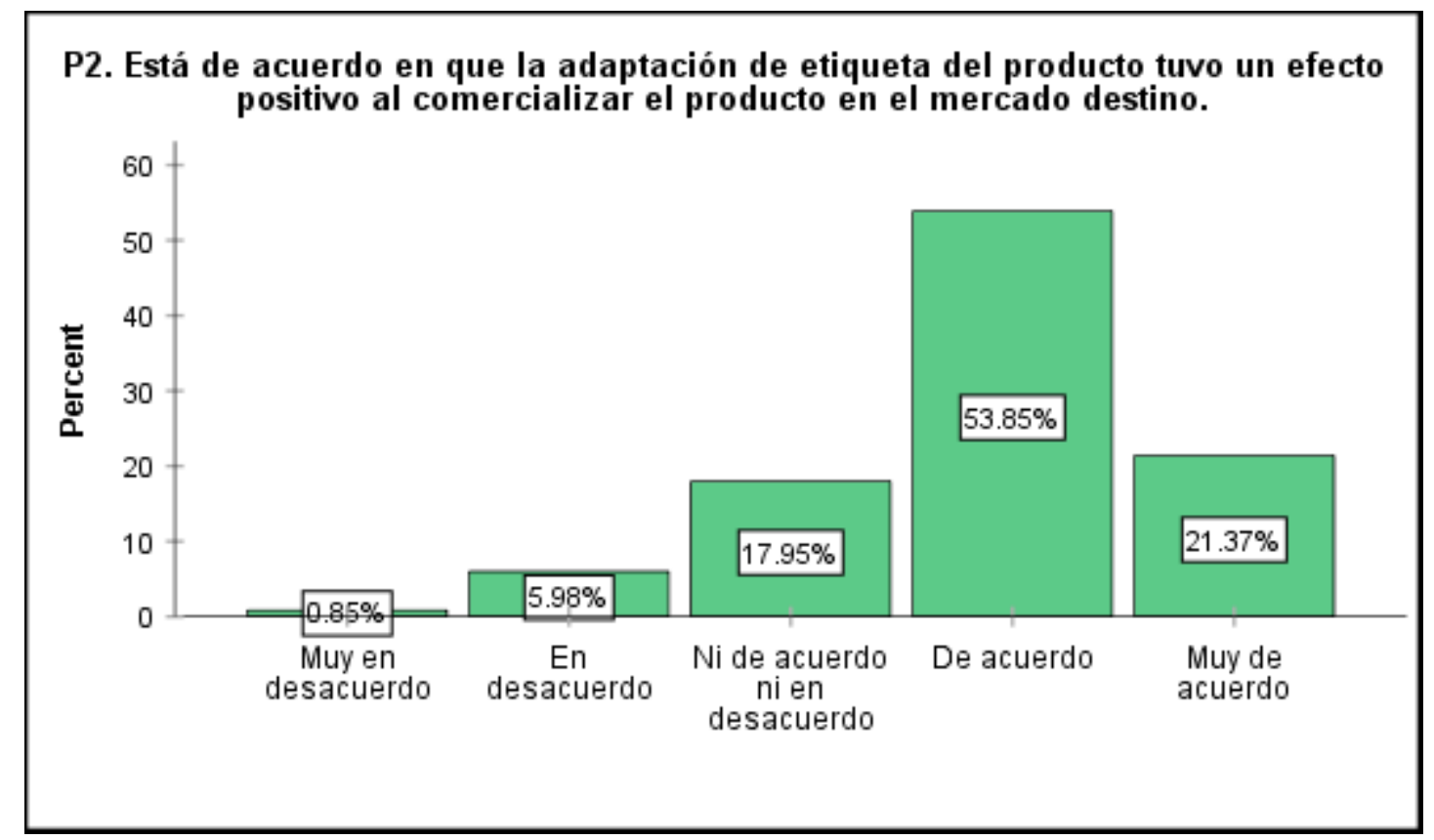

Figura 10. Etiqueta del producto.

Interpretación: Los resultados demuestran que un 75.2\% se encuentra de acuerdo con la afirmación "Está de acuerdo en que la adaptación de etiqueta del producto tuvo un efecto positivo al comercializar el producto en el mercado destino. Asimismo, un $17.9 \%$ se encuentra indeciso y por último un $6.9 \%$ está en desacuerdo con la afirmación.

Tabla 13

Pregunta 3. Está de acuerdo en que la adaptación de color del producto tuvo un efecto positivo al comercializar el producto en el mercado destino.

\begin{tabular}{llcccc}
\hline & Frecuencia & $\begin{array}{c}\text { Porcentaj } \\
\mathrm{e}\end{array}$ & $\begin{array}{c}\text { Porcentaje } \\
\text { válido }\end{array}$ & $\begin{array}{c}\text { Porcentaj } \\
\text { e } \\
\text { acumulad } \\
\text { o }\end{array}$ \\
\hline \multirow{3}{*}{ Valid } & $\begin{array}{l}\text { Muy en desacuerdo } \\
\text { En desacuerdo }\end{array}$ & 5 & 4.3 & 4.3 & 4.3 \\
& $\begin{array}{l}\text { Ni de acuerdo ni en } \\
\text { desacuerdo }\end{array}$ & 63 & 25.6 & 25.6 & 29.9 \\
& De acuerdo & 19 & 16.2 & 16.2 & 100.0 \\
\cline { 2 - 6 } & Total & 117 & 100.0 & 100.0 & \\
\hline
\end{tabular}

Fuente: Extraído de SPSS 26.0.0.0. Elaboración propia. 


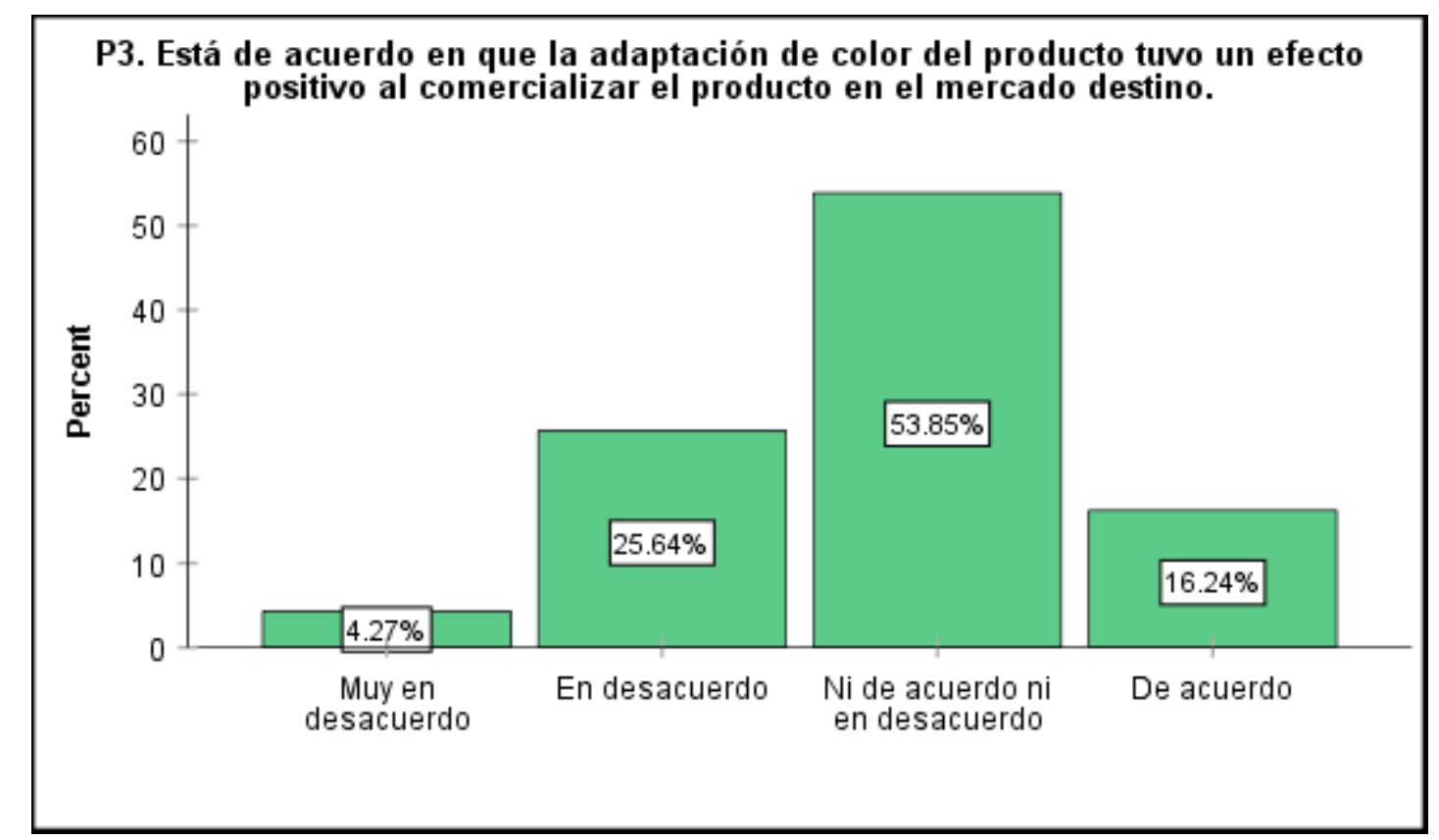

Figura 11. Color del producto.

Interpretación: Los resultados arrojan que un 53.8\% se encuentra indeciso con la afirmación "Está de acuerdo en que la adaptación de color del producto tuvo un efecto positivo al comercializar el producto en el mercado destino". Mientras que un $29.9 \%$ se encuentra en desacuerdo con la afirmación. Por otro lado $16.24 \%$ de los encuestados se encuentra de acuerdo.

En conclusión, un 18\% de los encuestados afirmaron que el nombre de marca del producto comercializado se encuentra adaptado al mercado destino, el $75.2 \%$ afirma que la etiqueta del producto exportado se encuentra adaptado a la demanda del mercado internacional. Finalmente, del total de los encuestados solo $16.24 \%$ se encuentran de acuerdo con la adaptación del color del producto. 


\section{Adaptación de diseño}

Tabla 14

Pregunta 4. Está de acuerdo en que la adaptación de diseño principal del producto tuvo un efecto positivo al comercializar el producto en el mercado destino.

\begin{tabular}{llcccc}
\hline & Frecuencia & $\begin{array}{c}\text { Porcentaj } \\
\mathrm{e}\end{array}$ & $\begin{array}{c}\text { Porcentaje } \\
\text { válido }\end{array}$ & $\begin{array}{c}\text { Porcentaje } \\
\text { acumulado }\end{array}$ \\
\hline \multirow{6}{*}{ Valid } & Muy en & 6 & 5.1 & 5.1 & 5.1 \\
desacuerdo & 22 & 18.8 & 18.8 & 23.9 \\
En desacuerdo & Ni de acuerdo ni & 46 & 39.3 & 39.3 & 63.2 \\
& en desacuerdo & 40 & 34.2 & 34.2 & 97.4 \\
& De acuerdo & 3 & 2.6 & 2.6 & 100.0 \\
\hline Muy de acuerdo & 117 & 100.0 & 100.0 & \\
\cline { 2 - 6 } & Total & & & & \\
\hline
\end{tabular}

Fuente: Extraído de SPSS 26.0.0.0. Elaboración propia

P4. Está de acuerdo en que la adaptación de diseño principal del producto tuvo un efecto positivo al comercializar el producto en el mercado destino.

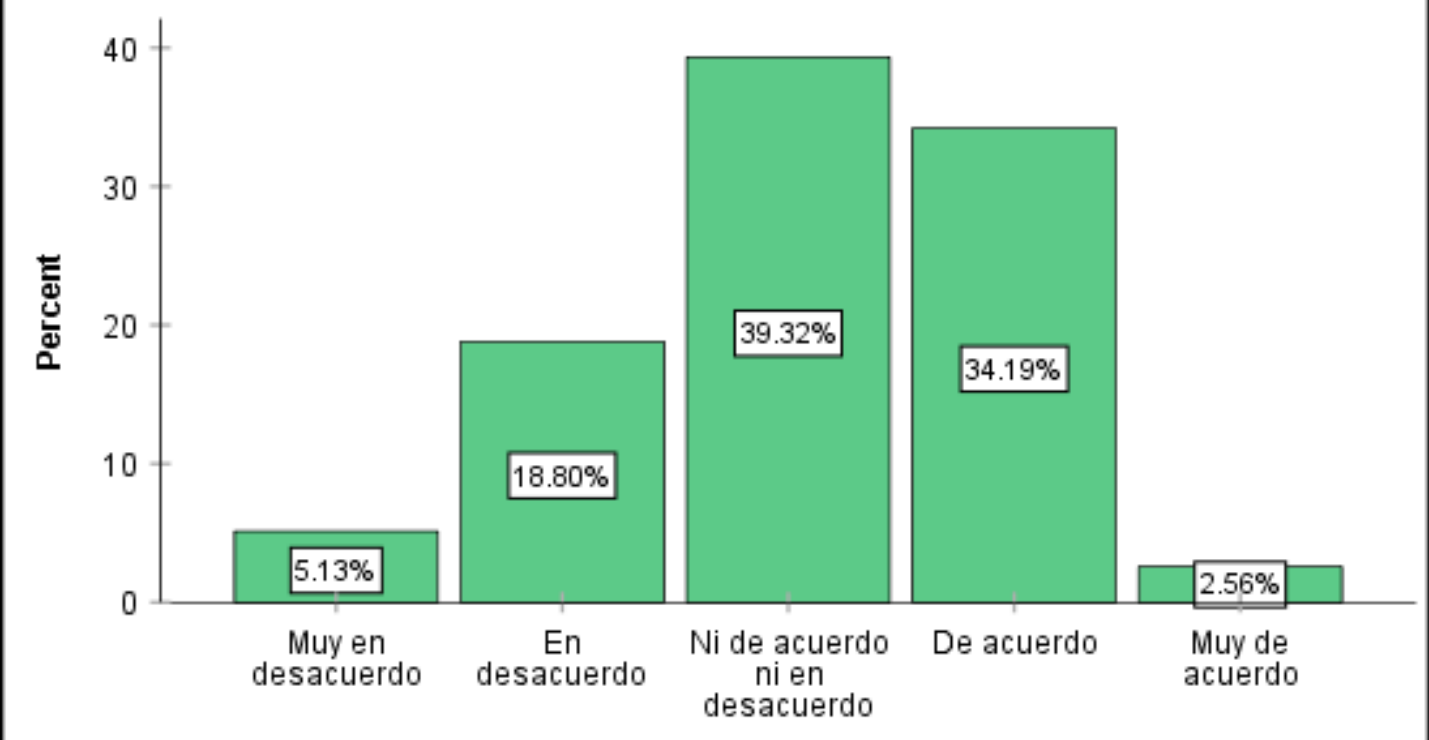

Figura 12. Diseño principal del producto.

Interpretación: Los resultados reflejan que un 36.8\% de los encuestados se encuentra de acuerdo con la afirmación "Está de acuerdo en que la adaptación de diseño principal del producto tuvo un efecto positivo al comercializar el producto en el mercado destino", mientras 
que el $39.3 \%$ se encuentra indeciso con esta afirmación y un total de $23.9 \%$ no está de acuerdo con la afirmación.

Tabla 15

Pregunta 5. Está de acuerdo en que la adaptación del número de líneas de producto tuvo una buena aceptación del consumidor al comercializar el producto en el mercado destino

\begin{tabular}{llcccc}
\hline & Frecuencia & Porcentaje & $\begin{array}{c}\text { Porcentaje } \\
\text { válido }\end{array}$ & $\begin{array}{c}\text { Porcentaj } \\
\text { e } \\
\text { acumulad } \\
\text { o }\end{array}$ \\
\hline \multirow{2}{*}{ Valid } & $\begin{array}{l}\text { Muy en } \\
\text { desacuerdo }\end{array}$ & 65 & 55.6 & 55.6 & 55.6 \\
& $\begin{array}{l}\text { En desacuerdo } \\
\text { Ni de acuerdo ni } \\
\text { en desacuerdo }\end{array}$ & 39 & 33.3 & 33.3 & 88.9 \\
\cline { 2 - 6 } & Total & 13 & 11.1 & 11.1 & 100.0 \\
\hline
\end{tabular}

Fuente: Extraído de SPSS 26.0.0.0. Elaboración propia.

P5. Está de acuerdo en que la adaptación del número de líneas de producto tuvo una buena aceptación del consumidor al comercializar el producto en el mercado destino.

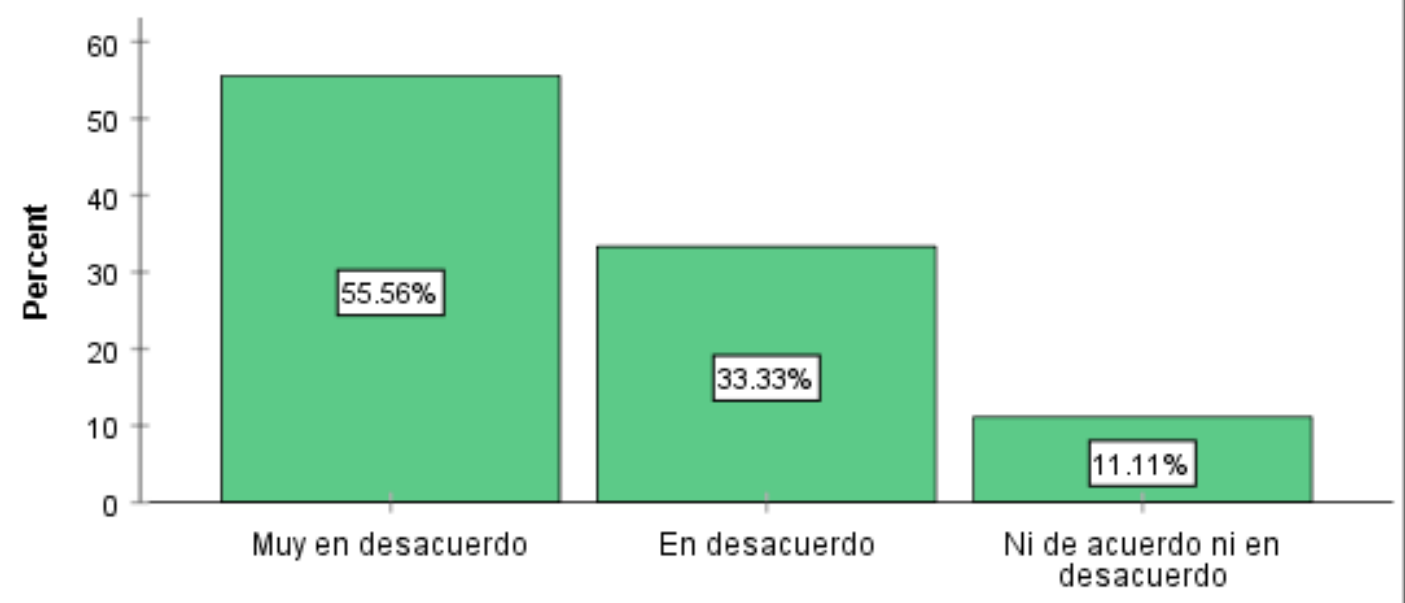

Figura 13. Número de líneas de producto.

Interpretación: Los resultados obtenidos arrojan que un $88.9 \%$ se encuentra en desacuerdo con la afirmación "Está de acuerdo en que la adaptación del número de líneas de producto tuvo 
una buena aceptación del consumidor al comercializar el producto en el mercado destino mientras que un $11.1 \%$ no se encuentran de acuerdo ni en desacuerdo con la afirmación.

En conclusión, los resultados indican que solo un $34.19 \%$ afirmaron que el diseño del producto se encuentra adaptado a las demandas del mercado destino, mientras que un $88.9 \%$ se encuentra en desacuerdo con la afirmación. 


\section{Adaptación de Calidad}

Tabla 16

Pregunta 6. Está de acuerdo en que la aceptación de garantía del producto tuvo una buena aceptación del consumidor al comercializar el producto en el mercado destino

\begin{tabular}{llcccc}
\hline & Frecuencia & Porcentaje & $\begin{array}{c}\text { Porcentaje } \\
\text { válido }\end{array}$ & $\begin{array}{c}\text { Porcentaje } \\
\text { acumulado }\end{array}$ \\
\hline \multirow{6}{*}{ Valid } & Muy en desacuerdo & 4 & 3.4 & 3.4 & 3.4 \\
& En desacuerdo & 23 & 19.7 & 19.7 & 23.1 \\
& Ni de acuerdo ni en & 28 & 23.9 & 23.9 & 47.0 \\
& desacuerdo & 53 & 45.3 & 45.3 & 92.3 \\
& De acuerdo & 9 & 7.7 & 7.7 & 100.0 \\
\cline { 2 - 6 } & Muy de acuerdo & 117 & 100.0 & 100.0 & \\
\hline
\end{tabular}

Fuente: Extraído de SPSS 26.0.0.0. Elaboración propia.

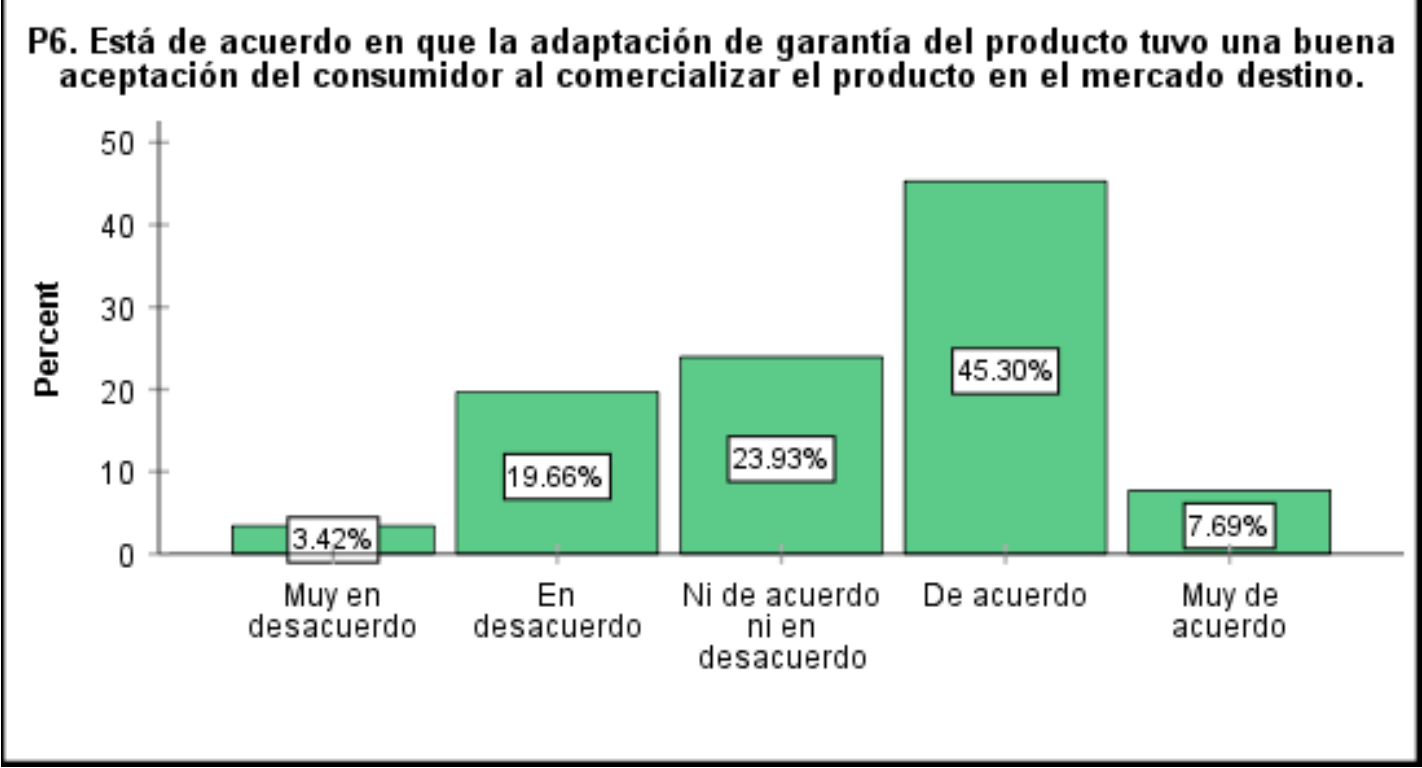

Figura 14. Garantía del producto.

Interpretación: Los resultados muestran que un 53.0\% se encuentra de acuerdo con la afirmación "Está de acuerdo en que la adaptación de garantía del producto tuvo una buena aceptación del consumidor al comercializar el producto en el mercado destino", mientras que el $23.9 \%$ se encuentra ni de acuerdo ni en desacuerdo, mientras que un $23.1 \%$ está en desacuerdo con la afirmación. 
Tabla 17

Pregunta 7. Está de acuerdo en que la adaptación de calidad del producto tuvo una buena aceptación del consumidor al comercializar el producto en el mercado destino.

\begin{tabular}{llcccc}
\hline & Frecuencia & Porcentaje & $\begin{array}{c}\text { Porcentaje } \\
\text { válido }\end{array}$ & $\begin{array}{c}\text { Porcentaje } \\
\text { acumulado }\end{array}$ \\
\hline \multirow{3}{*}{ Valid } & $\begin{array}{l}\text { En desacuerdo } \\
\text { Ni de acuerdo ni en }\end{array}$ & 4 & 3.4 & 3.4 & 3.4 \\
& $\begin{array}{l}\text { desacuerdo } \\
\text { De acuerdo }\end{array}$ & 33 & 19.7 & 19.7 & 23.1 \\
& Muy de acuerdo & 57 & 48.2 & 28.2 & 51.3 \\
\cline { 2 - 6 } & Total & 117 & 100.0 & 48.7 & 100.0 \\
\hline
\end{tabular}

Fuente: Extraído de SPSS 26.0.0.0. Elaboración propia

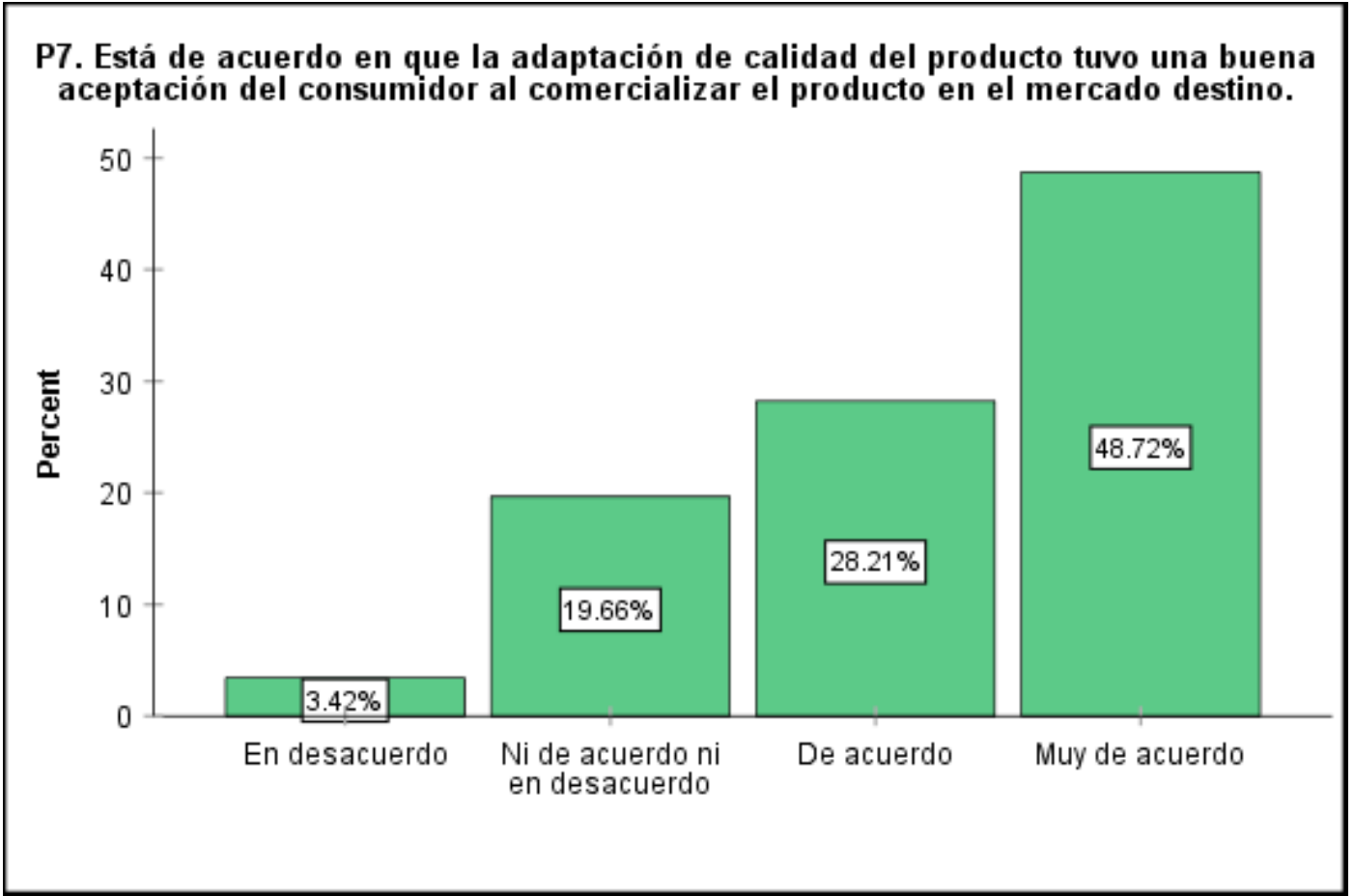

Figura 15. Calidad del producto.

Interpretación: Los resultados indican que un total de $76.9 \%$ de los encuestados, se encuentran de acuerdo con la afirmación "Está de acuerdo en que la adaptación de calidad del producto tuvo una buena aceptación del consumidor al comercializar el producto en el mercado destino". Por otro lado, el $28.2 \%$ se encuentra indeciso con respecto a la afirmación y un $3.42 \%$ del total de los encuestados se encuentra en desacuerdo con esta afirmación. 
En conclusión, los resultados obtenidos indican que el 53\% del total de los encuestados afirman que la garantía de los productos está adaptado al mercado y un $76.9 \%$ de los encuestados confirmaron que la calidad del producto está adaptado a la demanda en el mercado destino.

\subsubsection{Análisis descriptivos de los estudios del desempeño del exportador.}

\section{Desempeño del exportador - Financiero}

Tabla 18

Pregunta 8. En esta empresa exportadora el margen de beneficio de las exportaciones fue mejor que lo esperado.

\begin{tabular}{lcccc}
\hline & Frecuencia & Porcentaje & $\begin{array}{c}\text { Porcentaje } \\
\text { válido }\end{array}$ & $\begin{array}{c}\text { Porcentaje } \\
\text { acumulado }\end{array}$ \\
\hline Muy en desacuerdo & 11 & 9.4 & 9.4 & 9.4 \\
En desacuerdo & 26 & 22.2 & 22.2 & 31.6 \\
Ni de acuerdo ni en & 35 & 29.9 & 29.9 & 61.5 \\
Valid desacuerdo & 42 & 35.9 & 35.9 & 97.4 \\
De acuerdo & 3 & 2.6 & 2.6 & 100.0 \\
Muy de acuerdo & 117 & 100.0 & 100.0 & \\
\hline Total & & & & \\
\hline
\end{tabular}

Fuente: Extraído de SPSS 26.0.0.0. Elaboración propia

P8. En esta empresa exportadora el margen de beneficio de las exportaciones fue mejor que lo esperado.

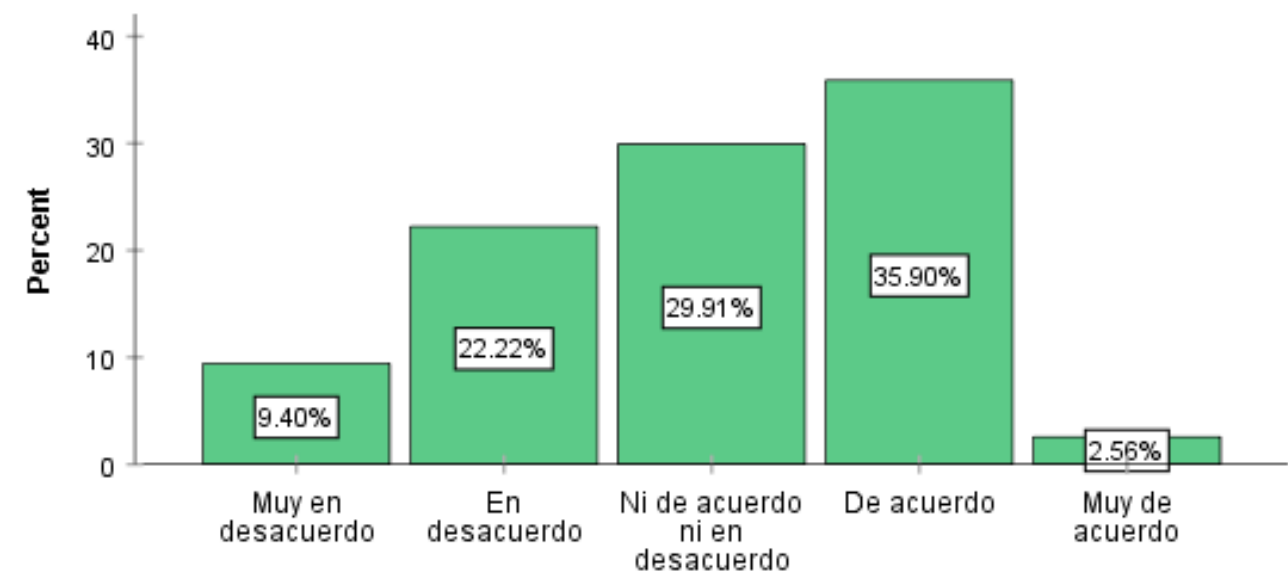

Figura 16. Rentabilidad. 
Interpretación: El 38.5\% del total de encuestados, señalan estar de acuerdo con la siguiente afirmación "En esta empresa exportadora el margen de beneficio de las exportaciones fue mejor que lo esperado", el 29.9\% no está de acuerdo ni en desacuerdo con la afirmación, mientras que el $31.62 \%$ de los encuestados se encuentran en desacuerdo con la afirmación previa.

Tabla 19

Pregunta 9. En esta empresa se ha generado un gran volumen de venta

\begin{tabular}{llcccc}
\hline & Frecuencia & Porcentaje & $\begin{array}{c}\text { Porcentaje } \\
\text { válido }\end{array}$ & $\begin{array}{c}\text { Porcentaje } \\
\text { acumulado }\end{array}$ \\
\hline \multirow{6}{*}{ Valid } & Muy en & 10 & 8.5 & 8.5 & 8.5 \\
& $\begin{array}{l}\text { desacuerdo } \\
\text { En desacuerdo }\end{array}$ & 27 & 23.1 & 23.1 & 31.6 \\
& Ni de acuerdo ni & 31 & 26.5 & 26.5 & 58.1 \\
& en desacuerdo & 41 & 35.0 & 35.0 & 93.2 \\
& De acuerdo & 8 & 6.8 & 6.8 & 100.0 \\
\cline { 2 - 6 } & Muy de acuerdo & 117 & 100.0 & 100.0 & \\
\hline
\end{tabular}

Fuente: Extraído de SPSS 26.0.0.0. Elaboración propia

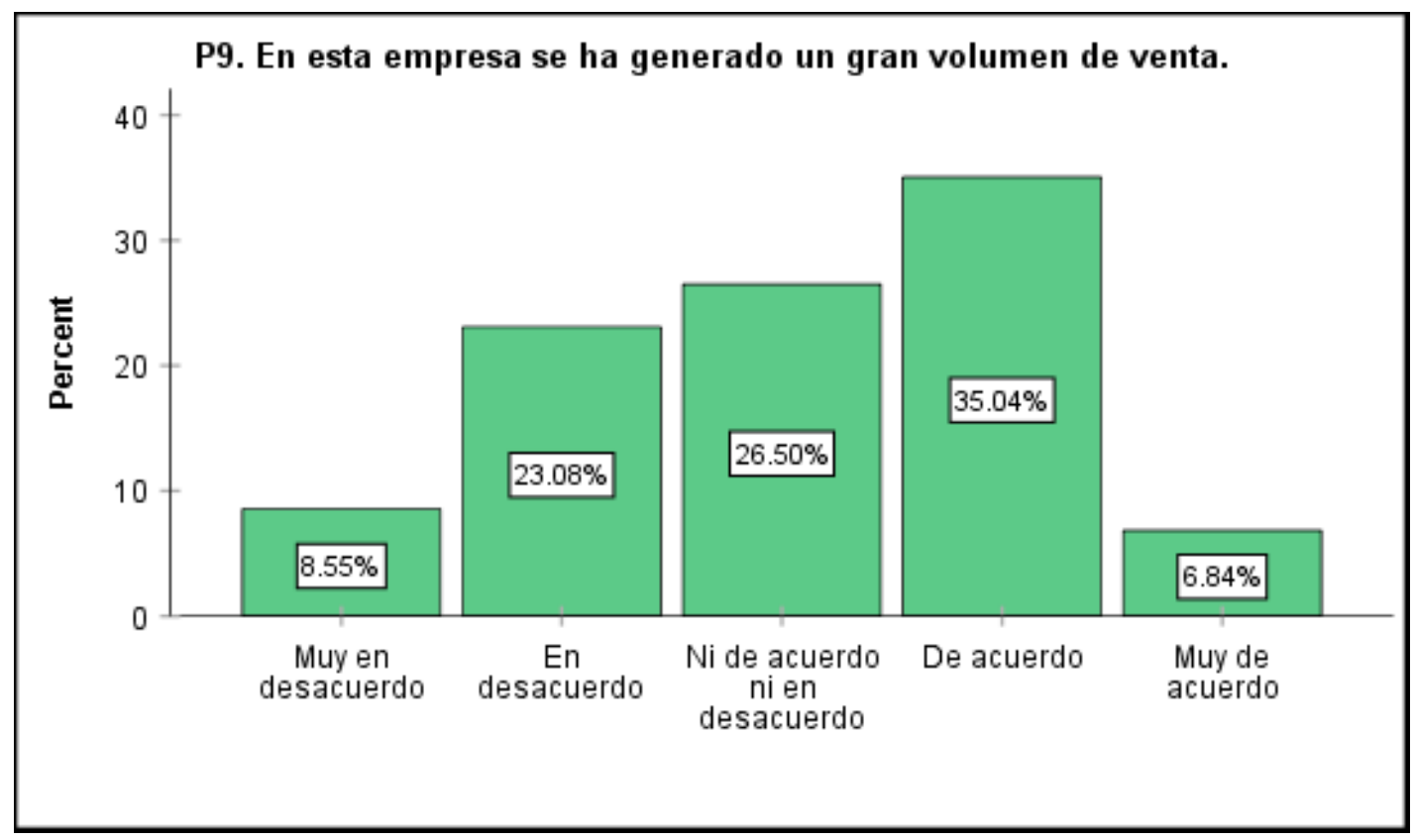

Figura 17. Ventas de exportaciones.

Interpretación: Los resultados indican que el 41.8\% de las empresas encuestadas están de acuerdo con la afirmación "En esta empresa se ha generado un gran volumen de venta". 
Asimismo, un $26.5 \%$ indico no estar de acuerdo ni en desacuerdo con la afirmación, mientras que un 31.6\% se mostró en desacuerdo con la afirmación.

Tabla 20

Pregunta 10. Esta empresa exportadora ha logrado un rápido crecimiento

\begin{tabular}{llcccc}
\hline & Frecuencia & Porcentaje & $\begin{array}{c}\text { Porcentaje } \\
\text { válido }\end{array}$ & $\begin{array}{c}\text { Porcentaje } \\
\text { acumulado }\end{array}$ \\
\hline \multirow{6}{*}{ Valid } & Muy en desacuerdo & 11 & 9.4 & 9.4 & 9.4 \\
& En desacuerdo & 27 & 23.1 & 23.1 & 32.5 \\
& Ni de acuerdo ni en & 30 & 25.6 & 25.6 & 58.1 \\
& desacuerdo & & 38.5 & 38.5 & 96.6 \\
& De acuerdo & 45 & 3.4 & 3.4 & 100.0 \\
\cline { 2 - 6 } & Muy de acuerdo & 4 & 100.0 & 100.0 & \\
\hline
\end{tabular}

Fuente: Extraído de SPSS 26.0.0.0. Elaboración propia

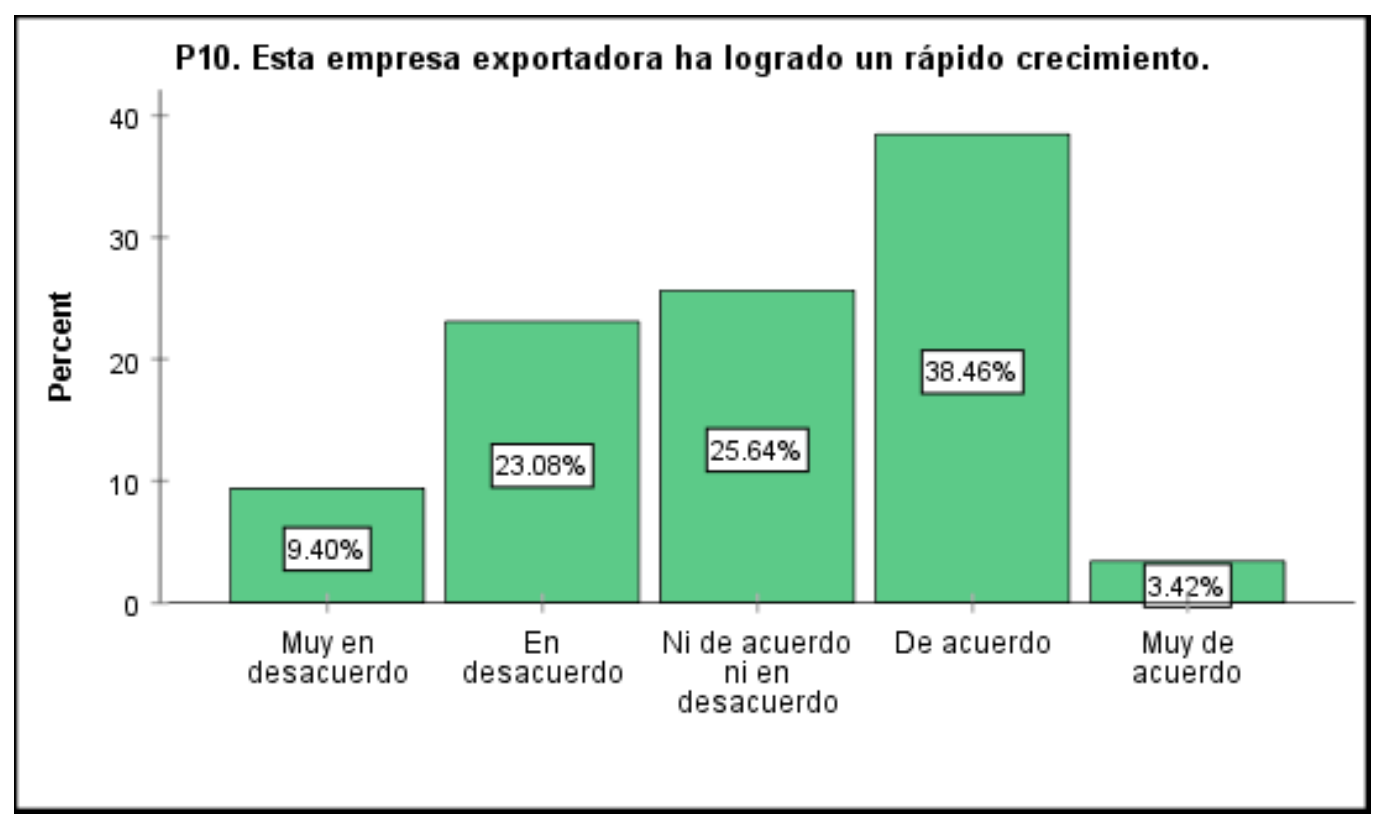

Figura 18. Crecimiento de las exportaciones.

Interpretación: Los resultados demuestran que el $41.9 \%$ del total de los encuestados están de acuerdo con la afirmación "Esta empresa exportadora ha logrado un rápido crecimiento". El $25.6 \%$ de los encuestados se encuentran indecisos con la afirmación planteada, mientras un $32.5 \%$ del total de encuestados está en desacuerdo con la afirmación. 
En conclusión, con respecto a la dimensión desempeño del exportador - financiero; los resultados obtenidos demuestran que el $38.5 \%$ de los encuestados están de acuerdo con haber obtenido un margen de ganancia mejor del esperado. Asimismo, un $41.8 \%$ confirman haber generado un gran volumen de ventas. Por otro lado, el $41.9 \%$ de las empresas encuestadas estarían de acuerdo con haber logrado un rápido crecimiento.

\subsection{Contrastación de hipótesis}

\subsubsection{Pruebas de normalidad de Kolmogorov-Smirnov y Shapiro-Wilk.}

Las pruebas de normalidad permiten confirmar si los datos obtenidos de las encuestas mantienen una distribución paramétrica o no paramétrica, debido a que se contrasta la normalidad de los datos. Por lo que se plantea lo siguiente:

\section{i. Hipótesis nula:}

$\mathrm{H}_{0}$ : Los datos se distribuyen normalmente

\section{Hipótesis alterna:}

$\mathrm{H}_{1}$ : Los datos no se distribuyen normalmente.

ii. Nivel de significancia: $\alpha=\mathbf{0 . 0 5}$

iii. Estadístico de prueba:

Efectuadas las pruebas de normalidad de Kolmogorov-Sminov y Shapiro-Wilk, siendo estas pruebas no paramétricas que determinarán el ajuste de un conjunto de datos a la distribución normal. Según Rial, A. \& Varela, J., la prueba de Shapiro-Wilk presenta resultados más exactos y es usado para conocer y contrastar la veracidad de la hipótesis nula. (Tabla 21) 
Tabla 21

Prueba de normalidad

\begin{tabular}{|c|c|c|c|c|c|c|}
\hline & \multicolumn{3}{|c|}{$\begin{array}{l}\text { Kolmogorov- } \\
\text { Smirnov }^{\mathrm{a}}\end{array}$} & \multicolumn{3}{|c|}{ Shapiro-Wilk } \\
\hline & Est. & GI. & Sig. & Est. & GI. & Sig. \\
\hline $\begin{array}{l}\text { P1. Está de acuerdo en que la } \\
\text { adaptación de nombres de marca tuvo } \\
\text { un efecto positivo al llegar al mercado } \\
\text { destino. }\end{array}$ & .281 & 117 & .000 & .871 & 117 & .000 \\
\hline $\begin{array}{l}\text { P2. Está de acuerdo en que la } \\
\text { adaptación de etiqueta del producto } \\
\text { tuvo un efecto positivo al comercializar } \\
\text { el producto en el mercado destino. }\end{array}$ & .305 & 117 & .000 & .835 & 117 & .000 \\
\hline $\begin{array}{l}\text { P3. Está de acuerdo en que la } \\
\text { adaptación de color del producto tuvo } \\
\text { un efecto positivo al comercializar el } \\
\text { producto en el mercado destino. }\end{array}$ & .295 & 117 & .000 & .839 & 117 & .000 \\
\hline $\begin{array}{l}\text { P4. Está de acuerdo en que la } \\
\text { adaptación de diseño principal del } \\
\text { producto tuvo un efecto positivo al } \\
\text { comercializar el producto en el mercado } \\
\text { destino. }\end{array}$ & .216 & 117 & .000 & .879 & 117 & .000 \\
\hline $\begin{array}{l}\text { P5. Está de acuerdo en que la } \\
\text { adaptación del número de líneas de } \\
\text { producto tuvo una buena aceptación del } \\
\text { consumidor al comercializar el producto } \\
\text { en el mercado destino. }\end{array}$ & .346 & 117 & .000 & .728 & 117 & .000 \\
\hline $\begin{array}{l}\text { P6. Está de acuerdo en que la } \\
\text { adaptación de garantía del producto } \\
\text { tuvo una buena aceptación del } \\
\text { consumidor al comercializar el producto } \\
\text { en el mercado destino. }\end{array}$ & .276 & 117 & .000 & .871 & 117 & .000 \\
\hline $\begin{array}{l}\text { P8. En esta empresa exportadora el } \\
\text { margen de beneficio de las } \\
\text { exportaciones fue mejor que lo } \\
\text { esperado. }\end{array}$ & .218 & 117 & .000 & .880 & 117 & .000 \\
\hline $\begin{array}{l}\text { P9. En esta empresa se ha generado un } \\
\text { gran volumen de venta. }\end{array}$ & .217 & 117 & .000 & .900 & 117 & .000 \\
\hline $\begin{array}{l}\text { P10. Esta empresa exportadora ha } \\
\text { logrado un rápido crecimiento. }\end{array}$ & .236 & 117 & .000 & .877 & 117 & .000 \\
\hline
\end{tabular}




\section{iv. Decisión}

Tal como muestra la tabla 21, se observa que los datos no tienen distribución normal, ya que los p valores son $0.00<0.05$. Por tanto, se rechazó la hipótesis nula (Ho). Puesto que se comprobó que los datos no tienen distribución normal; es decir corresponde realizar pruebas no paramétricas como la correlación de Rho de Spearman.

\subsubsection{Análisis Factorial Exploratorio.}

Ferrando y Anguiano-Carrasco (2010), indican que el análisis factorial es un modelo estadístico que ayuda a determinar las relaciones entre un grupo de variables. También, plantea que dichas relaciones se pueden explicar a partir de una serie de variables no observables llamadas factores, siendo el número de factores substancialmente menor que el de variables.

La utilidad del análisis factorial permitirá determinar la validez de los constructos estudiados en este caso adaptación de producto y desempeño del exportador. Es decir, qué tan bien el instrumento de medición está representado y midiendo los constructos (Hernández, Fernández \& Baptista, 2014).

Bajo esta premisa, en el presente trabajo de investigación se ha realizado un análisis factorial exploratorio, donde se fijaron los factores que componen cada constructo, efectuado a través de un análisis factorial de componentes principales. Se eligió este tipo de análisis debido a que es una de las técnicas usualmente aplicadas en estudios relacionados con el desarrollo y validación de tests, pues se utilizan para explorar el grupo de factores comunes o variables latentes que explican las respuestas a los ítems del test. (Lloret-Segura, Ferreres-Traver, Hernández-Baeza y Tomás-Marco, 2014).

Se realizaron también las pruebas de Kaiser-Meyer-Olkin (KMO) y Bartlett. El método de KMO, de acuerdo a Santiago de La Fuente Hernández (2011), es ideal para comparar las magnitudes de los coeficientes de correlación parcial; es decir, cuánto más pequeño sea su valor, mayor será el valor de los coeficientes de correlación parciales. El método de KMO 
indica si es factible realizar un análisis factorial a la muestra seleccionada. (Méndez y Rondón (2012), señala que se puede tomar valores entre 0 y 1 , por tanto, si los valores se encuentran entre 0.5 y 1 , sí se debe aplicar el análisis factorial. Por lo general, estos han sido interpretados de la siguiente forma: Si los valores resultan ser menores de 0,5 se consideran inaceptables; en oposición, si estos son de 0,5 a 0,59 ; serán resultados pobres; de 0,6 a 0,79 , regulares, y de 0,8 a 1, meritorios. El test de esfericidad de Barlett, indica la factibilidad de hacer un análisis factorial. Cuando la hipótesis nula es rechazada indica que la correlación entre las variables es nula. Se acepta como válido un p-valor menor a 0,05 .

Los resultados de la prueba KMO en relación a la variable de adaptación de producto revelaron en 0.674 con un Chi- cuadrado, el cual es una prueba estadística utilizada para poder evaluar las hipótesis acerca de la relación existente entre dos variables categóricas (Hernández et al., 2014), aproximado de 523.297 y una significancia de 0.000 , interpretándose así con resultados regulares, de acuerdo a la tabla 22.

Por último, los resultados de la prueba KMO en el desempeño exportador indicaron que se logró obtener una respuesta de 0.761 con un Chi- cuadrado de aproximadamente 254.311 y una significancia de 0,000, tal como se muestra en la tabla 23 .

Tabla 22

Prueba de KMO y Bartlett - Adaptación de producto

Prueba de KMO y Bartlett

\begin{tabular}{llc}
\hline \multicolumn{2}{c}{ Medida de Kaiser-Meyer-Olkin de Adecuación de } & .674 \\
\hline \multirow{2}{*}{ Prueba de Esfericidad } & Approx. Chi-Square & 523.297 \\
de Bartlett & GI & 21 \\
& Sig. & .000 \\
\hline
\end{tabular}

Fuente: Extraído de SPSS 26.0.0.0. Elaboración propia 
Tabla 23

Prueba de KMO y Bartlet - Desempeño del exportador

\begin{tabular}{|c|c|c|}
\hline \multicolumn{3}{|c|}{ Prueba de KMO y Bartlett } \\
\hline Medida de Kaiser-Me & $\begin{array}{l}\text {-Olkin de Adecuación de } \\
\text { streo }\end{array}$ & .761 \\
\hline \multirow{3}{*}{$\begin{array}{l}\text { Prueba de Esfericidad } \\
\text { de Bartlett }\end{array}$} & Approx. Chi-Square & 254.311 \\
\hline & GI & 3 \\
\hline & Sig. & .000 \\
\hline
\end{tabular}

Fuente: Extraído de SPSS 26.0.0.0. Elaboración propia.

Por último, concerniente a la varianza total explicada, la cual brinda un listado de valores propios de la matriz de varianza, y del porcentaje de la misma, que representa cada uno de ellos. En adición, los valores propios enuncian la cantidad de la varianza total que se encuentra explicada por cada factor, y los porcentajes de varianza, asociados a cada factor, los cuales se logran dividiendo su correspondiente valor por la suma de todos los valores propios (Coutiño, A., 2014). En la variable de adaptación de producto, se logró obtener una varianza de 87.073\% como se indica en la Tabla 24. Asimismo, se puede puntualizar tres factores, los cuales son la representación de las dimensiones de adaptación de producto. Al primer factor, le corresponde la adaptación de marca del producto con un porcentaje de $37.227 \%$; al segundo factor, le corresponde la adaptación de diseño del producto con un 26.297\%; y finalmente, al tercer factor le pertenece la dimensión de la adaptación de calidad del producto con un porcentaje de $23.55 \%$. 
Tabla 24

Varianza total explicada - Adaptación de producto

\begin{tabular}{|c|c|c|c|c|c|c|c|c|c|}
\hline \multirow[b]{2}{*}{ Factor } & \multirow[b]{2}{*}{ Total } & \multicolumn{2}{|c|}{$\begin{array}{l}\text { Valores propios } \\
\text { iniciales }\end{array}$} & \multicolumn{3}{|c|}{$\begin{array}{l}\text { Sumas de extracción de } \\
\text { cargas al cuadrado }\end{array}$} & \multicolumn{3}{|c|}{$\begin{array}{l}\text { Sumas de rotación de cargas } \\
\text { al cuadrado }\end{array}$} \\
\hline & & $\begin{array}{c}\% \\
\text { Varianza }\end{array}$ & $\begin{array}{c}\% \\
\text { Acumulado }\end{array}$ & Total & $\begin{array}{c}\% \\
\text { Varianza }\end{array}$ & $\begin{array}{c}\% \\
\text { Acumulado }\end{array}$ & Total & $\begin{array}{c}\% \\
\text { Varianza }\end{array}$ & $\begin{array}{c}\% \\
\text { Acumulado }\end{array}$ \\
\hline 1 & 3.401 & 48.579 & 48.579 & 3.401 & 48.579 & 48.579 & 2.606 & 37.227 & 37.227 \\
\hline 2 & 1.615 & 23.064 & 71.643 & 1.615 & 23.064 & 71.643 & 1.841 & 26.297 & 63.523 \\
\hline 3 & 1.08 & 15.43 & 87.073 & 1.08 & 15.43 & 87.073 & 1.648 & 23.55 & 87.073 \\
\hline 4 & 0.386 & 5.512 & 92.586 & & & & & & \\
\hline 5 & 0.248 & 3.547 & 96.132 & & & & & & \\
\hline 6 & 0.171 & 2.446 & 98.579 & & & & & & \\
\hline 7 & 0.1 & 1.421 & 100 & & & & & & \\
\hline
\end{tabular}

Fuente: Extraído de SPSS 26.0.0.0 Elaboración propia.

Así también, en la tabla 25, se puede apreciar lo siguiente: concerniente a la varianza total explicada en el desempeño exportador, la varianza resultó en un $86.338 \%$. Cabe resaltar que en la variable desempeño del exportador solo se trabaja con una dimensión, desempeño del exportador - financiero.

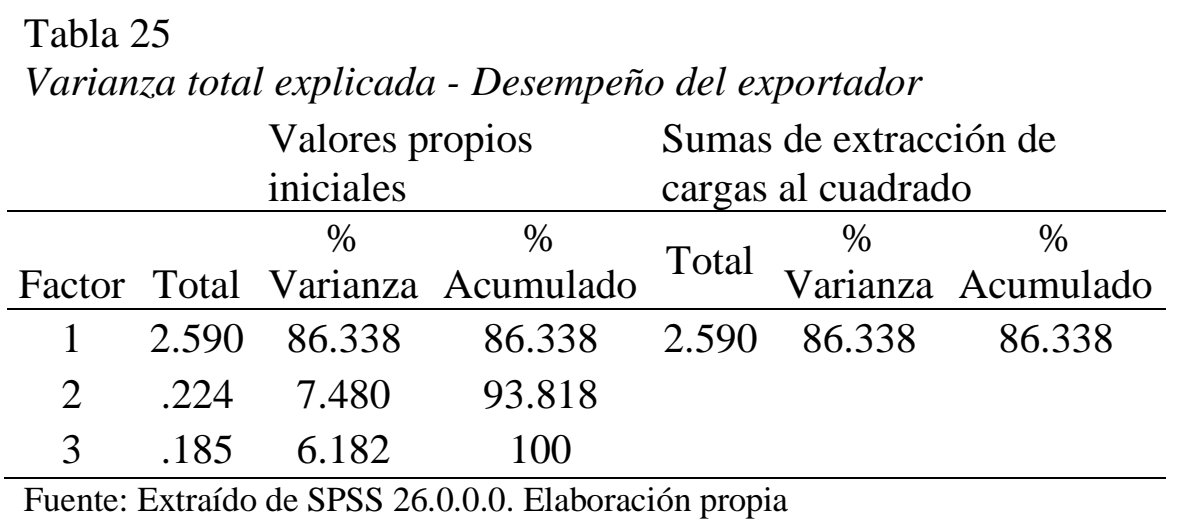

A continuación, se muestra la matriz de componente rotado, que permitirá identificar cual es la relación existente entre las variables, identificando cada una de las dimensiones; según el método Varimax con normalización Kaiser en la variable adaptación de producto, se puede observar que la dimensión marca esta agrupada en las preguntas 3,1,2 (Factor 1). Por otro lado, la dimensión calidad comprende las preguntas 7 y 6 (Factor 2), mientras que la dimensión diseño esta agrupada en las preguntas 5 y 4 (Factor 3). 
Métodos de rotación: Varimax con normalización Kaiser - Adaptación de producto

\begin{tabular}{|c|c|c|c|}
\hline & \multicolumn{3}{|c|}{ Factor } \\
\hline & 1 & 2 & 3 \\
\hline $\begin{array}{l}\text { 3. Está de acuerdo en que la adaptación de color del producto tuvo un } \\
\text { efecto positivo al comercializar el producto en el mercado destino. }\end{array}$ & .941 & & \\
\hline $\begin{array}{l}\text { 1. Está de acuerdo en que la adaptación de nombres de marca tuvo un } \\
\text { efecto positivo al llegar al mercado destino. }\end{array}$ & .906 & & \\
\hline $\begin{array}{l}\text { 2. Está de acuerdo en que la adaptación de etiqueta del producto tuvo } \\
\text { un efecto positivo al comercializar el producto en el mercado destino. }\end{array}$ & .904 & & \\
\hline $\begin{array}{l}\text { 7. Está de acuerdo en que la adaptación de calidad del producto tuvo } \\
\text { una buena aceptación del consumidor al comercializar el producto en } \\
\text { el mercado destino. }\end{array}$ & & .93 & \\
\hline $\begin{array}{l}\text { 6. Está de acuerdo en que la adaptación de garantía del producto tuvo } \\
\text { una buena aceptación del consumidor al comercializar el producto en } \\
\text { el mercado destino. }\end{array}$ & & .92 & \\
\hline $\begin{array}{l}\text { 5. Está de acuerdo en que la adaptación del número de líneas de } \\
\text { producto tuvo una buena aceptación del consumidor al comercializar } \\
\text { el producto en el mercado destino. }\end{array}$ & & & .894 \\
\hline $\begin{array}{l}\text { 4. Está de acuerdo en que la adaptación de diseño principal del } \\
\text { producto tuvo un efecto positivo al comercializar el producto en el } \\
\text { mercado destino. }\end{array}$ & & & .862 \\
\hline
\end{tabular}

Por último, se muestra la matriz de la variable desempeño del exportador, según el método Varimax con normalización Kaiser. La dimensión desempeño del exportador(financiero) esta agrupada en las preguntas 8,10,9 (Factor 1).

Tabla 27

Métodos de rotación: Varimax con normalización Kaiser - Desempeño del exportador

\begin{tabular}{lc}
\hline & Factor \\
\cline { 2 - 2 } 8. En esta empresa exportadora el margen de beneficio de las & 1 \\
exportaciones fue mejor que lo esperado. & .935 \\
10. Esta empresa exportadora ha logrado un rápido crecimiento. & .931 \\
9. En esta empresa se ha generado un gran volumen de venta. & .922 \\
\hline
\end{tabular}

Fuente: Extraído de SPSS 26.0.0.0. Elaboración propia

\subsubsection{Correlaciones Rho de Spearman.}

Según Hernández et al. (2014), esta medida de correlación de tipo no paramétrica, busca relacionar estadísticamente las escalas de tipo Likert. En esta investigación se hizo uso de la 
medida en un nivel ordinal, con la finalidad de medir la relación de las variables estudiadas, adaptación de producto y desempeño del exportador.

Los resultados que figuran en la tabla 28 , indicaría, en el caso del diseño y desempeño del exportador, que si existe una relación entre ambas dimensiones con un coeficiente $r=0.260$; p_valor $=0.005<0.05$. Asimismo, el coeficiente de la marca y desempeño del exportador es $\mathrm{r}=0.526$; $\mathrm{p} \_$valor $=0.000<0.05$, por lo que se puede inferir que existe relación en ambas dimensiones. Por otro lado, el resultado de calidad y desempeño del exportador demostró una relación positiva en dichas dimensiones con un coeficiente de $r=0.467$, p_valor $=0.000<0.05$.

Por último, en la tabla 29 se puede observar que la variable adaptación de producto tiene un efecto positivo en la variable desempeño del exportador con un coeficiente $r=.549$, y un valor de significancia(bilateral) p_valor $=0.000<0.05$.

Tabla 28

Correlación no paramétrica Rho de Spearman de las dimensiones

\begin{tabular}{|c|c|c|c|c|c|c|}
\hline \multicolumn{7}{|c|}{ Correlaciones } \\
\hline & & & Diseño & Marca & Calidad & $\begin{array}{l}\text { Desempeño } \\
\text { exportador }\end{array}$ \\
\hline \multirow{12}{*}{$\begin{array}{l}\text { Rho de } \\
\text { Spearman }\end{array}$} & \multirow{4}{*}{ Diseño } & Coeficiente correlacional & 1.000 & $.244^{* *}$ & $.287^{* *}$ & $.260^{* *}$ \\
\hline & & Sig. (bilateral) & . & .008 & .002 & .005 \\
\hline & & $\mathrm{N}$ & 117 & 117 & 117 & 117 \\
\hline & & Coeficiente correlacional & $.244^{* *}$ & 1.000 & $.426^{* *}$ & $.526^{* *}$ \\
\hline & \multirow[t]{2}{*}{ Marca } & Sig. (bilateral) & .008 & 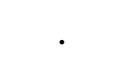 & .000 & .000 \\
\hline & & $\mathrm{N}$ & 117 & 117 & 117 & 117 \\
\hline & \multirow{3}{*}{ Calidad } & Coeficiente correlacional & $.287^{* *}$ & $.426^{* *}$ & 1.000 & $.467^{* *}$ \\
\hline & & Sig. (bilateral) & .002 & .000 & $\cdot$ & .000 \\
\hline & & $\mathrm{N}$ & 117 & 117 & 117 & 117 \\
\hline & \multirow{3}{*}{$\begin{array}{l}\text { Desempeño } \\
\text { exportador }\end{array}$} & Coeficiente correlacional & $.260^{* *}$ & $.526^{* *}$ & $.467^{* *}$ & 1.000 \\
\hline & & Sig. (bilateral) & .005 & .000 & .000 & 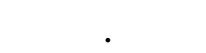 \\
\hline & & $\mathrm{N}$ & 117 & 117 & 117 & 117 \\
\hline
\end{tabular}

**. La correlación es muy significativa a partir del nivel 0.01 (bilateral).

*. La correlación es significativa a partir del nivel 0.05 (bilateral).

Fuente: Basado en la información recabada por aplicación del cuestionario. Extraído de SPSS 26.0.0.0.

Elaboración propia 
Tabla 29

Correlación no paramétrica Rho de Spearman de las variables

\begin{tabular}{|c|c|c|c|}
\hline \multicolumn{4}{|c|}{ Correlaciones } \\
\hline & & & $\begin{array}{l}\text { Desempeño } \\
\text { exportador }\end{array}$ \\
\hline \multirow{3}{*}{$\begin{array}{l}\text { Rho de } \\
\text { Spearman }\end{array}$} & Adaptación & $\begin{array}{l}\text { Coeficiente } \\
\text { correlacional }\end{array}$ & $.549^{* *}$ \\
\hline & de producto & Sig. (bilateral) & .000 \\
\hline & & $\mathrm{N}$ & 117 \\
\hline \multicolumn{4}{|c|}{ **. La correlación es muy significativa a partir del nivel 0.01 (bilateral). } \\
\hline \multicolumn{4}{|c|}{ *. La correlación es significativa a partir del nivel 0.05 (bilateral). } \\
\hline \multicolumn{4}{|c|}{ Fuente: Basado en la información recabada por aplicación del } \\
\hline
\end{tabular}

\subsubsection{Contrastación de hipótesis.}

Con el fin de realizar la contrastación de hipótesis generales y específicas se efectuó la prueba estadística de Rho de Spearman, evidenciándose lo siguiente:

\section{Hipótesis General.}

La adaptación de producto tiene relación con el desempeño del exportador en las empresas exportadoras de palta en Lima 2019.

\section{i. Hipótesis nula (Ho):}

$\mathrm{H}_{\mathrm{o}}: \rho=0$ (La adaptación del producto no se relaciona con el desempeño del exportador en las empresas exportadoras de palta en Lima del año 2019).

\section{- Hipótesis alterna $\left(\mathbf{H}_{1}\right)$}

$\mathrm{H}_{1}: \rho \neq 0$ (La adaptación del producto sí se relaciona con el desempeño del exportador en las empresas exportadoras de palta en Lima del año 2019).

\section{ii. Nivel de significancia $(\alpha)$ :}

El nivel de significancia que se utilizó para la investigación es de $\alpha=0.05$

\section{iii. Estadístico de prueba (Rho de Spearman):}


Tabla 30

Correlaciones en la hipótesis general

\begin{tabular}{|c|c|c|c|}
\hline \multicolumn{4}{|c|}{ Correlaciones } \\
\hline & & & $\begin{array}{l}\text { Desempeño } \\
\text { exportador }\end{array}$ \\
\hline $\begin{array}{l}\text { Rho de } \\
\text { Spearman }\end{array}$ & $\begin{array}{l}\text { Adaptación } \\
\text { de producto }\end{array}$ & $\begin{array}{l}\text { Coeficiente } \\
\text { correlacional } \\
\text { Sig. (bilateral) } \\
\text { N }\end{array}$ & $\begin{array}{c}.549^{* *} \\
.000 \\
117 \\
\end{array}$ \\
\hline \multicolumn{4}{|c|}{ **. La correlación es muy significativa a partir del nivel 0.01 (bilateral). } \\
\hline \multicolumn{4}{|c|}{ *. La correlación es significativa a partir del nivel 0.05 (bilateral). } \\
\hline \multicolumn{4}{|c|}{ Fuente: Basado en la información recabada por aplicación del cuestionario. Extraído } \\
\hline
\end{tabular}

iv. Toma de decisiones

Concerniente a la hipótesis general, teniendo un 5\% de nivel de significancia, se rechaza la hipótesis nula, interpretándose de la siguiente manera: $\mathrm{r}=0.549$; $\mathrm{p}$-valor $=0.000<0.05$, RH0, concluyendo la adaptación de producto sí tiene relación con el desempeño del exportador en las empresas exportadoras de Palta en el Lima del año 2019. De esta forma se comprueba que hay relación muy significativa entre las variables de adaptación de producto y desempeño del exportador; pues el p-valor es menor que 0.01 .

\section{Hipótesis Específica 1.}

La adaptación de marca está relacionada con el desempeño del exportador en las empresas exportadoras de palta en Lima 2019.

\section{i. Hipótesis nula (Ho):}

$\mathrm{H}_{\mathrm{o}}: \rho=0$ (La adaptación de la marca no se relaciona con el desempeño del exportador en las empresas exportadoras de palta en Lima 2019).

\section{- Hipótesis alterna $\left(\mathrm{H}_{1}\right)$}

$\mathrm{H}_{1}: \rho \neq 0$ (La adaptación de la marca sí se relaciona con el desempeño del exportador en las empresas exportadoras de palta en Lima 2019). 


\section{ii. Nivel de significancia $(\alpha)$ :}

El nivel de significancia que se utilizó para la investigación es de $\alpha=0.05$

iii. Estadístico de prueba (Rho de Spearman):

Tabla 31

Rho de Spearman - Hipótesis específica 1

\begin{tabular}{lcc}
\hline & Correlaciones & $\begin{array}{r}\text { Desempeño } \\
\text { exportador }\end{array}$ \\
\hline $\begin{array}{c}\text { Rho de } \\
\text { Spearman }\end{array}$ & $\begin{array}{c}\text { Coeficiente } \\
\text { correlacional } \\
\text { Sig. (bilateral) } \\
\mathrm{N}\end{array}$ & $.526^{* *}$ \\
**. La correlación es muy significativa a partir del nivel 0.01 (bilateral). \\
*. La correlación es significativa a partir del nivel 0.05 (bilateral). \\
Fuente: Basado en la información recabada por aplicación del cuestionario. \\
Extraído de SPSS 26.0.0.0. Elaboración propia
\end{tabular}

\section{iv. Toma de decisiones}

Con respecto a la hipótesis específica 1 , considerando un nivel de significancia de 5\%, se rechazó la hipótesis nula, interpretándose de la siguiente manera: r=0.526; p-valor = $0.000<0.05, \mathrm{RH}$, concluyendo la adaptación de la marca sí tiene relación con el desempeño del exportador en las empresas exportadoras de Palta en Lima del año 2019. De esta forma se comprueba que hay una relación muy significativa entre la adaptación de marca y desempeño del exportador; puesto que el p-valor es menor que 0.01 .

\section{Hipótesis Específica 2.}

La adaptación de diseño está relacionada con el desempeño del exportador en las empresas exportadoras de palta en Lima 2019.

\section{i. Hipótesis nula (Ho):}

$H_{0}: \rho=0$ (La adaptación de diseño no se relaciona con el desempeño del exportador en las empresas exportadoras de palta en Lima 2019). 


\section{- Hipótesis alterna $\left(\mathrm{H}_{1}\right)$}

$H_{1}: \rho \neq 0$ (La adaptación de diseño sí se relaciona con el desempeño del exportador en las empresas exportadoras de palta en Lima 2019).

\section{ii. Nivel de significancia $(\alpha)$ :}

El nivel de significancia que se utilizó para la investigación es de $\alpha=0.05$

\section{iii. Estadístico de prueba (Rho de Spearman):}

Tabla 32

Rho de Spearman - Hipótesis específica 2

\begin{tabular}{|c|c|c|c|}
\hline \multicolumn{4}{|c|}{$\begin{array}{ll}\text { Correlaciones } \\
\end{array}$} \\
\hline & & & $\begin{array}{l}\text { Desempeño } \\
\text { exportador }\end{array}$ \\
\hline $\begin{array}{l}\text { Rho de } \\
\text { Spearman }\end{array}$ & Diseño & $\begin{array}{l}\text { Coeficiente correlacional } \\
\text { Sig. (bilateral) } \\
\mathrm{N}\end{array}$ & $\begin{array}{l}.260 * * \\
.005 \\
117\end{array}$ \\
\hline
\end{tabular}

**. La correlación es muy significativa a partir del nivel 0.01 (bilateral).

*. La correlación es significativa a partir del nivel 0.05 (bilateral).

Fuente: Basado en la información recabada por aplicación del cuestionario.

Extraído de SPSS 26.0.0.0. Elaboración propia.

\section{iv. Toma de decisiones}

Con respecto a la hipótesis específica 2, considerando un nivel de significancia de 5\%, se rechazó la hipótesis nula, interpretándose de la siguiente manera: r=0.260; p-valor = 0.005<0.05, RH, concluyendo la adaptación de diseño sí tiene relación con el desempeño del exportador en las empresas exportadoras de Palta en Lima del año 2019. De esta forma se logró comprobar que existe una relación muy significativa entre la adaptación de diseño y desempeño del exportador; debido al valor de p-valor es menor que 0.01 .

\section{Hipótesis Específica 3.}

La adaptación de calidad está relacionada con el desempeño del exportador en las empresas exportadoras de palta en Lima 2019. 


\section{i. Hipótesis nula (Ho):}

$H_{\mathrm{o}}: \rho=0$ (La adaptación de calidad no se relaciona con el desempeño del exportador en las empresas exportadoras de palta en Lima 2019).

\section{- Hipótesis alterna $\left(\mathbf{H}_{1}\right)$}

$\mathrm{H}_{1}: \rho \neq 0$ (La adaptación de calidad sí se relaciona con el desempeño del exportador en las empresas exportadoras de palta en Lima 2019).

\section{ii. Nivel de significancia $(\alpha)$ :}

El nivel de significancia que se utilizó para la investigación es de $\alpha=0.05$

\section{iii. Estadístico de prueba (Rho de Spearman):}

\section{Tabla 33}

Rho de Spearman - Hipótesis específica 3

\begin{tabular}{|c|c|c|c|}
\hline \multicolumn{4}{|c|}{ Correlaciones } \\
\hline & & & $\begin{array}{l}\text { Desempeño } \\
\text { exportador }\end{array}$ \\
\hline \multirow{3}{*}{$\begin{array}{l}\text { Rho de } \\
\text { Spearman }\end{array}$} & \multirow{3}{*}{ Calidad } & $\begin{array}{l}\text { Coeficiente } \\
\text { correlacional }\end{array}$ & $.467 * *$ \\
\hline & & Sig. (bilateral) & .000 \\
\hline & & $\mathrm{N}$ & 117 \\
\hline \multicolumn{4}{|c|}{ **. La correlación es muy significativa a partir del nivel 0.01 (bilateral) } \\
\hline \multicolumn{4}{|c|}{ *. La correlación es significativa a partir del nivel 0.05 (bilateral). } \\
\hline \multicolumn{4}{|c|}{ Fuente: Basado en la información recabada por aplicación del } \\
\hline & & & \\
\hline
\end{tabular}

\section{iv. Toma de decisiones}

Respecto a la hipótesis específica 3, teniendo en cuenta un nivel de significancia de 5\%, se rechaza la hipótesis nula y se interpretó de la siguiente manera: $r=0.467$; $p$-valor $=0.000<0.05$, RH, concluyendo la adaptación de calidad sí tiene relación con el desempeño del exportador en las empresas exportadoras de Palta en Lima del año 2019. De esta manera se logró comprobar que existe una relación muy significativa entre la adaptación de calidad y desempeño del exportador; ya que el de p-valor resultó menor que 0.01 . 


\subsection{Discusión}

En la presente investigación que lleva por título "Relación entre adaptación de producto y el desempeño del exportador de las empresas exportadoras de palta en Lima 2019", se desarrolló a través de encuestas dirigida a gerentes y administradores. Con respecto a las variables tomadas para el desarrollo de la investigación, se consideró el cuestionario de adaptación de producto y desempeño del exportador de los investigadores Tantong, Karande, Nair \& Singhapakdi (2010), cuyo objetivo se centra en determinar la relación que existe entre las variables ya mencionadas, en las empresas exportadoras de palta en Lima 2019. Los resultados obtenidos a través de la administración de las encuestas mostraron la similitud con los resultados obtenidos por otros investigadores tal y como se mostrarán en la siguiente parte.

\section{Hipótesis General.}

Con respecto a la hipótesis general, las investigaciones anteriores permiten afirmar que existe una relación positiva entre el nivel de adaptación de producto y el desempeño del exportador. Se halló que existe una relación positiva en ambas variables con un coeficiente $\mathrm{r}=0.549$ y p_valor $=0.000<0.05, \mathrm{RH}$., concluyendo en la relación existente entre las variables adaptación de producto y desempeño del exportador de las empresas exportadoras de palta en Lima 2019, ya que la hipótesis nula fue rechazada.

Según lo expuesto, la relación existente entre ambas variables puede estar evidenciada en las afirmaciones de los siguientes investigadores:

Cavusgil y Zou (1996) señalan que la adaptación hace al producto más atractivo para los consumidores y en consecuencia tiene un efecto positivo en el desempeño de la empresa exportadora.

Lages y Montgomery (2004) indican que el desempeño del exportador se relaciona con la adaptación de producto. El desempeño del exportador sería una variable usada por los gerentes para definir las estrategias de exportación, como por ejemplo el grado de adaptación de 
productos, sin embargo, señalan que los gerentes tienden a realizar cambios a corto plazo, lo cual no les ha permitido ver mejoras en el desempeño a largo plazo de las estrategias planteadas.

Lee y Griffith (2004) afirman que la estrategia de adaptación de producto de las empresas exportadoras coreanas tuvo un efecto positivo en el desempeño del exportador, enfatizando que las empresas que están dispuestas a realizar una adaptación enfocada a las necesidades del cliente en el extranjero logran mejores resultados que aquellas que están enfocadas en una estrategia de estandarización.

Calantone, Schmidt y Cavusgil (2006) afirman que el desempeño del exportador está vinculado positivamente con el nivel de la estrategia de adaptación de producto, en donde las empresas con alta dependencia hacia las exportaciones tendrán una estrategia de adaptación de producto más agresiva. Asimismo, las firmas más abiertas a la innovación y que realizan mejoras en la comunicación tendrán un mejor desempeño del exportador.

Hultman, Robson y Katsikeas (2009) afirman que la estrategia de adaptación de producto con un enfoque "strategic fit" tiene relevancia en el desempeño. Sin embargo, el patrón de hallazgos significativos y no significativos resultan de las diversas variables ambientales en el momento de la conceptualización de la estrategia "fit" producto-ambiente al vincularla con el desempeño.

\section{Hipótesis específica 1.}

La hipótesis específica 1, la adaptación de la marca del producto, se encuentra relacionada con el desempeño exportador con un coeficiente $r=0.526$ y p_valor $=0.000<0.05$, RH, por tanto, la hipótesis nula fue rechazada, concluyendo que la adaptación de marca mantiene una relación muy significativa con el desempeño exportador de las empresas exportadoras de palta en Lima del año 2019. 
De acuerdo con la primera hipótesis específica, la relación que se obtiene entre la adaptación de marca y el desempeño exportador es relacionada con los siguientes autores:

Menguc (2017) afirma que en una empresa la marca representa y unifica el nombre, símbolo y signo permitiendo diferenciar el producto frente a sus competidores. Este es considerado un importante activo que requiere también un cierto grado de inversión alto para desarrollarse.

Whitelock (1987) descubrió que la adaptación del diseño, el color y la marca eran considerados importantes para el éxito en la industria británica dedicadas al negocio de ropa de cama.

De manera similar, Zou, Andrus y Norvell (1997) dedujeron que la estandarización de las marcas y características obtuvo una relación negativa con la intensidad de las exportaciones.

Por último, empresas provenientes de mercados desarrollados pueden tener menos presión para la adaptación de la marca, debido a que la homogeneización en los gustos de los consumidores tiende a ocurrir en muchos mercados hacia los estándares occidentales (Levitt 1983). En consecuencia, las empresas de los mercados emergentes según Zou, Andrus y Norvell (1997) como Tailandia la adaptación de marca parece ser más crítica; debido a su mayor dependencia de los diversos mercados de exportación. Incluso las empresas de países que no dependen tanto de los mercados de exportación pueden tener que adaptarse; Tesar y Tarleton (1982) encontraron que las empresas estadounidenses adaptaban sus productos a medida que ingresaban a los mercados internacionales.

\section{Hipótesis específica 2.}

La hipótesis específica 2, la adaptación de diseño del producto tiene una relación positiva con el desempeño exportador, con un coeficiente $r=0.260$ y p_valor $=0.005<0.05$, RH. Ya que la hipótesis nula fue rechazada, se concluye que la adaptación de marca tiene una relación muy significativa con el desempeño exportador de las empresas exportadoras de palta en Lima del año 2019. 
De acuerdo con la primera hipótesis específica, la relación entre la adaptación de diseño y el desempeño exportador esta evidenciada por los siguientes investigadores:

Tantong et al. (2010), señalaron la existencia de la relación positiva(significativa) entre el diseño de producto y el desempeño del exportador, enfatizando la urgencia de adoptar esta estrategia en las firmas de mercados emergentes, ya que estos países se caracterizan por su dependencia de las exportaciones realizadas en distintos mercados. Si bien los autores señalaban en un inicio, que la eficacia de la adaptación de diseño no estaba muy clara, autores como Weinrauch y Rao (1974), señalaban la importancia de la adaptación de diseño del producto. Asimismo, autores como Zou, Andrus, and Norvell (1997) hallaron que había un compromiso por parte de las empresas exportadoras de Colombia hacia la adaptación de diseño, añadiendo que este proceso de adaptación demanda altos costos, por lo que algunas empresas optaban por la estandarización.

\section{Hipótesis específica 3.}

La hipótesis específica 1, la adaptación de la calidad del producto se encuentra relacionada con el desempeño exportador, con un coeficiente $r=0.467$ y p_valor $=0.000<0.05$, RH. por tanto, la hipótesis nula fue rechazada, concluyendo que la adaptación de calidad mantiene una relación muy significativa con el desempeño exportador de las empresas exportadoras de palta en Lima del año 2019.

En el estudio de Tantong et al. (2010), los autores Hooker y Caswell (1996), señalaron que las empresas deberían adaptar la calidad sobre todo en el caso de la industria de alimentos para asegurarse que los productos cumplan los estándares de inocuidad relacionado a la cantidad de pesticidas, pureza, y aditivos. Asimismo; indicaron que, si las empresas ofrecen un producto con mayores garantías, esto tendría una respuesta positiva como señal de tener una alta calidad.

Tal es el caso de las empresas surcoreanas, automotriz, como Hyundai, ofrecieron una garantía de 10 años en algunos mercados, con el fin de atraer a los compradores de la 
competencia como Honda y Toyota, quienes tenían incertidumbres sobre la calidad y confiabilidad que tiene Hyundai.

En un estudio de las subsidiarias estadounidenses de empresas europeas, Ward (1973) reveló que las adaptaciones del producto con respecto a la calidad eran tan trascendentes para los clientes estadounidenses como otros aspectos tales como el etiquetado, el diseño y el empaque.

Asimismo, los autores Hooker y Caswell (1996), mencionan otro modelo como el caso de la India. Las empresas de pepinillo exportados a mercados occidentales deben desarrollar sus productos en variedades, por ejemplo, los que la empresa supone "suave en picante" y también "muy picante" no es el mismo rango para los consumidores en destino. Asimismo, muchos productos alimenticios son empaquetados para incluir la información nutricional y calórica que no son demandadas cuando se vendieron en el mercado de origen.

Por otro lado, Zamiska (2007) confirma la importancia de la adaptación de calidad al referirse en un caso especial de alimentos para animales. Este había sido contaminado por un aditivo tóxico que generó la muerte de muchos animales, por ello enfatiza en incrementar los estándares de calidad conforme la empresa va incursionando en nuevos mercados.

El autor Porter (1990), citado por Tantong et al. (2010), demostró que en países desarrollados los exportadores deben asegurarse que sus productos estén sujetos a una alta prueba de testeo en calidad, pues en estos mercados los consumidores son más sofisticados con altas expectativas de calidad debido a que tienen una gran cantidad de opciones provenientes de mercados competitivos que analizan al momento de realizar la compra.

\subsection{Conclusiones}

De acuerdo a los resultados obtenidos en la investigación cuyo objetivo era determinar si existe una relación entre la adaptación del producto y desempeño exportador, se concluye lo siguiente: 
La investigación comprobó la relación existente entre las variables adaptación de producto y desempeño del exportador. El coeficiente Rho de Spearman resultó 0.549 en donde el nivel de significancia fue de 0.000 entre ambas variables, rechazando la hipótesis nula, lo que permite afirmar lo siguiente: "La adaptación de producto si se relaciona con la variable desempeño del exportador de las empresas exportadoras de palta en Lima. Tal y como se evidenció en la investigación de los autores Tantong et al. (2010) en donde señalaban la relación positiva entre ambas variables.

Así también, la investigación validó la existencia de relación entre las dimensiones de adaptación de la marca del producto y desempeño exportador en las empresas exportadoras de palta en Lima. Respaldada en la investigación realizada por Whitelock (1987) en el cual señaló que elementos tales como el etiquetado, empaque, estilo, estética del empaque y color son trascendentes para el desempeño exportador de las empresas. Asimismo, el coeficiente de Rho de Spearman arrojó un resultado de 0,526 entre ambas dimensiones; rechazando la hipótesis nula. Concluyendo que "La adaptación de la marca del producto sí se relaciona con el desempeño exportador en las empresas exportadoras de palta en Lima del año 2019”

Igualmente, se halló que existe una relación entre la adaptación de diseño y el desempeño del exportador, que coincide con lo señalado por los autores Tantong et al. (2010) quienes hallaron una relación significativa entre la adaptación de diseño y el desempeño del exportador, afirmando la necesidad de adoptar esta estrategia en las empresas de mercados emergentes teniendo en cuenta la dependencia en los diversos mercados de exportación. La hipótesis nula fue rechazada, pues el Rho de Spearman resultó, 0.005 y el coeficiente fue de 0.260 , se concluye que "la adaptación de diseño si se relaciona con el desempeño exportador en las empresas exportadoras de palta en Lima 2019”.

Finalmente, la investigación obtuvo como resultado una relación significativa entre la adaptación de la calidad del producto con el desempeño exportador en empresas exportadoras 
de palta en Lima, con un coeficiente de 0.467. Respaldado por los autores Hooker y Caswell (1996), quienes señalaron que adaptación de la calidad en los productos resulta de importante valor para los consumidores y más aún en el caso de industrias alimentarias donde se tiene que cumplir con estándares de inocuidad entre otros los cuales serán beneficiosos para los consumidores. Asimismo, indicaron que, si las empresas ofrecen un producto con mayores garantías, esto tendría una respuesta positiva como señal de tener una alta calidad.

\subsection{Recomendaciones}

A continuación, las siguientes recomendaciones son útiles para todo aquel lector que pueda usar esta información a su conveniencia. Ideales para las empresas exportadoras de palta en Lima, los cuales contribuyeron para la obtención de resultados de la presente investigación. En consiguiente, se sugiere implementar los siguientes puntos:

- Es importante considerar la estrategia de adaptación de la marca, diseño y calidad del producto en las empresas exportadoras de palta, pues este presenta un impacto positivo en el desempeño de los exportadores. Asimismo, se recomienda a las empresas tener un compromiso por brindar siempre un buen producto, comunicación permanente y cercana con el cliente para fortalecer y acrecentar el vínculo empresarial, a través participación en ferias internacionales, ruedas de negocio. Asimismo, es importante aprovechar los recursos del gobierno concerniente a las ruedas de negocio, ferias, talleres de exportación, entre otros, que usualmente brinda Promperú. En cuanto a ferias del sector, la Expoalimentaria es una de las principales plataformas en Latinoamérica pues reúne a los sectores de maquinarias, bebidas, servicios, envases y embalajes de la industria alimentaria. Es organizada por ADEX en conjunto con Mincetur, Minagri, Ministerio de Relaciones exteriores y Promperú. De esta forma, el exportador tendría la oportunidad de estar en contacto con los keyplayers de la cadena de producción y 
distribución además de programar citas de negocios, asistir a conferencias, realizar cotizaciones y acceder a la plataforma B2Peru.

- En relación a la adaptación de la marca, muchas de las empresas usan marca blanca pues es más fácil la entrada que empezar con una propia. Sin embargo, se recomienda usar marca propia pues dejaría un mayor margen de ganancia al evitar intermediarios en la logística internacional, permitiendo tener un trato directo con el cliente y afianzar las relaciones. Asimismo, se sugiere el posicionamiento de una marca propia asociando el producto a la marca Perú y/o trabajando con marcas del sector, "Avocados from Peru", lo que permitirá tener más confianza y presencia en el extranjero. Con respecto a la Marca Perú, se puede obtener la licencia para hacer uso de la marca cumpliendo todos los requisitos solicitados por Promperú, tiene una vigencia de dos años con opción a renovación. Cabe resaltar que la marca Perú tuvo su origen en el 2011, es reconocida mundialmente y transmite con eficacia la propuesta de valor de nuestro país.

- En cuanto a la adaptación de diseño, es indispensable para las empresas exportadoras de palta tener acceso, de por lo menos uno a dos sistemas o plataformas de inteligencia de mercado tales como Trademap, Adex Data Trade, Veritrade, entre otros. Esto les brindará data real de importación, exportaciones, estadísticas, principales compradores, competidores, presentación del producto. Toda esta información ayudará a conocer nuevas tendencias e insights respecto al mercado de destino y el producto que ayudará a definir mejor el posicionamiento de la empresa, repercutiendo finalmente en el desempeño exportador de empresas de palta. Asimismo, se recomienda la afiliación a las cámaras de comercio, en donde se dan conferencias o talleres del sector. También asociándose a marcas del sector como "Avocados del Perú" el cual es un grupo de promoción agrícola 
establecido en 2002 para promover el consumo de aguacates Hass en los Estados Unidos, el cual es recurso esencial para la industria del Aguacate Hass que proporciona datos e investigaciones oportunas y relevantes para los productores e importadores nacionales que representa. Así el exportador peruano tendrá mucha más información de las tendencias a nivel mundial y podrá usar esta data a su favor.

- Finalmente, en cuanto a la adaptación de calidad, que implica los conceptos de garantía y calidad. La apertura de oficinas en el país destino asegura el servicio de post venta al consumidor certificando la garantía del producto. Esto, les permite a las empresas, a la vez, conocer tanto las tendencias del consumidor en el mercado local, como las regulaciones que estén relacionadas con los estándares de calidad para el ingreso de bienes en el país. Sin embargo, teniendo en cuenta que hay una gran cuota de empresas que son de la categoría MYPE, se sabe que la apertura de una filial en el extranjero representaría un alto costo. Por ello, se debe trabajar en conjunto con las Oficinas Comerciales del Perú en el Exterior - OCEX, pues los consejeros comerciales poseen información del mercado local. Por otro lado, se debería aprovechar las capacitaciones dadas por SENASA que están enfocadas en controlar las plagas en los cultivos y las capacitaciones para el cultivo de paltas, teniendo en cuenta que SENASA es la entidad encargada de inspeccionar, verificar y certificar. Es importante un compromiso del exportador para la producción a largo plazo que garantice una calidad de oferta exportable, en nuestro país el porcentaje mínimo de materia seca para la exportación de palta Hass es de 21.5\%, sin embargo, se debería trazar objetivos que mejoren este porcentaje, lo cual mejoraría la imagen como exportador puesto que está asociada con calidad en el mercado exterior. Cabe resaltar que en México el porcentaje de materia seca de palta fluctúa entre $19 \%$ y $25 \%$, en Colombia $24 \%$, y en Chile es de $23 \%$. Por otro 
lado, se recomienda obtener la certificación de comercio justo (Fair Trade), que garantiza el origen del producto reflejando la responsabilidad de la empresa en temas sociales, ambientales y puedan contribuir económicamente a través de "prácticas comerciales éticas”. Cabe resaltar que es importante para las empresas dar prioridad a la globalización del mercado orgánico; comunicando a sus clientes su compromiso con el medio ambiente, social y económico durante el proceso de producción. Lo que conllevaría a una diferenciación de sus competidores a través de estas prácticas en el mercado internacional. 


\section{Referencias}

Asociación de Productores de Paltas Hass del Perú - Prohass. (2018). Revista de la Asociación de Productores de Palta Hass del Perú (Edición N¹4). Lima: Integra Comunicación Corporativa S.A.C

Asociación de Gremios Productores Agrarios del Perú (2020). La agricultura peruana: Valor en tiempos de pandemia. [agapperu.org]. Recuperado de: https://agapperu.org/laagricultura-peruana-valor-en-tiempos-de-pandemia/

Brei, V. A., d'Avila, L., Camargo, L. F., \& Engels, J. (2011). The influence of adaptation and standardization of the marketing mix on performance: A meta-analysis. BAR-Brazilian Administration Review, 8(3), 266-287.

Cadilhon, J., \& Officer, M. (2009). The market for organic products in Asia-Pacific. China BioFach.

Calantone, R. J., Kim, D., Schmidt, J. B., \& Cavusgil, S. T. (2006). The influence of internal and external firm factors on international product adaptation strategy and export performance: a three-country comparison. Journal of Business Research, 59(2), 176185.

Calantone, R. J., Tamer Cavusgil, S., Schmidt, J. B., \& Shin, G. C. (2004). Internationalization and the dynamics of product adaptation-An empirical investigation. Journal of Product Innovation Management, 21(3), 185-198.

Carneiro, J., Rocha, A. D., \& Silva, J. F. D. (2011). Determinants of export performance: a study of large Brazilian manufacturing firms. BAR-Brazilian Administration Review, $8(2), 107-132$.

Cavusgil, S. T., \& Zou, S. (1994). Marketing strategy-performance relationship: an investigation of the empirical link in export market ventures. The Journal of Marketing, $1-21$.

Costello, A.B., y Osborne, J. (2005). Best practices in exploratory factor analysis: four recommendations for getting the most from your analysis. Practical Assessment 
$\begin{array}{llll}\text { Research } \quad \& \quad \text { Evaluation, } & \text { 10(7). }\end{array}$ http://pareonline.net/getvn.asp?v=10\&n=7

Del Medio Ambiente, P. G., \& del Banco Mundial, G. (2017) Tomando Impulso en la Agricultura Peruana: Oportunidades para aumentar la productividad.

ELGRAINI, M., \& TAMIRI, M. A. Networking, internationalization of SMEs and export performance: A theoretical framing.

Espilco, A., Kimberly, T., \& Ramos Almeida, A. F. (2018). La relación de adaptación de producto y orientación de mercado con el desempeño exportador de las Mypes de Gamarra del sector confecciones 2018.

Euromonitor International. (2015, Octubre). Millennials: Impact of their behaviour on global consumer markets. Recuperado de http://www.euromonitor.com/

Euromonitor International. (2018, Junio). Consumer Lifestyles in Germany. Recuperado de http://www.euromonitor.com/

Euromonitor International. (2018, Mayo). Consumer Lifestyles in Hong Kong, China. Recuperado de http://www.euromonitor.com/

Euromonitor International. (2019, Enero). Consumer Lifestyles in Japan. Recuperado de http://www.euromonitor.com/

FAO. (June 15, 2020). Production of avocado in Peru from 2010 to 2018 (in 1,000 metric tons) [Graph]. In Statista. Retrieved September 19, 2020, from https://www.statista.com/statistics/934855/peru-avocado-production-volume/

Horská, E., Ubreziova, I., \& Kekäle, T. (2007). Product adaptation in processes of internationalization: Case of the Slovak food-processing companies. Baltic Journal of Management, 2(3), 319-333.

Horta, R. (2015). Conceptualización del desempeño exportador: análisis de los avances en la literatura de los negocios internacionales. Oikos $N^{o} 40,137$ - 150, Escuela de Administración y Economía, Universidad Católica Silva Henríquez (UCSH), Santiago de Chile. 
Hultman, M., Robson, M. J., \& Katsikeas, C. S. (2009). Export product strategy fit and performance: An empirical investigation. Journal of International Marketing, 17(4), 123.

Lages, L. F., \& Montgomery, D. B. (2004). Export performance as an antecedent of export commitment and marketing strategy adaptation. European Journal of Marketing.

Lages, L. F., Silva, G., \& Styles, C. (2009). Relationship capabilities, quality, and innovation as determinants of export performance. Journal of international Marketing, 17(4), 4770.

Lee, C., \& Griffith, D. A. (2004). The marketing strategy-performance relationship in an export-driven developing economy. International Marketing Review.

Leonidou, L. C., Katsikeas, C. S., \& Samiee, S. (2002). Marketing strategy determinants of export performance: a meta-analysis. Journal of Business research, 55(1), 51-67.

Li, L. Y. (2010). Factors that reduce rigid product adaptation decisions: The case of exporting firms in China. Industrial Marketing Management, 39(4), 531-537.

Melgar, Z., \& Clelia, S. (2018). Impacto de la adaptación del producto en el desempeño exportador de las empresas exportadoras de café en Lima 2018.

Mengüç, B. (1997). Product adaptation practices in the context of export activity: an empirical study of Turkish manufacturing firms. Journal of Euromarketing, 6(2), 25-56.

Ministerio de Agricultura y Riego (2017). Palta Avocado Fact Sheet: Palta peruana para el mundo [www.gob.pe]. Recuperado de: http://agroaldia.minagri.gob.pe/biblioteca/download/pdf/tematicas/ftaxonomia_plantas/f01-cultivo/palta.pdf

Ministerio de Agricultura y Riego (2015). La Palta "Producto estrella de exportación" [www.gob.pe]. Recuperado de: http://siea.minagri.gob.pe/siea/?q=la-palta-peruana

Ministerio de Agricultura y Riego (2017). Palta Avocado Fact Sheet: Palta peruana para el mundo [www.gob.pe]. Recuperado de: http://agroaldia.minagri.gob.pe/biblioteca/download/pdf/tematicas/ftaxonomia_plantas/f01-cultivo/palta.pdf 
Ministerio de Agricultura y Riego (2019). La situación del mercado internacional de la palta [www.gob.pe]. Recuperado

de: http://agroaldia.minagri.gob.pe/biblioteca/download/pdf/tematicas/ftaxonomia_plantas/f01-cultivo/2018/situacion_palta.pdf

Mundo empresarial. (2015, 06 de junio). Mundo empresarial 2015 - Prohass (06-06-2015) $\begin{array}{llll}\text { [archivo de } & \text { vídeo]. } & \text { Recuperado }\end{array}$ https://www.youtube.com/watch?v=dAtqnVqd5eE\&feature=youtu.be

Nature's Pride (2019) Ripening [naturespride.eu]. Recuperado de https://www.naturespride.eu/ripe

Revista Industrial del Campo. (2014, 12, diciembre). Crecerá un 10\% la producción de aguacate, [2000agro.com.mx]. Recuperado de http://www.2000agro.com.mx/agroindustria/crecera-un-10-la-produccion-deaguacate/

Roxo, M., Silva, S. C., \& Lisboa, A. (2014). The influence of internal and external variables in the export performance.

Santo, E., \& de Moura, M. (2014). Export performance: the case of the exports of cork stoppers from Portugal to emergent economies (Doctoral dissertation).

Shoham, A. (1998). Export performance: a conceptualization and empirical assessment. Journal of International Marketing, 6(3), 59-81.

Sohail, M. S., \& Alashban, A. (2009). An analysis of product-market strategy and export performance: Evidence from SMEs in Saudi Arabia. Sohail, Sadiq M and Ashban. A (2009). "An analysis of product-market strategy and export performance: evidence from SMEs in Saudi Arabia". International Journal of Entrepreneurship, 13, 49-66.

Sousa, C. M., Martínez-López, F. J., \& Coelho, F. (2008). The determinants of export performance: A review of the research in the literature between 1998 and 2005. International Journal of Management Reviews, 10(4), 343-374. 
Tantong, P., Karande, K., Nair, A., \& Singhapakdi, A. (2010). The effect of product adaptation and market orientation on export performance: A survey of Thai managers. Journal of Marketing Theory and Practice, 18(2), 155-170.

Vásquez, K. (2015). Determinantes del crecimiento agroexportador en el Perú. Banco Central de Reserva del Perú. Recuperado de http://www.bcrp.gob.pe/docs/Publicaciones/Revista-Moneda/moneda-161/moneda161-05.pdf

Vladimirova, Y. N. (2013). Internationalization and the dynamics of product adaptation: The Case of Parfois.

Zander, K., Stolz, H., \& Hamm, U. (2013). Promising ethical arguments for product differentiation in the organic food sector. A mixed methods research approach. Appetite, 62, 133-142.

Zghidi, A. B. Y., Boubakri, W. B., y Zaiem, I. (2013). Factors determining export performance: a comparative study of three industrial sectors. International Journal of Business Competition and Growth, 3(1), 43-66.

Zou, S., \& Stan, S. (1998). The determinants of export performance: a review of the empirical literature between 1987 and 1997. International Marketing Review, 15(5), 333-356.

Öz, F., \& Özmen, A. (2019) The relationship between product adaptation and export performance: a research on the furniture, ready-to-wear, and leather sectors. Mehmet Akif Ersoy Üniversitesi Sosyal Bilimler Enstitüsü Dergisi, 11(29), 550-579. 


\section{Anexos}

Anexo 1. Matriz de Consistencia

\begin{tabular}{|c|c|c|c|c|}
\hline Problema & Objetivo & Hipótesis & Variables & Metodología \\
\hline Adap & de $\mathrm{p}$ & una relación & & Tip \\
\hline $\begin{array}{l}\text { de las empresas exportadoras } \\
\text { de palta en Lima } 2019 ? \\
\text { Problemas específicos }\end{array}$ & $\begin{array}{l}\text { de las empresas exportadoras } \\
\text { de palta en Lima } 2019 . \\
\text { Objetivos Específicos }\end{array}$ & $\begin{array}{l}\text { desempeño del exportador de } \\
\text { las empresas exportadoras de } \\
\text { palta en Lima } 2019 .\end{array}$ & $\begin{array}{l}\text { X1: Adaptación } \\
\text { de marca. }\end{array}$ & $\begin{array}{l}\text { Investigación } \\
\text { imental transversal y } \\
\text { nal }\end{array}$ \\
\hline $\begin{array}{l}\text { de las empresas } \\
\text { exportadoras de palta en } \\
\text { Lima 2019? }\end{array}$ & $\begin{array}{l}\text { exportador de las } \\
\text { empresas exportadoras } \\
\text { de palta en Lima } 2019 .\end{array}$ & $\begin{array}{lcr}\text { desempeño } & & \text { del } \\
\text { exportador } & \text { de } & \text { las } \\
\text { empresas } & \text { exportadoras }\end{array}$ & $\begin{array}{l}\text { X3: Adaptación } \\
\text { de calidad. }\end{array}$ & $\begin{array}{l}\text { mento de Investigación } \\
\text { sta: Administrado a un } \\
\text { específico de empresarios }\end{array}$ \\
\hline $\begin{array}{l}\text { - ¿Cómo se relaciona la } \\
\text { adaptación de diseño en el } \\
\text { desempeño del exportador } \\
\text { de las empresas } \\
\text { exportadoras de palta en }\end{array}$ & $\begin{array}{l}\text { - Determinar la relación de } \\
\text { la adaptación de diseño } \\
\text { con el desempeño del } \\
\text { exportador de las } \\
\text { empresas exportadoras }\end{array}$ & $\begin{array}{l}\text { de palta en Lima } 2019 . \\
\text { La adaptación de diseño } \\
\text { está relacionada con el } \\
\text { desempeño } \\
\text { exportador de del }\end{array}$ & $\begin{array}{l}\text { Y: Desen } \\
\text { exportad }\end{array}$ & $\begin{array}{l}\text { ctividad está enfocada en } \\
\text { xportación de palta. } \\
\text { es y administradores) } \\
\text { ría: Empresas } \\
\text { doras de palta. }\end{array}$ \\
\hline
\end{tabular}

Fuente: Elaboración propia. 


\section{Anexo 2. Instrumento de Investigación: Cuestionario Adaptación de Producto y Desempeño del Exportador.}

Datos generales:

Edad:

Sexo: $F_{-}-\mathrm{M}$

Grupos ocupacionales: Gerente__ Administrador_

Especifique área:

El presente estudio tiene un enfoque de estrategia de marketing internacional. Estudia la relación entre la adaptación del producto y desempeño del exportador en las empresas exportadoras de palta en Lima 2019.

A continuación, encontrará proposiciones sobre aspectos relacionados con las características del ambiente de trabajo que usted frecuenta. Cada una tiene 5 opciones para responder de acuerdo a lo que describa mejor la situación en su centro laboral.

El cuestionario contiene 10 afirmaciones que están relacionadas a situaciones que se presentan en un entorno laboral. Marque con una X en una de las 5 opciones donde 1 (muy en desacuerdo), 2 (en desacuerdo), 3 (ni de acuerdo ni en desacuerdo), 4(de acuerdo) y 5 (muy de acuerdo).

\begin{tabular}{llccccc}
\hline $\mathrm{N}^{\circ}$ & \multicolumn{1}{c}{ Muy en } & $\begin{array}{c}\text { En } \\
\text { Ítem }\end{array}$ & $\begin{array}{c}\text { Ni de } \\
\text { acuerdo } \\
\text { ni en } \\
\text { desacuerd } \\
\text { desacuerd } \\
\text { desacuerd } \\
\text { o }\end{array}$ & $\begin{array}{c}\text { De } \\
\text { acuerd } \\
\text { o }\end{array}$ & $\begin{array}{c}\text { Muy de } \\
\text { acuerdo }\end{array}$ \\
\cline { 3 - 7 } & & 1 & 2 & 3 & 4 & 5 \\
\hline 1 & $\begin{array}{l}\text { Están de acuerdo en que la } \\
\text { adaptación de nombres de } \\
\text { marca tuvo un efecto positivo } \\
\text { al llegar al mercado destino. }\end{array}$ & & & & \\
\hline 2 & $\begin{array}{l}\text { Está de acuerdo en que la } \\
\text { adaptación de etiqueta del } \\
\text { producto tuvo un efecto } \\
\text { positivo al comercializar el }\end{array}$
\end{tabular}




\begin{tabular}{|c|c|}
\hline & $\begin{array}{l}\text { producto en el mercado } \\
\text { destino. }\end{array}$ \\
\hline 3 & $\begin{array}{l}\text { Está de acuerdo en que la } \\
\text { adaptación de color del } \\
\text { producto tuvo un efecto } \\
\text { positivo al comercializar el } \\
\text { producto en el mercado } \\
\text { destino. }\end{array}$ \\
\hline 4 & $\begin{array}{l}\text { Está de acuerdo en que la } \\
\text { adaptación de diseño principal } \\
\text { del producto tuvo un efecto } \\
\text { positivo al comercializar el } \\
\text { producto en el mercado } \\
\text { destino. }\end{array}$ \\
\hline 5 & $\begin{array}{l}\text { Está de acuerdo en que la } \\
\text { adaptación del número de } \\
\text { líneas de producto tuvo una } \\
\text { buena aceptación del } \\
\text { consumidor al comercializar el } \\
\text { producto en el mercado } \\
\text { destino. }\end{array}$ \\
\hline 6 & $\begin{array}{l}\text { Está de acuerdo en que la } \\
\text { adaptación de garantía del } \\
\text { producto tuvo una buena } \\
\text { aceptación del consumidor al } \\
\text { comercializar el producto en el } \\
\text { mercado destino. }\end{array}$ \\
\hline 7 & $\begin{array}{l}\text { Está de acuerdo en que la } \\
\text { adaptación de calidad del } \\
\text { producto tuvo una buena } \\
\text { aceptación del consumidor al } \\
\text { comercializar el producto en el } \\
\text { mercado destino. }\end{array}$ \\
\hline & Desempeño del exportador \\
\hline 8 & $\begin{array}{l}\text { En esta empresa exportadora } \\
\text { el margen de beneficio de las } \\
\text { exportaciones fue mejor que lo } \\
\text { esperado. }\end{array}$ \\
\hline 9 & $\begin{array}{l}\text { En esta empresa se ha } \\
\text { generado un gran volumen de } \\
\text { ventas. }\end{array}$ \\
\hline 10 & $\begin{array}{l}\text { Esta empresa exportadora ha } \\
\text { logrado un rápido crecimiento. }\end{array}$ \\
\hline
\end{tabular}




\section{Anexo 3. Validación de jueces}

Juez N$^{\circ}$ 1: Miguel Loo Rodríguez - Coordinador académico de la Universidad San Ignacio de Loyola.

\section{INSTRUMENTO PARA LA VALIDEZ DE CONTENIDO (JUICIO DE EXPERTOS)}

El presente instrumento tiene como finalidad validar el formulario de adaptación de producto y desempeño del exportador, el mismo que será aplicado a los administradores, gerentes de marketing o gerentes del área comercial, gerentes del área de investigación y desarrollo o jefes del área de comercio exterior de las empresas exportadoras de palta en Perú que forman parte del estudio "RELACION ENTRE ADAPTACION DE PRODUCTO Y EL DESEMPEÑO DEL EXPORTADOR DE EMPRESAS EXPORTADORAS DE PALTA EN PERU 2019", que corresponde a un diseño correlacional no experimental transversal.

\section{Instrucciones}

La evaluación requiere de la lectura detallada y completa de cada uno de los ítems propuestos a fin de cotejarlos de manera cualitativa con los criterios propuestos relativos a: Claridad de la redacción, Congruencia con el contenido, Contexto correcto del item y Dominio del Constructo. Para ello deberá asignar una valoración si el ítem presenta o no los criterios propuestos, y en caso necesario se ofrecen un espacio para las observaciones si hubiera.

Juez $N^{\circ}$ :

Fecha actual:

10 Unlio $20 / 9$

Nombres y Apellidos de Juez: MIGUEL E. I00

Institución donde labora: USiL Años de experiencia profesional o científica: $>40$ años

Grado de Instrucción:

Puesto que desempeña:

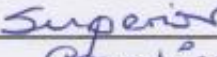

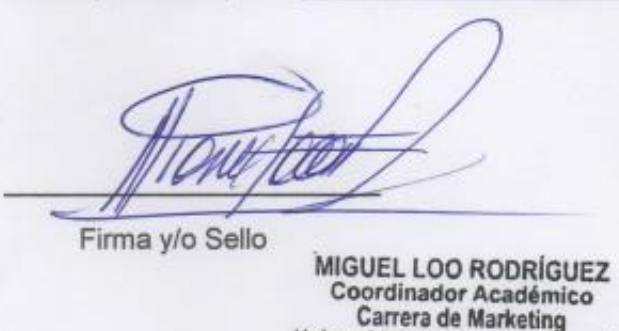

Universidad San Ignacio de Loyola 


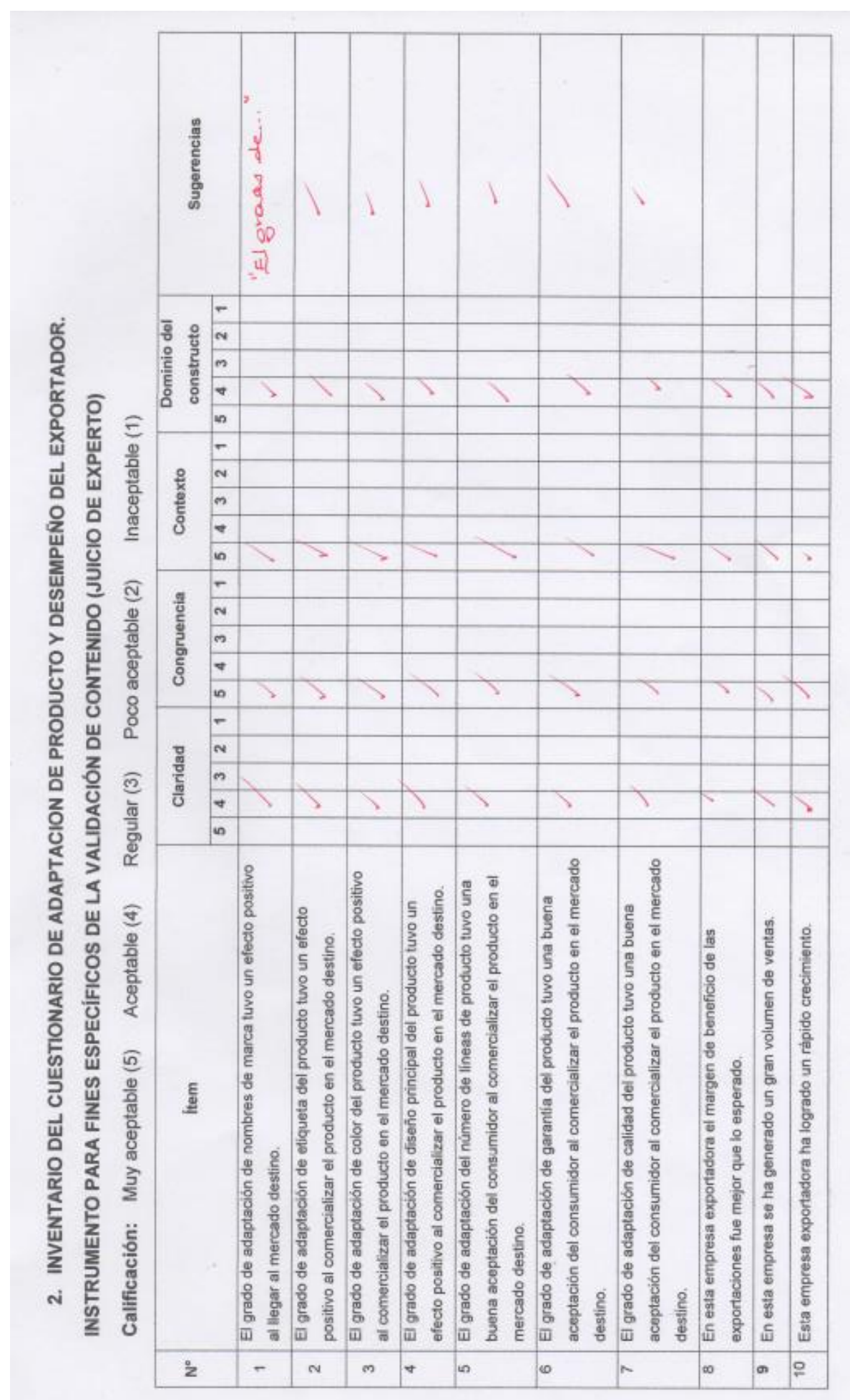


Juez N²: Carla Arriola Alvarado - Coordinadora académica de la Universidad San Ignacio

de Loyola.

\author{
INSTRUMENTO PARA LA VALIDEZ DE CONTENIDO \\ (JUICIO DE EXPERTOS)
}

El presente instrumento tiene como finalidad validar el formulario de adaptación de producto y desempeño del exportador, el mismo que será aplicado a los administradores, gerentes de marketing o gerentes del área comercial, gerentes del área de investigación y desarrollo o jefes del área de comercio exterior de las empresas exportadoras de palta en Perú que forman parte del estudio "RELACION ENTRE ADAPTACION DE PRODUCTO Y EL DESEMPEÑO DEL EXPORTADOR DE EMPRESAS EXPORTADORAS DE PALTA EN PERU 2019", que corresponde a un diseño correlacional no experimental transversal.

\title{
Instrucciones
}

La evaluación requiere de la lectura detallada y completa de cada uno de los ítems propuestos a fin de cotejarlos de manera cualitativa con los criterios propuestos relativos a: Claridad de la redacción, Congruencia con el contenido, Contexto correcto del ítem y Dominio del Constructo. Para ello deberá asignar una valoración si el ítem presenta o no los criterios propuestos, y en caso necesario se ofrecen un espacio para las observaciones si hubiera.

Juez $\mathrm{N}^{\mathrm{o}}$ :

Fecha actual:

Nombres y Apellidos de Juez:

Institución donde labora: $27 / 08 / 2019$

Años de experiencia profesional o científica: $<10$ años

Grado de Instrucción: Magister

Puesto que desempeña: Coordinadora Académica

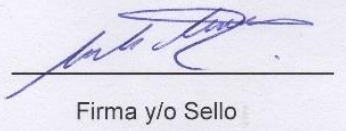

CARLA ARRIOLA ALVARADO
Coordinadora Aciademic..

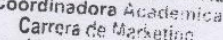

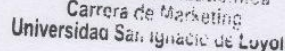




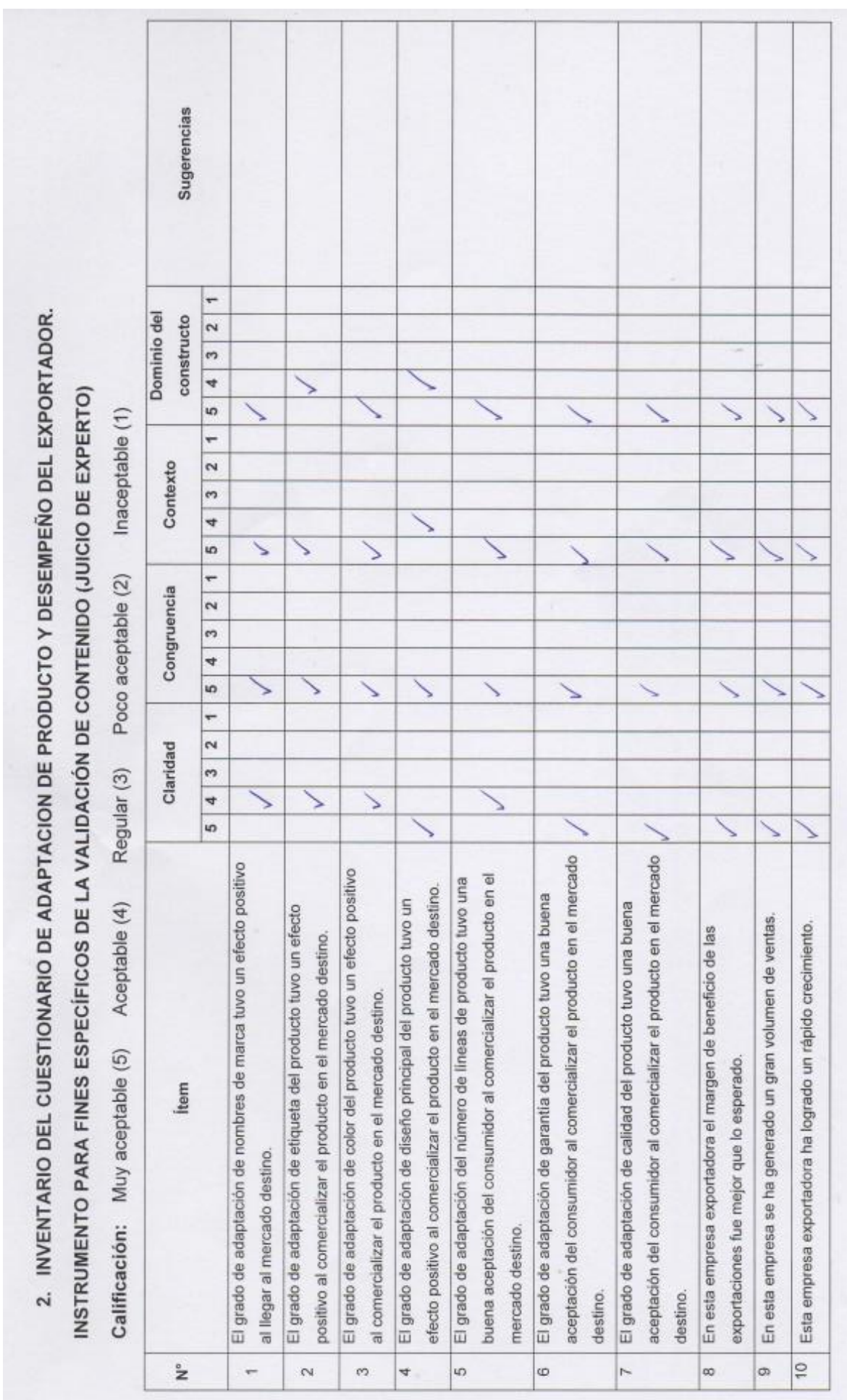


Juez N³: Jimmy Elías Sánchez Gómez - Docente de la Universidad San Ignacio de Loyola

\author{
INSTRUMENTO PARA LA VALIDEZ DE CONTENIDO
}

(JUICIO DE EXPERTOS)

El presente instrumento tiene como finalidad validar el formulario de adaptación de producto y desempeño del exportador, el mismo que será aplicado a los administradores, gerentes de marketing o gerentes del área comercial, gerentes del área de investigación y desarrollo o jefes del área de comercio exterior de las empresas exportadoras de palta en Perú que forman parte del estudio "RELACION ENTRE ADAPTACION DE PRODUCTO $Y$ EL DESEMPEÑO DEL EXPORTADOR DE EMPRESAS EXPORTADORAS DE PALTA EN PERU 2019", que corresponde a un diseño correlacional no experimental transversal.

Instrucciones

La evaluación requiere de la lectura detallada y completa de cada uno de los ítems propuestos a fin de cotejarlos de manera cualitativa con los criterios propuestos relativos a: Claridad de la redacción, Congruencia con el contenido, Contexto correcto del ítem y Dominio del Constructo. Para ello deberá asignar una valoración si el ítem presenta o no los criterios propuestos, y en caso necesario se ofrecen un espacio para las observaciones si hubiera.

Juez $\mathrm{N}^{0}$ :

Fecha actua:

Nombres y Apellidos de Juez: Timmy Sánchez

Institución donde labora:

USI L

Años de experiencia profesional o científica: 15 años

Grado de Instrucción: Nagister
Puesto que desempeña:

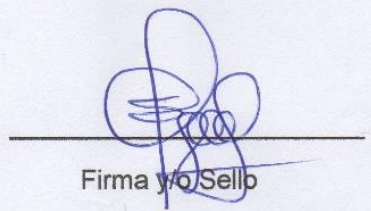




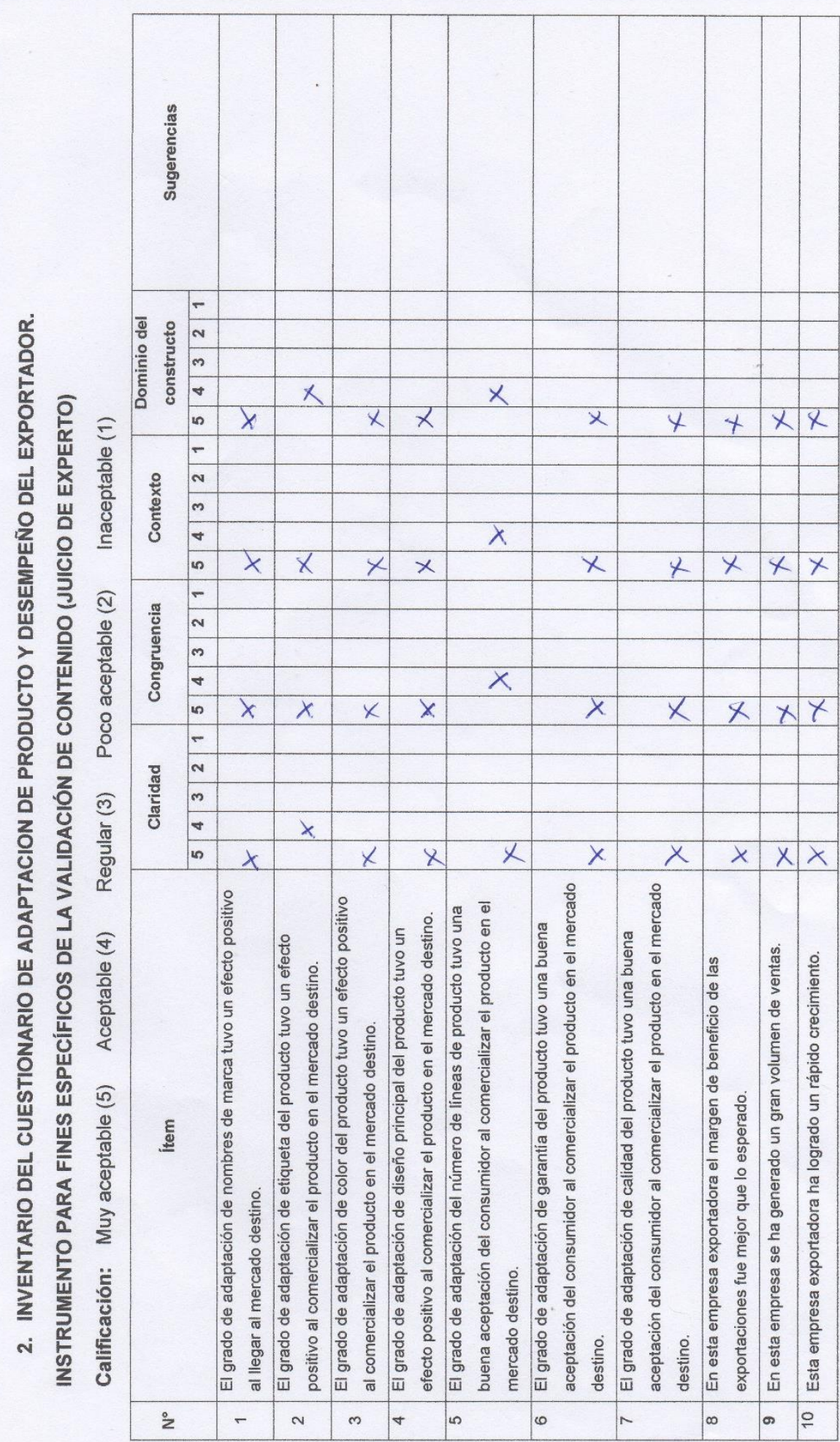




\section{Anexo 4. Alfa de Cronbach}

\section{Adaptación de Producto:}

\begin{tabular}{|c|c|c|c|}
\hline \multicolumn{4}{|c|}{ Resumen de Procesamiento } \\
\hline & & $\mathrm{N}$ & $\%$ \\
\hline \multirow[t]{3}{*}{ Casos } & Valid & 117 & 100.0 \\
\hline & Excluded $^{\mathrm{a}}$ & 0 & .0 \\
\hline & Total & 117 & 100.0 \\
\hline
\end{tabular}

a. Listwise deletion based on all variables in the procedure.

\begin{tabular}{cc}
\hline \multicolumn{2}{c}{ Reliability Statistics } \\
\hline Cronbach's Alpha & N of Items \\
\hline .817 & 7 \\
\hline
\end{tabular}

\begin{tabular}{|c|c|c|c|c|}
\hline \multicolumn{5}{|c|}{ Item-Total Statistics } \\
\hline & $\begin{array}{l}\text { Scale } \\
\text { Mean if } \\
\text { Item } \\
\text { Deleted }\end{array}$ & $\begin{array}{c}\text { Scale } \\
\text { Variance } \\
\text { if Item } \\
\text { Deleted }\end{array}$ & $\begin{array}{l}\text { Corrected } \\
\text { Item-Total } \\
\text { Correlatio } \\
\mathrm{n}\end{array}$ & $\begin{array}{l}\text { Cronbach' } \\
\text { s Alpha if } \\
\text { Item } \\
\text { Deleted }\end{array}$ \\
\hline $\begin{array}{l}\text { AP1. Está de acuerdo en que la adaptación de } \\
\text { nombres de marca tuvo un efecto positivo al } \\
\text { llegar al mercado destino. }\end{array}$ & 18.93 & 12.478 & .609 & .783 \\
\hline $\begin{array}{l}\text { AP2. Está de acuerdo en que la adaptación de } \\
\text { etiqueta del producto tuvo un efecto positivo al } \\
\text { comercializar el producto en el mercado destino. }\end{array}$ & 17.89 & 12.600 & .604 & .784 \\
\hline $\begin{array}{l}\text { AP3. Está de acuerdo en que la adaptación de } \\
\text { color del producto tuvo un efecto positivo al } \\
\text { comercializar el producto en el mercado destino. }\end{array}$ & 18.96 & 12.834 & .652 & .778 \\
\hline $\begin{array}{l}\text { AP4. Está de acuerdo en que la adaptación de } \\
\text { diseño principal del producto tuvo un efecto } \\
\text { positivo al comercializar el producto en el } \\
\text { mercado destino. }\end{array}$ & 18.68 & 12.997 & .466 & .809 \\
\hline $\begin{array}{l}\text { AP5. Está de acuerdo en que la adaptación del } \\
\text { número de líneas de producto tuvo una buena } \\
\text { aceptación del consumidor al comercializar el } \\
\text { producto en el mercado destino. }\end{array}$ & 20.22 & 14.209 & .427 & .812 \\
\hline $\begin{array}{l}\text { AP6. Está de acuerdo en que la adaptación de } \\
\text { garantía del producto tuvo una buena aceptación } \\
\text { del consumidor al comercializar el producto en } \\
\text { el mercado destino. }\end{array}$ & 18.44 & 11.972 & .574 & .791 \\
\hline $\begin{array}{l}\text { AP7. Está de acuerdo en que la adaptación de } \\
\text { calidad del producto tuvo una buena aceptación } \\
\text { del consumidor al comercializar el producto en } \\
\text { el mercado destino. }\end{array}$ & 17.56 & 12.473 & .586 & .787 \\
\hline
\end{tabular}




\section{Desempeño del exportador:}

\begin{tabular}{cccc}
\hline \multicolumn{3}{c}{ Resumen de Procesamiento } \\
\hline & & $\mathrm{N}$ & $\%$ \\
\hline \multirow{4}{*}{ Cases } & Valid & 117 & 100.0 \\
& Excludeda & 0 & .0 \\
& Total & 117 & 100.0 \\
\hline
\end{tabular}

a. Listwise deletion based on all variables in the procedure.

\begin{tabular}{cc}
\hline \multicolumn{2}{c}{ Reliability Statistics } \\
\hline Cronbach's Alpha & N of Items \\
\hline .920 & 3 \\
\hline
\end{tabular}

\begin{tabular}{lcccc}
\hline \multicolumn{5}{c}{ Item-Total Statistics } \\
& $\begin{array}{c}\text { Scale } \\
\text { Mean if } \\
\text { Item } \\
\text { Deleted }\end{array}$ & $\begin{array}{c}\text { Scale } \\
\text { Variance } \\
\text { if Item } \\
\text { Deleted }\end{array}$ & $\begin{array}{c}\text { Corrected } \\
\text { Item- } \\
\text { Total } \\
\text { Correlatio } \\
\text { n }\end{array}$ & $\begin{array}{c}\text { Cronbach' } \\
\text { s Alpha if } \\
\text { Item } \\
\text { Deleted }\end{array}$ \\
\hline $\begin{array}{l}\text { DE1. En esta empresa exportadora el margen de } \\
\text { beneficio de las exportaciones fue mejor que lo } \\
\text { esperado. }\end{array}$ & 6.12 & 4.158 & .851 & .876 \\
$\begin{array}{l}\text { DE2. En esta empresa se ha generado un gran } \\
\text { volumen de venta. }\end{array}$ & 6.03 & 3.999 & .825 & .897 \\
$\begin{array}{l}\text { DE3. Esta empresa exportadora ha logrado un } \\
\text { rápido crecimiento. }\end{array}$ & 6.09 & 4.062 & .841 & .883 \\
\hline
\end{tabular}


Anexo 5. Valor de Aiken

\begin{tabular}{|c|c|c|c|c|c|c|c|c|c|c|c|c|c|c|}
\hline $\begin{array}{c}\text { JUECE } \\
\mathrm{S}\end{array}$ & \multicolumn{4}{|c|}{ JUEZ 1} & \multicolumn{4}{|c|}{ JUEZ 2} & \multicolumn{4}{|c|}{ JUEZ 3} & SUMA & $\begin{array}{c}\text { V } \\
\text { AIKE } \\
\mathrm{N}\end{array}$ \\
\hline ITEM & $\begin{array}{c}\text { CLA } \\
\text { RID } \\
\text { AD }\end{array}$ & $\begin{array}{c}\text { CONGR } \\
\text { UENCI } \\
\text { A }\end{array}$ & $\begin{array}{l}\text { CONT } \\
\text { EXTO }\end{array}$ & $\begin{array}{c}\text { DOMI } \\
\text { NIO } \\
\text { DE } \\
\text { CONS } \\
\text { TRUC } \\
\text { TO } \\
\end{array}$ & $\begin{array}{l}\text { CLAR } \\
\text { IDAD }\end{array}$ & $\begin{array}{l}\text { CONGR } \\
\text { UENCIA }\end{array}$ & $\begin{array}{c}\mathrm{CO} \\
\mathrm{NTE} \\
\mathrm{XT} \\
\mathrm{O}\end{array}$ & $\begin{array}{c}\text { DOMINI } \\
\text { O DE } \\
\text { CONSTR } \\
\text { UCTO }\end{array}$ & $\begin{array}{l}\text { CL } \\
\text { AR } \\
\text { ID } \\
\text { AD }\end{array}$ & $\begin{array}{c}\text { CONG } \\
\text { RUEN } \\
\text { CIA }\end{array}$ & $\begin{array}{c}\text { CO } \\
\text { NTE } \\
\text { XT } \\
\text { O }\end{array}$ & $\begin{array}{c}\text { DOMI } \\
\text { NIO } \\
\text { DE } \\
\text { CONST } \\
\text { RUCT } \\
\text { O }\end{array}$ & & \\
\hline AP1 & 4 & 5 & 5 & 4 & 4 & 5 & 5 & 5 & 5 & 5 & 5 & 5 & 57.00 & 0.95 \\
\hline AP2 & 4 & 5 & 5 & 4 & 4 & 5 & 5 & 4 & 4 & 5 & 5 & 4 & 54.00 & 0.90 \\
\hline AP3 & 4 & 5 & 5 & 4 & 4 & 5 & 5 & 5 & 5 & 5 & 5 & 5 & 57.00 & 0.95 \\
\hline AP4 & 4 & 5 & 5 & 4 & 5 & 5 & 4 & 4 & 5 & 5 & 5 & 5 & 56.00 & 0.93 \\
\hline AP5 & 4 & 5 & 5 & 4 & 4 & 5 & 5 & 5 & 5 & 4 & 4 & 4 & 54.00 & 0.90 \\
\hline AP6 & 4 & 5 & 5 & 4 & 5 & 5 & 5 & 5 & 5 & 5 & 5 & 5 & 58.00 & 0.97 \\
\hline AP7 & 4 & 5 & 5 & 4 & 5 & 5 & 5 & 5 & 5 & 5 & 5 & 5 & 58.00 & 0.97 \\
\hline \multicolumn{14}{|c|}{ V AIKEN } & 0.94 \\
\hline DE1 & 4 & 5 & 5 & 4 & 5 & 5 & 5 & 5 & 5 & 5 & 5 & 5 & 58.00 & 0.97 \\
\hline DE2 & 4 & 5 & 5 & 4 & 5 & 5 & 5 & 5 & 5 & 5 & 5 & 5 & 58.00 & 0.97 \\
\hline DE3 & 4 & 5 & 5 & 4 & 5 & 5 & 5 & 5 & 5 & 5 & 5 & 5 & 58.00 & 0.97 \\
\hline \multicolumn{14}{|c|}{ VALOR DE AIKEN } & 0.97 \\
\hline $\begin{array}{l}\text { NUMER( } \\
\text { JUECES } \\
\text { NUMER } \\
\text { VALORE }\end{array}$ & $\begin{array}{l}\mathrm{DE} \\
\mathrm{DE}\end{array}$ & $\begin{array}{l}3.00 \\
5.00\end{array}$ & & & & & & & & & & & & \\
\hline
\end{tabular}

